\title{
Business Model Design for Social Goods and Services in Developing Economies
}

Mirella Lindsay Haldimann

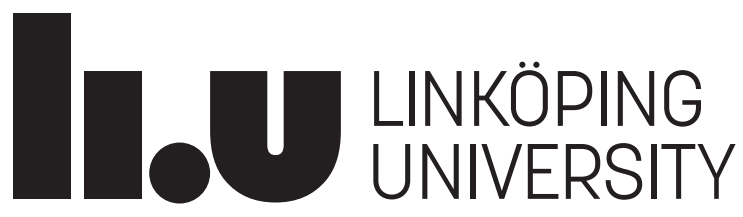




\section{Business Model Design for Social Goods and Services in Developing Economies}

Mirella Lindsay Haldimann

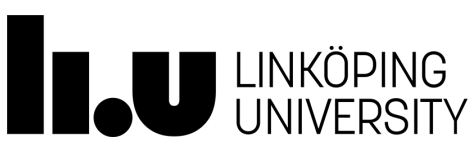

2019 
Department of Management and Engineering Linköping University, SE-581 83 Linköping, Sweden 
(C) Mirella L. Haldimann, 2019, unless otherwise noted

Business Model Design for Social Goods and Services in Developing Economies

Linköping Studies in Arts and Sciences No. 772

ISBN: 978-91-7685-032-9

ISSN: 0282-9800

Printed by LiU-Tryck, Linköping, 2019

Distributed by:

Linköping University

Department of Management and Engineering

SE-581 83 Linköping, Sweden 


\section{Abstract}

Over the past decade there have been increasing calls for alternative ways of tackling poverty problems in developing economies. Rather than aid or charity approaches that have traditionally dominated this area, an alternative line of discussion around base-of-the-pyramid approaches has emerged which emphasizes the role of innovation and pro-poor entrepreneurship. These developments are consequently reshaping our current views on organizational sectors, vulnerable communities, and sources of value creation.

Social businesses trailblazing these approaches however may find it difficult to provide customers at the very base of the economic pyramid with products and services in financially sustainable ways. Markets in remote rural areas are characterized by severe resource scarcity and pervasive institutional voids which make the pursuit of designing adequate value creation and appropriation mechanisms a challenging undertaking. Additionally, the commercialization of social goods further compounds these challenges, because hybrid missions demand the simultaneous generation of social and commercial value.

In this dissertation, I aim to shed light on these issues and examine how successful social businesses have emerged in the context of the unfolding pro-poor informal water market. This setting lent itself especially well to such study because the lack of safe and affordable water access prominently affects severely poor and secluded geographies to which sustainable solutions in profit, non-profit or governmental form have not yet emerged; yet successful solutions by social businesses have.

Building on the emergent research on social businesses, I suggest that these organizations established viable business ventures by designing a type of business model that caters to the needs of socially constrained base-of-the-pyramid communities despite the afore-mentioned managerial challenges. With a focus on theory development, I employ a multi-qualitative approach consisting of multiple case studies to develop a conceptual framework of these social business models and various propositions as to what may underpin their successful development.

The empirical foundation for these elaborations consists of five studies. These highlight distinct value creation and appropriation mechanisms as well as capabilities that social businesses employ to circumnavigate resource scarcity and institutional voids. Consequently, focusing on the design of value creation and appropriation mechanisms, we gain deeper insights as to why some social businesses may outperform other organizations. The thesis concludes with implications for base-of-the-pyramid, social entrepreneurship and business model literature, as well as avenues for future research. 


\section{Sammanfattning}

Under det senaste decenniet har det blivit ökande uppmaningar till alternativa sätt att hantera fattigdomsproblem i utvecklingsekonomier. I stället för hjälp eller välgörenhetsmetoder som traditionellt dominerat detta område har en alternativ diskussionslinje kring "base-of-the-pyramid" tillvägagångssätt uppstått som betonar rollen som innovation och fattig entreprenörskap. Denna utveckling förändrar följaktligen våranuvarande syn på organisationssektorer, utsatta samhällen och källor av värdeskapandet.

Sociala företag som leder till dessa tillvägagångssätt kan dock ha svårt att tillhandahålla kunder på grunden av ekonomins pyramid med varor och tjänster på ekonomiskt hållbara sätt. Marknader i avlägsna landsbygdsområden kännetecknas av svår bristande resursbrist och genomgripande institutionella tomrum som gör strävan att utforma adekvata värdeskapande och värdefångande mekanismer ett utmanande gåtagande. Dessutom förvärrar kommersialiseringen av sociala varor dessa utmaningar, eftersom hybriduppdrag kräver samtidig generering av socialt och kommersiellt värde.

I den här avhandlingen undersöker jag hur framgångsrika sociala företag har uppstått i samband med den outvecklade pro-fattiga vattenmarknaden. Jag föreslår att dessa sociala företag etablerat lönsamma affärsverksamheter genom att utforma en typ av affärsmodell som tillgodoser behoven hos socialt begränsade base-of-the-pyramid samhällen trots de ovan nämnda ledarskapsutmaningarna.

Med fokus på teoriutveckling använder jag en mångsidig kvalitativ forskningsansats som består av flera fallstudier för att utveckla ett konceptuellt ramverk för dessa sociala affärsmodeller och olika förslag till vad som kan stödja deras framgångsrika utveckling.

Den empiriska grunden för dessa utarbetningar består av fem studier. Dessa lyfter fram tydliga värdeskapande och värdefångande mekanismer samt kompetenser som sociala företag använder för att kringgå resursbrist och institutionella tomrum. Därför får vi djupare insikter om att vissa sociala företag kan överträffa andra organisationer, med fokus på utformningen av värdeskapande och värdefångande mekanismer. 


\section{Acknowledgements}

First, I would like to express my sincere gratitude and appreciation to my advisor Prof. Dr. Heiko Gebauer for his continuous support and encouragement throughout my Ph.D. journey. His introduction to engaged research will clearly not go unnoticed throughout this thesis. I am also very much indebted to Prof. Dr. Lars Witell, Prof. Dr. Thomas Frandsen, and Dr. Aku Valtakoski for serving on my dissertation committee with their constructive insights that have shaped many views and outcomes embedded in this dissertation.

Moreover, much data was collected for this research and many people supported these efforts. My special gratitude thus goes out to the Swiss Agency for Development, the International Water and Sanitation Centre (IRC), and the World Health Organization who have enabled the access to organizations that successfully strive to address sustainable development goals with market-based approaches through a joint and collaborative research program.

Aside from other local research assistants, I would especially like to thank Andrea van der Kerk from IRC who accompanied me on multiple field trips. Her international aid research experiences that collided with my Industrial Engineering background were incredibly useful in retrieving and reflecting on field data. In this context, I should probably also thank Dr. med. Thomas Fellmann who advised me to operate a foot injury prior to a lengthy field trip to South East Asia. The crutches were a complete nuisance; yet enabled many delightful and insightful discussions with empathizing case informants.

I must also express my deepest gratitude to my mentioned co-authors for their research support, and the interesting related studies they invited me to work on, beyond the scope of this thesis. In this vein, many thanks also go to Prof. Dr. Fisk and his colleagues at the Marketing Faculty of Texas State University, where I gained valuable comments on my research and insights into the importance of social value creation in a variety of other market contexts today. Moreover, I want to express my deep gratitude to my former colleagues at the Environmental Social Sciences division at the Swiss Federal Institute of Aquatic Science and Technology of the ETH who provided a highly intellectually stimulating environment, enriched my epistemological horizons and were a constant cornucopia of invaluable feedback.

Furthermore, I must acknowledge the funding sources that made this Ph.D. work possible. Many thanks are due to the Swiss National Science Foundation (SNSF) as well as the Bill and Melinda Gates Foundation for their bursary and investment in this research during my first two years; and I was honored to be a SNSF Fellow in my final year. 
Study I Gebauer, H., Saul, C. J., Haldimann, M. (2017). "Business model innovation in base-of-the-pyramid markets". Journal of Business Strategy, 38(4), 38-46.

Study II Gebauer, H., Haldimann, M., Saul, C. J. (2017). Business model innovations for overcoming barriers in the base-of-the-pyramid markets. Industry \& Innovation, 24(5), 543-568.

Study III Haldimann, M. (2019). Framing Social Issues: Business Model Design at the economic Base of the Pyramid Working paper.

Presented as Haldimann, M. (2018). Design of Business Models for Social Goods and Services in Low-income Markets. Sustainable Business Model Conference (SBMC), Sofia.

Haldimann, M., Moellers, T., Gebauer H. (2019). 'Opening up' Business Study IV Models in poverty-stricken Markets. Working paper.

Presented as Haldimann, M., (2018). Opening Up' of Social Business Models in BoP Markets. World Open Innovation Conference (WOIC), Berkeley (considered for best paper award).

Haldimann, M., Gebauer H. (revision for re-submission to new journal). Embracing Hybridity: exploring Paradoxes and Response Study V Strategies in Ambidextrous Social Enterprises. Working paper.

Presented as Haldimann, M., (2017). The Social Entrepreneur's Dilemma: applying Paradox Theory to Social versus Economic Value Creation. European Academy of Management (EURAM), Glasgow. 


\section{Abbreviations}

$\mathrm{BM}$

BMD

BMI

$\mathrm{BoP}$

e.g.

fig.

i.e.

MRQ

NRBV

NGO

NPO

No.

RBV

RQ

SNSF

SRBV

tab.

ToP
Business Model

Business Model Design

Business Model Innovation

Base of the Pyramid

exempli gratia

Figure

id est

Main Research Question

Natural Resource Based View (of the Firm)

Non-Governmental Organization

Not-for-Profit Organization

Number

Resource Based View (of the Firm)

Research Question

Swiss National Science Foundation

Social Resource Based View (of the Firm)

Table

Top of the Pyramid 


\section{List of Figures \& Tables}

Figure 1-1

Figure 1-2

Figure 1-3

Figure 2-1

Figure 2-2

Figure 2-3

Figure 3-1

Figure 3-2

Figure 3-3

Figure 3-4

Figure 3-5

Figure 4-1

Figure 4-2

Figure 5-1

Table 1-1

Table 2-1

Table 3-1

Table 3-2

Table 3-3

Table 3-4

Table 4-1

Table 4-2

Table 4-3

Table 4-4
Empirical Context of the Dissertation

p. 11

Delimitations of the Empirical Context

p. 12

Composition of the Dissertation

p. 15

Overview of Theoretical Streams

p. 17

Overview of Business Model Literature

p. 27

No. of Publications on Business Models and Dynamic Capabilities

p. 29

Overview of Methodology

p. 41

Key Steps taken in Research Process

p. 46

Key Methodological Choices in Research Design

p. 47

Schematic Overview of Case Selection Process

p. 49

Forms of Engaged Scholarship

p. 56

A Model of Social BM Design

p. 67

Ambidextrous Responses

p. 72

Related Research Streams

p. 73

Overview of Research Questions with related Publications

p. 8

Seminal Business Model Definitions

p. 31

Major Concepts from Critical Realism

p. 42

Overview of Case Studies

p. 50

Overview of Data Corpus and Collection Methods

p. 52

Overview of Operational Measures

p. 56

Overview of Studies in the Scope of Research

p. 59

Design Themes and identified Approaches

p. 61

BMI Patterns and related Managerial Challenges

p. 64

Co-creation Themes in the BoP

p. 69 


\section{Table of Contents}

Abstract iii

Sammanfattning iv

Acknowledgements iv

Main Studies

Abbreviations vii

List of Figures \& Tables viii

Table of Contents ix

1 Introduction $\quad 1$

1.1 Context of Study

1.2 Theory Background 3

1.3 Research Question, Setting and Approach $\quad 7$

1.4 Scope of Research 11

1.5 Composition of the Thesis 11

2 Theoretical Outline $\quad 17$

2.1 Background Literature $\quad 18$

2.1.1 The Resource-based View 18

2.1.2 The Social Resource-based View

2.2 Focal Literature: BoP, Hybrid Organizing and Business Models 21

2.2.1 Base of the Pyramid 21

2.2.2 Hybrid Organizing $\quad 24$

$\begin{array}{ll}2.2 .3 \text { Business Model Theory } & 27\end{array}$

2.3 Research Gap: Social Business Models

3 Research Strategy $\quad 41$

3.1 Research Paradigm $\quad 42$

3.2 Research Approach $\quad 44$

3.3 Research Process $\quad 46$

$\begin{array}{ll}3.4 \text { Research Design } & 47\end{array}$

3.4.1 Research Setting $\quad 47$

3.4.2 Case Selection $\quad 49$

3.4.3 Data Collection $\quad 51$

3.4.4 Data Analysis $\quad 54$

$\begin{array}{ll}3.4 .5 \text { Rigor } & 55\end{array}$

3.5 Dissemination 56 
4.1 Exploring Design Themes for Social Business Models 60

$\begin{array}{ll}4.2 \text { Overcoming constraints in BoP Markets } & 63\end{array}$

4.3 Design of Social Business Model 66

4.4 Social Business Model Development through Co-creation 68

4.5 Maintaining hybridity during social business model development $\quad 70$

\section{Discussion}

$\begin{array}{ll}5.1 \text { Theoretical Contributions } & 73\end{array}$

$\begin{array}{ll}\text { 5.1.1 BoP Research } & 74\end{array}$

$\begin{array}{ll}\text { 5.1.2 Social Entrepreneurship } & 76\end{array}$

$\begin{array}{ll}\text { 5.1.3 Business Model Theory } & 78\end{array}$

$\begin{array}{ll}\text { 5.2 Managerial Implications } & 79\end{array}$

5.3 Policy Implications $\quad 81$

5.4 Limitations $\quad 82$

$\begin{array}{ll}5.5 \text { Future Research } & 84\end{array}$

$\begin{array}{lr}6 \text { Conclusion } & 87\end{array}$

$\begin{array}{ll}7 \text { References } & \mathbf{8 9}\end{array}$

$\begin{array}{lr}\text { A-M } & 89\end{array}$

$\begin{array}{ll}\mathrm{N}-\mathrm{Z} & 98\end{array}$

8 Appendices $\quad 107$

8.1 Appendix I: Literature Reviews 107

8.2 Appendix II: Case Summaries 113

8.3 Appendix III: Appended Papers 114 


\section{Introduction}

Recently, business models (BM's) have been proposed for poverty alleviation outcomes in form of socially beneficial goods and services (Prahalad, 2009; Prahalad and Hart, 2002). Successful BM design however requires the translation of entrepreneurial opportunity into a viable BM (Amit and Zott, 2001). That is, the fundamental way in which an organization aims to create yet also appropriate value from a customer (Teece, 2010). Recent work focusing on BM's of new ventures concludes that design choices and approaches are instrumental in establishing a BM (e.g., Amit and Zott, 2007; Andries and Debackere, 200). Still, it remains unclear how this process takes shape in the context of poverty in which goods and services offered may involve a social value component (George et al., 2012). This introductory chapter aims to provide the relevant background on this managerial context as well as relevant concepts that inform this line of research. The chapter then outlines the associated research aims, questions, study scope and overview of this thesis.

\subsection{Context of Study}

In the following, I provide two problem descriptions of different social businesses because they were confronted with such BM design in remote rural areas ${ }^{1}$. The first scenario involves the issues that a CEO perceived when his social business was devising their BM. In this critical situation, he was faced with important BM design choices of his venture. The second scenario describes challenges that another social business experienced after successfully implementing their devised BM. In this situation, the management team concluded that the BM had to be further developed to align with their mission.

\section{Problem Description 1: Devising a BM - The founders of the organization had run two pilots} to test their business idea which involved selling drinking water to severely poor communities, otherwise disenfranchised from affordable or potable water. Based on the positive responses, the founders appointed a CEO with previous business experience in this particular market. Under this new management, the founders expected to see the social project turn into a successful social business because a commercial approach promised a level of financial immunity against donations, on which the project so far relied on. Moreover, if a BM was implemented successfully, it could mean an increase in potential reach of the organization and employment opportunities for locals.

\footnotetext{
${ }^{1}$ remote rural regions typically refer to non-urbanized, sparsely populated areas in developing economies, characterized by low levels of income, education and infrastructure, and thus experience a lack of public or private services (e.g., Brezzi et al., 2011; OECD, 2016). As a result of these characteristics, inhabitants often remain secluded from formal markets.
} 
The new CEO had previously gained substantial know-how as a senior manager of a national firm that operated in poverty-stricken markets. With his appointment of a newly founded social business, he was excited to apply his experience. Nonetheless, the CEO struggled in his first year to devise an effective model. Customers appeared unaware of health threats related to contaminated water. Consequently, they were often not willing to pay for, to them, indistinguishable water. Moreover, a lack of skilled work force, infrastructure (e.g., roads) and access to finance all caused for other deep concerns that hampered quality controls and overall growth of the business. The few existing banks had already refused to provide loans due to the high risks associated with the business venture; and it remained unclear how locally rooted institutions with similar social objectives or their beneficiaries would respond to their market entry. How would he proceed to translating this business idea into a viable BM?

Problem Description 2: Developing a BM - Similarly to the previous example, this organization was founded on the mission to provide safe and affordable drinking water to people in a remote rural area. Over the course of nine years, the organization was able to build the operations necessary to make and sell ceramic water filters to NGO's who would distribute them to poor communities for free. Although the organization up to this point had seen growth in sales and overall profit, the management team observed multiple issues. Filters were prone to breakage due to cheap materials used, customers were often not properly instructed about usage and maintenance, nor the overall importance of water filtration. Moreover, filter sales could fluctuate strongly by month which made it difficult for production sometimes to timely procure raw materials. The management team growingly grew convinced that they fell short on their social objectives.

These issues led the management team to substantially change the way they ran the business venture. In other words, they reconfigured the entire BM. Key modifications included the direct sales to customers which required a more expensive filter design and a sales force on the ground. To help customers finance these filters, they introduced installment-based financing options. This substantial change in the BM allowed the now social business to better estimate sales and build up a strong customer relationship. In turn, customers were better informed about water related hygiene practices, were able to properly maintain their filters, and were able to get in touch with the organization for repairs. 
These case descriptions highlight the key processes observed when social businesses design their $\mathrm{BM}$ and the various managerial challenges that may be connected to them, such as technical and market feasibility (Anderson and Tushman, 1990). Indeed, when devising and developing their BM's, social businesses face substantial uncertainties typically associated with new venture creation (Dutta and Crossan, 2005). However, the case descriptions also showcase that these processes are subjected to a series of market barriers inherent to poverty contexts and the dual mission of the organization. These issues need to be addressed by the BM design.

\subsection{Theory Background}

Much of the traditional business research has predominantly focused on commercially informed competitive advantage, while the inclusion of poverty and related social value creation has comparatively received lesser attention (see section 2.1). As a result, it remains unclear which resources and capabilities may guide effective new venture creation processes in severely low-income areas. By drawing on the idea that the design of adequate BM's can inform this practice and research gap (cf. Seelos and Mair, 2007; Yunus et al., 2010), I briefly summarize the relevant literature on baseof-the-pyramid (BoP) and hybrid organizing which help illustrate how social constraints may affect $\mathrm{BM}$ design in poverty contexts.

BoP literature proposes that the saturation of mature markets in industrialized nations implies that new business opportunities ought to be sought in BoP markets (Prahalad and Hart, 2002; Kayser and Budinich, 2015). The BoP represents a substantial share of the human population that lives at the base of the economic pyramid. It is estimated that this market collectively represents around 60 percent of the global population who currently live outside of the global market system due to low incomes between two to four US dollars per day; of which every fifth lives under extreme poverty with less than two US dollars per day (UN, 2017). This population is mainly spread across impoverished regions in Africa, Latin America and South-East Asia. Despite large cultural and geographical differences, communities living at the base typically experience similar social constraints such as poor nutrition, lacking sanitation, limited education and work opportunities.

Research in this vein suggests that the implementation of BM's to address these constraints in many cases has proven to be more challenging than expected (Kistruck et al., 2012). Difficulties include economic constraints in form of access to traditional venture capital markets, low gross domestic products and increased susceptibility toward market shocks (Upreti et al., 2015). 
Infrastructure challenges such as lack of reliable electricity (Panapanaan et al. 2016) or weak physical infrastructure constrain distribution channels in already fragmented market environments (De Soto, 2000; Kistruck et al., 2013). Political and governmental constraints can manifest in poor governance, corruption or weak legal systems (Kaufmann et al., 2009), such that businesses must operate based on oral contracts (Bucher et al., 2016; Godfrey, 2011); with market participants that may not necessarily be monitored, regulated or taxed by governments (Webb et al., 2009; Anokhin and Schulze, 2009). Additionally, socio-cultural issues manifest in cultural and educational disparities, which have shown to produce purchasing decisions that may differ significantly from developed market contexts (Viswanathan et al., 2010; Viswanathan et al., 2014).

Consequently, a central tenet of the BoP proposition is that commercial approaches can alleviate poverty in economically feasible ways and, in certain cases, may provide a more effective means compared to philanthropic practices (Prahalad, 2004; 2009). As a result, the BoP proposition presents the world's low-income majority in a new way, as active consumers rather than passive recipients of aid (Hart, 2005). Yet, at the same time previous research shows that new business ventures face extreme resource scarcity on the one hand (Chiliova and Ringov, 2017; Seelos and Mair, 2007), and institutional voids on the other (Mair and Marti, 2009; Mair et al., 2012). Consequently, $\mathrm{BM}$ design may be informed by managerial issues that may differ substantially from ones researched at the 'top of the pyramid' (ToP) substantially (Chiliova and Ringov, 2017; George et al., 2012).

Informed by the hybrid organizational literature ${ }^{2}$, research on social enterprises (SE's) provides complementary insights into BM design of new venture creation in poverty contexts. Similarly to BoP literature, research on Social Entrepreneurship mirrors the emergence of organizations that voice larger concerns of different stakeholders regarding the ability of governments, charity and larger businesses to meaningfully address a wide array of pressing social issues (Wilson and Post, 2013). SE's cater then to needs related to such issues through their business venture, thereby operating across well-established sectors (Battilana and Lee, 2014). Foremost due to their pursuit of revenue generation associated with organizations in the private sector, and the achievement of social and environmental goals associated with nonprofit and governmental organizations (Mair and Martì, 2006; Di Domenico et al., 2010).

\footnotetext{
2 the study on hybrid organizations involves the study of activities, structures, processes and meanings by which these organizations make sense of and combine aspects of multiple organizational forms (Battilana and Lee, 2014).

3 the terms social business (Yunus et al. 2010) and social enterprise (Dees, 2001) are treated synonymously throughout the dissertation.
} 
SE's hence deviate from socially legitimate templates for organizing and combine aspects of multiple organizational forms, which make them inherently hybrid (Besharov and Smith, 2014). In line with BoP literature, 'doing social business' hence is grounded in a rational that organizations can seek returns by turning previously impoverished and vulnerable people into consumers, but importantly also by improving their standard of living simultaneously (Calvano, 2008).

This hybrid nature of social businesses further complicates BM design. Increasingly, research on SE's suggest that social businesses are challenged by their pursuit of a dual mission (Pache and Santos, 2010; 2013). The underlying dual objectives of social and commercial performance are not necessarily aligned and oftentimes contradictory (Ebrahim et al., 2014). SE's that operate in resource constrained environments, such as the BoP, are particularly prone to becoming resource dependent toward constituents that span different sectors. These sectors then reify conflicting institutional logics (Pache and Santos, 2013). As a result, SE's manage conflicting and competing logics related to their commercial and social activities (Battilana and Dorado, 2010). These complexities not only intensify prevailing management challenges (Pache and Santos, 2013), but must also be managerially balanced to ensure commercial and social value creation (Battilana and Lee, 2014). When social businesses devise and develop their BM's, resource dependencies and related activities will affect BM design choices.

More recently, scholars in either research stream suggest that social businesses can mitigate these managerial issues by adopting 'reshaped' BM's for poverty alleviation outcomes (cf. Prahalad, 2009: Massa and Tucci, 2013). For example, Seelos and Mair (2007) draw on two case examples to propose BoP models as a complementary framework to research how BoP initiatives are successfully designed; arguing that they demonstrate how resources, capabilities and constituencies with different strategic objectives are combined. Similarly, Yunus and colleagues (2010) draw on the case of a successful SE to highlight how dual missions manifest in what they coin a social BM. Hence, social BM's at the BoP can be understood as a BM archetype that cater to basic human needs of extremely resource-constrained customers (cf. Seelos and Mair, 2005). By drawing on the BM as a unit of analysis and analytical lens, these authors aim to provide a construct with which to examine the differences of $\mathrm{BM}$ designed for the BoP compared to the ToP; and hence seek explanations as to how companies can create and appropriate binate value in these markets.

Considering the firm as a bundle of resources and capabilities (Barney, 1991), a business model (BM) thereby describes the fundamental logic or architecture by which firms create, deliver and 
appropriate value from customers (Teece, 2010). From an essentialist view ${ }^{4}$, the BM perspective facilitates a holistic understanding about how resource and managerial capability transactions are orchestrated that allow the firm to create value based on the firm's unique resource and capability base (Morris et al., 2005; Sirmon et al., 2011). From a functionalist view ${ }^{5}$, the BM perspective helps explain how firms engage in BM design more broadly. That is, through either the implementation of novel models or reconfiguration of existing models (Massa and Tucci, 2013). Here, the BM enacts as a calculative and narrative means, allowing entrepreneurial organizations to explore commercialization strategies (Doganova and Eyquem-Renault, 2009). As such, recent BM research suggests that i) BM's as models (Baden-Fuller and Morgan, 2010) provide a composite but integral construct for understanding value creation (Amit and Zott, 2015; Kulins et al., 2016); and that ii) BM's as boundary objects (Bechky, 2003) help reframing, communication and coordination during strategy endowment (Amit and Zott, 2001) $)^{6}$.

Yet the design of financially sustainable solutions for the BoP by social businesses seems to be problematic from both a practical and scholarly perspective. Reality has lags the rhetoric of social BM's, and few examples of social businesses targeting the BoP have been able to design and scale viable BM's at larger scale (Kayser and Budinich, 2015; Kistruck et al., 2012). In a series of cases they have not survived, even when being financially backed by known non-profit and profit-oriented organizations. For example, DuPont touted a venture that sold soy-fortified snack foods in India to alleviate malnutrition, but eventually shut the project down due to lack of profitability. Procter \& Gamble, a large fast moving good company, invented a water-purification powder called PUR for the same market which ended as a commercial, technical and environmental failure. In 2007, household product giant SC Johnson launched a cleaning service company in Kenya with the aim of employment creation. Eventually, the lack of profits led the company to spin off the venture into a non-profit (Simanis, 2012).

Furthermore, the BoP and SE literature addresses the issue of BM design in a fragmented way, largely ignoring theoretical developments related to $\mathrm{BM}$ design in ToP markets. In recent years, management scholars have contributed to a growing body of research on the phenomenon of BM's (see Foss and Saebi, 2017), and BM design specifically (Amit and Zott, 2015). At the ToP, the systematic

\footnotetext{
${ }^{4}$ Essentialism is the view that every entity has a set of attributes that are necessary to its identity and function (Cartwright, 1968).

${ }^{5}$ Functionalism is a view that mental states (beliefs, desires, etc.) are constituted solely by their functional role - that is, they have causal relations to other mental states, numerous sensory inputs, and behavioral outputs (Ned, 1996).

${ }^{6}$ the essentialist and the functionalist view on BM's are further elaborated on in section 2.3
} 
replication of certain capabilities related to BM's have been advocated as key mechanisms behind larger scale BM's. Yet there has been relatively little exploration of the relevance of such theoretical guidance for organizations attempting venture creation and growth at the BoP (George et al., 2012), a context that appears distinct across several important dimensions such as resource scarcity, institutional voids and hybrid motivations.

The aim and implied theoretical elaborations of this dissertation may specifically contribute to our understanding of effective BM design in the context of hybrid organizing in resource constrained market environments which is in line with recent calls in BM research (see Foss and Saebi, 2017). Moreover, such a study pursuit provides an alternative perspective to the mainstream Social Entrepreneurship literature that for the most part draws on institutional theory (Scott, 1987) to better understand how SE's can gain legitimacy and in turn better deal with isomorphic pressures they face (Dacin, 1997; Suchman, 1995), which can stand in stark contrast to means of value appropriation, as introduced with the concept of the BM.

Managerially, this pursuit also contributes towards a better understanding of what kind of competencies are required for creating what Porter and Kramer (2017) have termed shared value within new venture settings. This is likely to become an important issue viewing expanding pro-poor social entrepreneurship sector ${ }^{7}$, addressing issues of poverty per se and closely related issues of education, health, gender equality, water and social justice ${ }^{8}$ in remote rural areas. In this sense, this dissertation represents one attempt at exploring and parsing elements that may guide a more systematic BM design and innovation process in the context of low-income markets for social goods and services.

\subsection{Research Questions, Setting and Approach}

Building on the afore-mentioned gap in practice and theory, the thesis sets out to answer the question of how social BM's are designed. Two overarching research questions inform this inquiry. From an essentialist view, I first explore the nature of social BM's by posing the question of how BM's are devised (MQ1). From a complementary functionalist view, I then inquire into the mechanisms that enabled social businesses to successfully develop the BM (MQ2). These two main research questions have guided the research process and have resulted in five more specific research questions that comprise the research pursuit (RQ1-5). These are now briefly visited. An overview of these questions and related research paper that compose the scholarly foundation of this thesis are provided in table 1.

\footnotetext{
${ }^{7}$ see The Economist, ““'Impact investing” inches from niche to mainstream", 05.01.2017.

${ }^{8}$ for a commensurate list of societal issues, consider the agendas by the United Nations General Assembly, such as the Millennium or Sustainable Development Goals, which act as broad intergovernmental agreements.
} 
Tab. 1-1. Overview of Research Questions and Related Publications

\begin{tabular}{|c|c|c|}
\hline Main RQ's & RQ's & Related Studies \\
\hline \multirow{2}{*}{$\begin{array}{l}\text { MQ1: How are } \\
\text { social business } \\
\text { models devised? }\end{array}$} & I & $\begin{array}{l}\text { What guides social businesses in devising their social business models? } \\
\text { Gebauer, H., Saul, C. J., Haldimann, M. (2017). "Business model innovation in base of the } \\
\text { pyramid markets", Journal of Business Strategy, 38(4), 38-46. }\end{array}$ \\
\hline & II & $\begin{array}{l}\text { What challenges are associated with devising social business models? } \\
\text { Gebauer, H., Haldimann, M., Saul, C. J. (2017). Business model innovations for overcoming } \\
\text { barriers in the base-of-the-pyramid market. Industry \& Innovation, 24(5), 543-568. }\end{array}$ \\
\hline \multirow{4}{*}{$\begin{array}{l}\text { MQ2: How are } \\
\text { social business } \\
\text { models } \\
\text { developed? }\end{array}$} & III & $\begin{array}{l}\text { How are social business models implemented? } \\
\text { Haldimann, M., (1st submission). Design of Business Models for Social Goods and Services in } \\
\text { Low-income Markets. Long Range Planning. }\end{array}$ \\
\hline & IV & $\begin{array}{l}\text { How are value creation and appropriation mechanisms developed? } \\
\text { Haldimann, M., Moellers, T., Gebauer H. (1st submission). 'Opening Up' of Social Business }\end{array}$ \\
\hline & & Models in BoP Markets, Stanford Social Innovation Review. \\
\hline & V & $\begin{array}{l}\text { How do social businesses maintain balance between commercial and social value } \\
\text { creation and appropriation activities? } \\
\text { Haldimann, M., Gebauer H. (1st submission). Ambidextrous responses to paradoxes of hybrid } \\
\text { organizations in bottom-of-the-pyramid markets. Journal of Service Research. }\end{array}$ \\
\hline
\end{tabular}

Source: own table

MQ1: How are BM's devised? Increasingly, market-based solutions are sought after for poverty related outcomes. Successful exploitation of social needs requires the translation of said needs into financially viable BM's. Social businesses must hence make strategic choices and weave together a set of interdependent activities, which in turn shape the BM design (Casadesus-Masanell and Ricart, 2010; Amit and Zott, 2010). As such BM design is detrimental in defining and refining a firm's strategy (e.g., Porter, 2001; Chesbrough and Rosenbloom, 2002; Osterwalder et al., 2005), and in turn will affect the initial performance of entrepreneurial organizations (cf. Amit and Zott, 2015).

My literature review, presented in Chapter 2, reveals that the research on this topic remains fragmented and limited ${ }^{9}$. On the one hand, few studies have conceptually adapted and examined BM frameworks that eventually constitute a social BM. Thus, we lack a deeper understanding about the ways in which such a taxonomy differs from others (e.g. sustainable or service BM's); and in turn, the defining and distinguishing elements for devising BM's that generate both commercial and social value. On the other hand, research on SE's in BoP contexts has for the most part focused on individual venture design challenges in particular those related to value creation (e.g., Seelos and Mair, 2005;

\footnotetext{
${ }^{9}$ reviewed literature is presented in full, under Appendix I.
} 
Mair and Schoen, 2007). Consequently, we know less about how value is appropriated from value generating activities. By adopting an essentialist view of the BM, we may reduce the contention that exists about archetypical elements of social BM's (see 2.2.3) and better understand how they interlink and reinforce one another. These themes are examined mainly in study I-II which set out to explore social BM's and design themes that may guide them.

MQ2: How are social BM's developed? Particularly with regard to BM development of social enterprises, relevant literatures seldom shed light on the intra-firm processes leading to BM development and innovation. Instead, most of the related literatures concentrate on specific external factors, events, and developments that influence the novel BM (cf. Halme et al., 2012). Rather than paying attention to intra-organizational events surrounding the development of a social BM or how organizational members experience them, the impression typically rendered in such pursuits is that a group of founders design and implement the BM, and are sequentially subjected to a series of market barriers and actors (Yunus et al., 2010; Seelos and Mair, 2007). Such a static perspective disregards however the very processes that may underpin the BM development, which are key to dealing with high levels of uncertainty that BoP context raise. The following three studies hence take on such a dynamic and more functionalist perspective to explore different capabilities that appeared to affect the process of BM design: namely, managerial cognition (study III), co-creation (study IV), and ambidexterity (V).

To address the research questions, I examine how social businesses have emerged in the context of the unfolding pro-poor informal water market in developing economies. This setting lent itself to the study since it takes place due to a prominent poverty related need. It concerns the access to affordable drinking water in still severely poor and geographical secluded areas in developing economies; to which sustainable solutions in profit, non-profit or governmental form have not yet emerged. The successful social businesses that have emerged in this context have thus managed to grow in market environments highly prone to resource scarcity, institutional voids, based on their hybrid mission. In turn, they represent what some may term unusual populations (Flyvbjerg, 2006).

I thus drew on the informal water market revolution as a critical situation (Giddens, 1984) within which to examine how these organizations designed their BM's. Such situations are generally composed of fateful moments when events come together in such a way that an individual or group stands, as it were, at a crossroads in their existence. While there is a certain contingency or uncertainty associated with these moments, there is also a set of experiences, abilities, and knowledge that can be 
used as a guide through such situations. This particular situation described here were considered of such criticality since both entrepreneurs and customers consciously relied on the business venture to be successful to ensure some part of their livelihood (health, employment, et cetera...).

This critical situation and actions therein then informed contingencies and mechanisms ${ }^{10}$ respectively that produced viable BM designs and their implementation (Easton, 2010). This thesis thus adopts a critical realist stance (Sayer, 1992), since inferences were made by examining related events and postulating mechanisms that were capable of producing them, considering given contingencies. Specifically, I drew on two types of case study methodologies to explore BM design related mechanisms. The first two studies rely on a replication logic based case study with a higher amount of selected organizations (Yin, 2017), while the remaining studies considered a subset of highly successful case organizations in-depth and longitudinally (Gioia et al., 2013). These methodologies allowed for data collection techniques ${ }^{11}$ in the field that strongly shaped and developed my understanding of the phenomenon (cf. Lee et al., 1999; Siggelkov, 2007), but in combination proved also highly conducive for explorative theory development (Easton, 2010).

Due to the different research questions entailed, the five studies were informed by different sets of case organizations that illustrated the relevant theoretical topic at hand. Yet, the cases nonetheless shared important key characteristics for comparability, such as customer type, technology, organizational type and industry (cf. Eisenhardt, 1989). As such, all the studies were informed by (different) means of purposeful as well as theoretical case selection strategies (Patton, 2005). During the actual fieldwork data was collected and analysed iteratively. Moving back and forward between theory and the observed, content analysis was used to examine the interview transcripts and the additionally gained data (Miles and Huberman, 1984). The process resulted in individual case descriptions for each case and themes observed across cases.

The engaged research approach became salient as an iterative and pluralist learning process through the continuous synthesis and division of gained data from field studies, practice and the underlying literature. That is, based on theoretical and empirical preconceptions, research questions were developed which created the foundation for the empirical data collection. The then gained

\footnotetext{
${ }^{10}$ in this sense, mechanisms are ways in which structured entities by means of their powers and liabilities act and cause particular events (Sayer, 1992).

${ }^{11}$ I begin to elaborate on the data collection techniques (participant observations, archival data, and semi-structured interviews ) in Chapter 3 since they vary for the different studies.
} 
empirical insights led to critical reflections of the observed reality and to distinctions, abstractions and potentially changes in perspectives on the theoretical counterpart. These series of steps were run through iteratively and eventually influenced the final knowledge gain in form of theoretical framing as well as the final contributions to theory and practice in each study and the dissertation overall (cf. Easton, 2010). Departing from an empirical phenomenon, the overall research process can thus also be characterized as phenomenon-based, in which research aims involve the identification, description and conceptualization of a novel or recent phenomenon of interest that is relevant to management research and organization science (Schwarz and Stensaker, 2014; von Krogh et al., 2012).

\section{BoP Context}

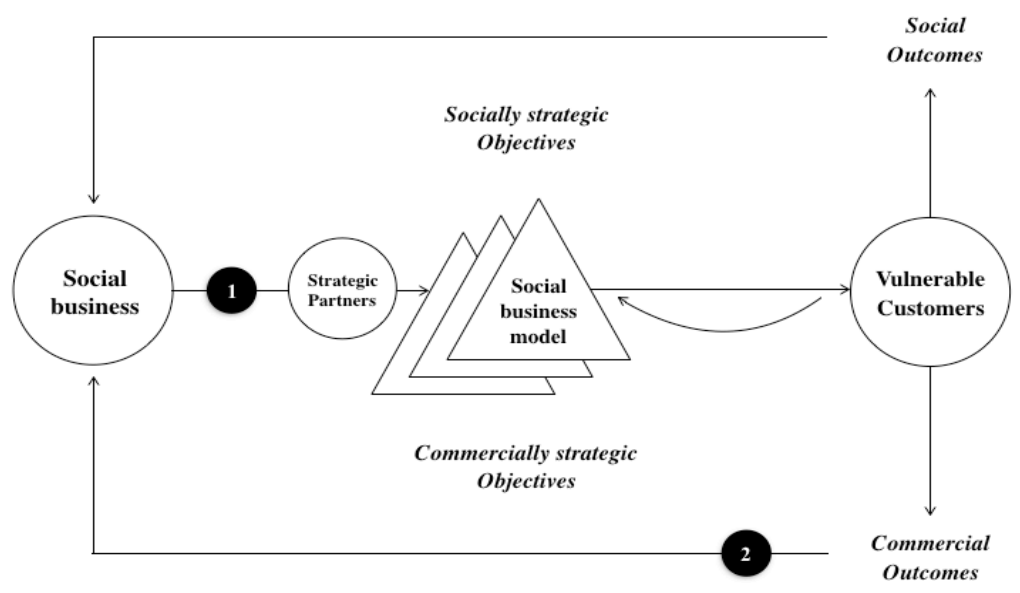

fig.1-1. Empirical Context of the Dissertation

\subsection{Scope of the Dissertation}

In this dissertation, I build and extend on the idea that the design of contextually adequate BM's represents a critical success factor for commercial approaches to poverty-related issues, and theorize how these are achieved in consideration of the afore-mentioned challenges that BoP and hybrid organizational contexts raise. My research thus seeks to shed light on what may constitute social BM's; by examining (1) how social business devise their BM's; and (2) the managerial mechanisms that underpin the design and development of social BM`s, as illustrated in figure 1-1 (p.12). 
Within the scope of the dissertation, the unit of analysis thus shifts from examining social BM 's to the 'firm' level. It encompasses the hybrid organizations that pursue social and commercial objectives simultaneously and the mechanisms they apply to realize the social BM. As illustrated in figure 1-1, this enactment is complex since it may involve strategic partners with similar or different objectives and customers who are vulnerable in terms of purchasing power and other potentially disadvantageous predispositions (illiteracy, cultural heuristics, et cetera ...). BM's are thus understood as mental models and boundary objects that help orchestrate and organize resource and capability combinations beyond the firm boundaries. Directed at customers, this process brings about different types of outcomes that iteratively provide the social business with feedback as to whether objectives have been met or not which in turn leads to continuous adaptation of the BM during the design phase.

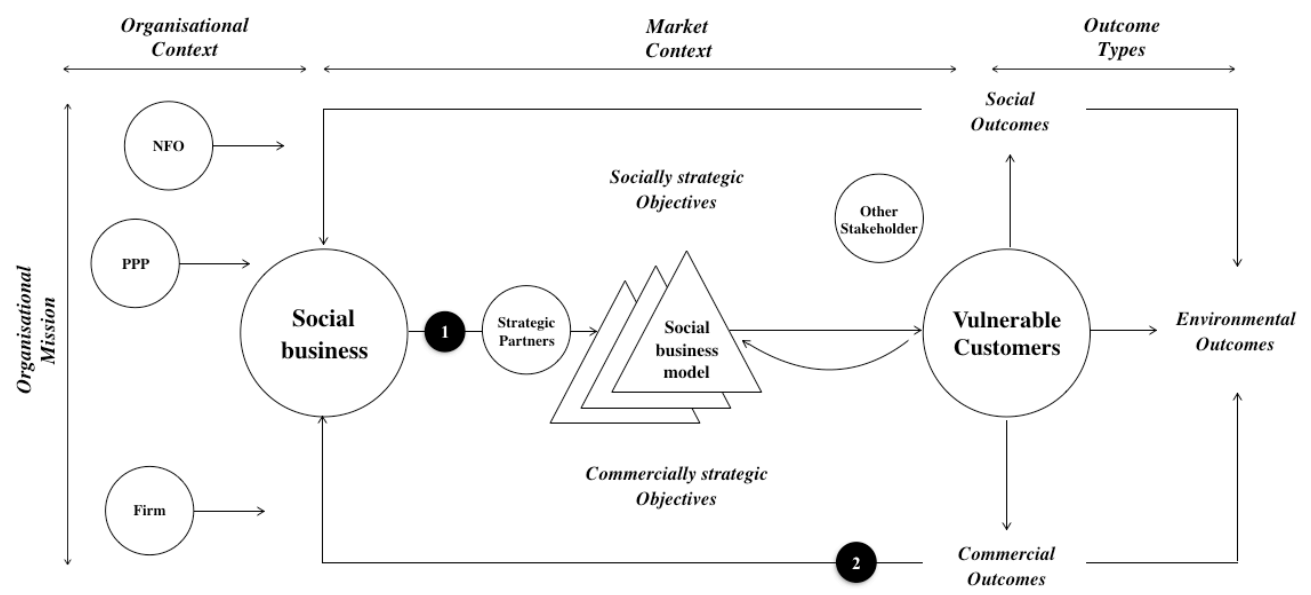

fig. 1-2. Delimitations of the Empirical Context

However, in describing the scope of this thesis, it may also be helpful to briefly address what may not fall under its scope. That is because BoP and SE approaches can lead to variegated choices in organizational set-ups, market environments, and outcomes (see fig. 1-2, p. 13). This complexity is further compounded by the burgeoning number of concepts which abound due the infancy of business solutions for poverty alleviation (Halme et al., 2012). I thus briefly delimit key concepts from related literatures with the aim of reducing potential conceptual opacities. 
In studying SE's operating in the BoP, it is important to point out that the hybrid organizations here studied do not separate social and profit related activities and corresponding missions. Unlike for example organizations such as Non-Profit Organizations (NPO's) that purse Non-Profit Expansion (Bloom and Chatterji, 2009; Westley, 2010) or profit-oriented firms that engage in Corporate Social Responsibility (Blowfield, 2004; Jenkins, 2005) ${ }^{12}$. These forms may share some theoretical overlap with the here illustrated empirical context, yet are less prone to the struggles laid out in the introduction due to their prioritization of one mission closely intertwined with their organizational set-up.

By focusing on SE's as vehicles for market-based poverty alleviation, it is also worth noting that SE's may operate under different market environments (Kerlin, 2013), and governance forms (Ebrahim et al., 2014). Clearly, SE's in developed contexts are less affected by market impediments faced at the BoP, and are likely to experience other managerial challenges more dominantly that did not become salient in the conducted studies. Further, it remains unclear whether approaches discussed in the following hold in the case of differentiated hybrids where consumers do not act as the direct beneficiaries of the business venture (see Battilana et al., 2012). In integrated hybrids, studied in this dissertation, commercial and social activities are interwoven in such a way that consumers act as direct beneficiaries.

Finally, the pursuit of realizing social and commercial outcomes may bring about other forms of direct positive or negative externalities (e.g. environmental implications), as well as indirect externalities (e.g. local economic development). In the scope of this thesis, I focused on the direct social and commercial impacts, experienced. Environmental outcomes and indirect externalities were considered equally important, and were even reported in some case observations. However, the systematic study of these impacts would have likely gone beyond the scope of inquiry due to necessitated changes of analytical levels (Lavrakas, 2008; Davidsson and Wiklund, 2007). These changes would have added to the existing difficulties associated with the retrieval of reliable data in lesser developed poverty contexts at each respective analytical level (cf. Christensen et al., 2017)

\subsection{Composition of the Thesis}

The arguments unfold across the remaining five chapters, illustrated in figure 1-3. The thesis continues with the presentation of its theoretical outline in chapter Two. Therein I present relevant theory streams

\footnotetext{
${ }^{12}$ my aim is to provide archetypical examples, yet clearly a myriad of related concepts exists. These are resumed exhaustively elsewhere (e.g., Aguinis and Glavas, 2013; Cooney and Shanks, 2010; Kolk et al., 2014).
} 
and their theoretical roots. Moreover, I review the current understanding of BM's, develop a perspective on BM design, and articulate theoretical gaps related to the empirical context.

In chapter Three, I provide an overview of the research methodology, the underlying Science of Philosophy, and the research design, as well as reflections regarding the overall research process. Due to the engaged aspect of the research approach (Van de Ven, 2007), I also comment on how research at different points in time during the research process were disseminated with academics and practitioners.

In chapter Four, I argue for the potential of 'social business models' and report on the results of the conducted studies. In particular, I propose a distinct taxonomy of BM's for social goods and services in low-income contexts and explore how BM design takes place in such a context.

Stepping back from the empirical findings, I then discuss the key contributions of the conducted studies to theory, as well as their implications for managerial and institutional practice. Chapter Five also includes considerations about the limitations of the dissertation and avenues for further research.

In the final chapter, I conclude the dissertation with a summary of the dissertation. This summary is followed by a reference list that contains all the works referenced throughout this thesis. Additionally, I appended a selection of research artifacts that resulted from the research process, the main studies, as well as a list of related publications. 


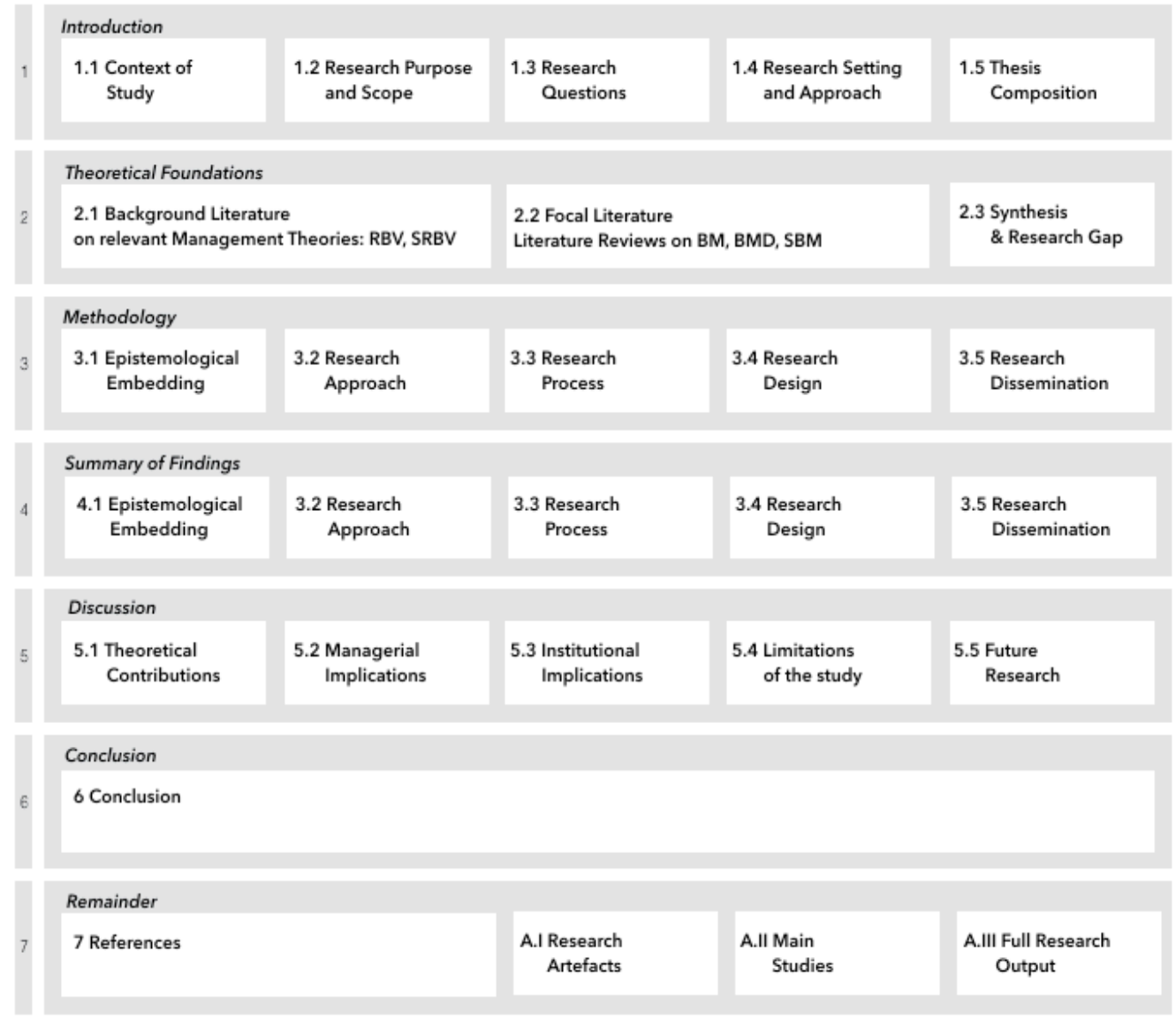

fig. 1-3. Composition of the Thesis 


\section{Theoretical Outline}

It is challenging for organizations to develop social business ventures in BoP contexts. This chapter provides a theoretical frame of reference to better understand this circumstance, by defining and explaining relationships between relevant theory streams (see fig. 2-1). The theoretical outline begins with a brief revisit of key background streams and their underlying perspectives on firm performance. Specifically, I draw on the resource based view of the firm (RBV) and extend this view primarily with considerations about social resources (see 2.1). This discussion allows to extend traditional ideas of firm performance to the context of business solutions for poverty alleviation outcomes. By drawing on the idea that the design of adequate BM's can inform such a research area, I then turn to the focal literatures: BoP, Social Entrepreneurship and BM theory (see 2.2). In the latter section, I define and develop my conceptualizations of BM's and BM design based on self-conducted, systematic literature reviews which have guided the empirical research ${ }^{13}$. I then conclude the chapter with a synthesis that takes place at the intersection of BM's, BoP and SE to conceive BM design in poverty contexts as a theoretical gap (see 2.3).

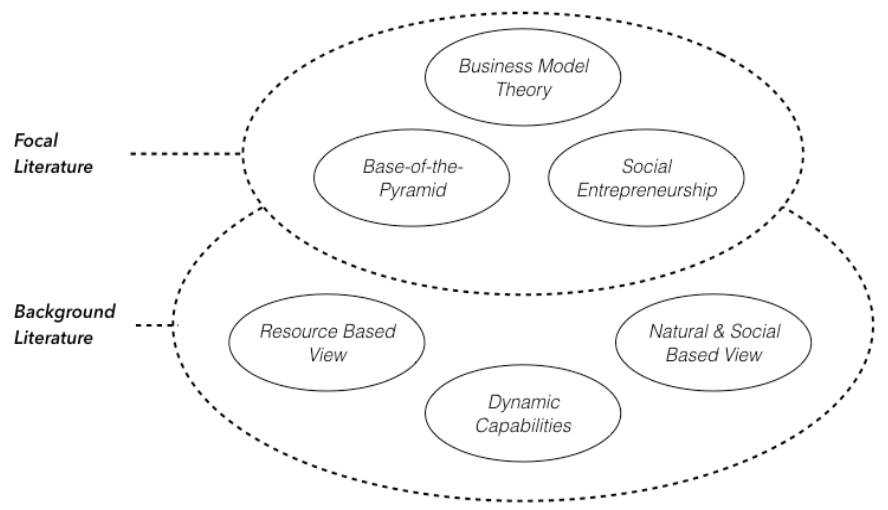

fig. 2-1. Overview of Theory Streams

\footnotetext{
${ }^{13}$ the presented literature reviews were conducted in 2016 and were updated in October-December 2018. The reviews are presented under Appendix I.
} 


\subsection{Background Literature}

Strategic management deals with intended initiatives taken by managers to enhance firm performance, which involves decisions as to how key resources are utilized (Nag et al., 2007). Management research deals thus with developing concepts that help illuminate and solve challenges that relate to resource endowment. At present, the resource-based view (RBV) of the firm (Wernerfelt, 1984) is considered the most influential framework for understanding how to combine resource bases (Newbert, 2007). These perspectives on firm performance and organizational change are briefly revisited. It is well beyond the scope of this dissertation to provide a full review of the RBV, and such reviews have already been undertaken elsewhere (e.g., Acedo et al., 2006; Barney, 2001a). It is, however, fitting to briefly discuss the elements, - such as the extensions to RBV that consider non-traditional resources of environmental and social nature, - which are important for understanding the theoretical underpinnings that have guided my ideas on BM design in the context of social needs in developing economies.

\subsubsection{The Resource-based View}

A longstanding importance has been attributed to the nexus between firms' strategic choices and environmental conditions (Thompson, 1967). In this context, the RBV emphasizes the role of resources as the genesis of competitive advantage (Newbert, 2007). A resource thereby represents an asset of financial, physical, or human nature which a firm may possess (Wernerfelt, 1984). As resources are heterogeneously distributed across competing organizations and some are imperfectly mobile, resource heterogeneity can persist over time (Penrose, 1959). A central proposition in the RBV is that if a firm is to achieve a state of sustained competitive advantage, it must acquire, exploit and bundle valuable, rare, inimitable, and non-substitutable resources (Barney, 2001b).

While it is now generally understood that resources must be valuable, rare, inimitable, and nonsubstitutable, these conditions have also been deemed insufficient (e.g., Bourgeois and Eisenhardt, 1989; Teece et al., 1997). Recent research suggests that the average period for which firms can sustain competitive advantage has decreased over time with the increasing frequency of major, discrete environmental shifts in competitive, technological, social, and regulatory domains (D’Aveni, 1994; Wiggins and Ruefli, 2005). Consequently, firms need to create temporary advantages successively to effectively respond to environmental shocks (Eisenhardt and Martin, 2000). To do so firms apply dynamic capabilities, such that relevant resources can be acquired or altered in a way that their full potential is realized (Teece et al., 1997). Capabilities are understood as something a firm is able to perform, which stems from resources and routines upon which the firm can draw (Karim and Mitchell, 
2000; Winter, 2000). Dynamic capabilities thus refer to an organization's capacity to purposefully create, expand or modify its resource base (Eisenhardt and Martin, 2000; Winter, 2003); and in this vein, extend the premise of the RBV (Wang and Ahmed, 2007).

These theories however do not escape the general problem of finding an appropriate unit of analysis (Foss, 1998). A common choice to study competitive advantage across the contributions within the RBV is the individual resource or capability in focus (Newbert, 2007; Williams, Kraatz and Zajac). Such a choice is particularly sensible when relevant resources are sufficiently well-defined and free-standing. However, if, in contrast, there are strong relations of complementarity and cospecialization among resources or resource-capability combinations, it is the way resources are clustered and how they interplay and fit into the system that is important to the understanding of competitive advantage (cf. Foss, 1998, Miller, 2003). These assertions are in line with more contemporary RBV studies that recognize that possessing relevant resources and capabilities alone does not automatically lead to better performance. Instead resources "must be effectively bundled and deployed [...] to realize a competitive advantage" (Sirmon et al., 2008, p. 919).

In this context, the BM has thus been considered a useful unit of analysis to understand resource and capability combinations; and the RBV as an appropriate theoretical foundation for BM research vice versa (cf. Amit and Zott, 2001; Spieth and Schneider, 2013). Such a perspective puts a focus on sound managerial choices (e.g., Sirmon et al., 2007; Holcomb et al., 2009), but also the ways in which these choices manifest in effective resource and capability combinations. In particular when such efforts regard the development of "novel ways in which to combine those resources and capabilities" (Newbert, 2008, p.761). BM's can thus be understood as a means by which managers align firm assets with their choices to garner better performance. In the context of this dissertation, I hence draw on these assertions and by building on the understanding of BM's as a unit of analysis with the potential of illustrating resource and capability configurations and reconfigurations thereof (see 2.2.3).

\subsubsection{The Social Resource-based View}

Environmentally, the global resource footprint after the millennium required approximately 1.5 planets to sustain life and has surpassed budgeted resources (Global Footprint Network, 2017; Moore et al., 2012). Socially, roughly 900 million people in the developing world live below 1.90 USD per day and possess restricted access to rapidly diminishing natural resources (World Bank, 2016). These challenges are increasingly finding an audience in the wider business sector. On the one hand, 
coverage of CSR topics regarding social and environmental issues in annual reports suggests a growing awareness of additional stakeholder concerns (Tate et al., 2010). On the other hand, firms are increasingly deprecated publicly when not responding more holistically to the call from disadvantaged stakeholders to consider the aim of increased collective wealth as opposed to the wealth of a single firm (Elkington, 1998; Porter and Kramer, 2006; 2011).

These developments suggest that while corporations may still be highly influenced by profit creation for shareholders (Friedman, 1970), competitive advantage may increasingly also be governed by considerations of environmental and social constraints. Since business research has predominantly focused on how companies achieve commercially informed competitive advantage however, the resources and capabilities required to address ecological and, particularly, social issues remain comparatively underexplored (Hart and Milstein, 2003). As a result, it remains unclear which resource and capabilities are of importance and how these are effectively combined. In this context, the natural based view and social based view of the firm have been proposed to extend the theoretical foundations of competitive advantage.

Hart (1995) proposed a natural based view of the firm (NRBV), in which he posits that the natural environment creates constraints on firms' attempts which demand new capabilities to create sustained competitive advantage. Specifically, he argued that "it is likely that strategy and competitive advantage in the coming years will be rooted in capabilities that facilitate environmentally sustainable economic activity" (Hart, 1995, p.991). The NRBV argues that there are three key strategic capabilities. Pollution prevention, which seeks to prevent emissions and waste in a way that is associated with lower costs. Product stewardship, which expands the scope of pollution prevention to include the entire value chain or "life cycle" of the firm's product systems. Finally, a sustainable development strategy, which includes production in a way that can be maintained indefinitely into the future as well as the consideration of related socio-economic concerns.

While the RBV brought to research the terminology and framework needed to understand how companies derive economic sustained competitive advantage from resources and capabilities, and the NRBV addressed the resources and capabilities on the environmental outcome side, neither have focused on social resource or related capabilities. Tate and Bals (2018) specifically built on these views to elaborate on a social resource based view (SRBV). They contend that social resources are informed by commitment from the consumer, connections that allow for social embeddedness in a value network, 
and consistency in regard to behavior change over time (Murphy and Coombes, 2009). As such the focus of the organization lies on the amelioration of a situation experienced by a community in which a challenge resides in (Yunus et al., 2010), and to address these issues through the business venture, all while being responsive and constrained by the need for economic viability (Weerawardena and Mort, 2006).

As social constraints are brought into focus, there is a need to broaden the scope beyond the market and natural environment, to further include a more heterogeneous stakeholder base, more closely linked to the social success of a firm (Tate and Bals, 2018). For that purpose, the BoP and social enterprise literatures offer interesting insights, as they have a long tradition of looking at broad stakeholder bases (e.g., vulnerable communities, traditional providers of social goods, government), often with a focus on poverty settings. In other words, the SRBV becomes especially apparent with the emergence of business ventures that aim to address key societal issues (Lyons, 2013); and stakeholders subjected to this type of issues predominantly live in BoP contexts (London and Hart, 2011). Consequently, BoP and hybrid organizing have emerged as two prominent streams that have informed the theoretical underpinning of this dissertation and help illuminate the social constraints that may affect the resource-capability base and hence performance of a firm (see 2.2).

\subsection{Focal Literature: BoP, Hybrid Organizing and BM's}

As noted, since business research has predominantly focused on how companies achieve commercially informed competitive advantage, the resources and capabilities required to address social issues remain comparatively underexplored (cf. Hart and Dowell, 2011; Tate and Bals, 2016) ${ }^{14}$. As a result, it remains unclear which resource and capabilities are of importance and how these are effectively combined. By drawing on the idea that the design of adequate BM's can inform this research gap (e.g., Seelos and Mair, 2007; Yunus et al., 2010), I thus review the relevant literature on BoP and hybrid organizing which help illustrate how social constraints may affect business ventures in poverty contexts, and systematically review the BM and BM design concepts that are drawn on throughout the appended studies.

\subsubsection{Base of the Pyramid}

Social constraints are particularly prominent in BoP contexts. The BoP represents a large share of the

\footnotetext{
${ }^{14}$ in a recent review, Hart and Dowell (2011) find that the then nascent literature drawing on the natural and social RBV of the firm have mainly centered around pollution prevention and product stewardship, noting that academic inquiry about the link between sustainable development strategies and firm performance have remained "virtually nonexistent" (p.1470).
} 
human population that live at the base of the world's economic pyramid. It counts around one billion people of which the individual survives on roughly less than two dollars per day ${ }^{15}$. These people included in the BoP reside across a wide range of cultures and geographies (Rivera-Santos and Rufin, 2010, Simanis and Hart, 2009). Nonetheless, certain characteristics are common to these contexts, namely that they are often economically constrained and in related social dimensions (London and Hart, 2011; Christensen et al. 2015). Communities living in these impoverished regions within Africa, Latin America, and South-East Asia for example face poor nutrition, lack of public sanitation facilities, limited access to basic health services, or limited education and work opportunities (Calton et al. 2013)

The original BoP proposition propagated that multinational companies could address such issues by selling products to the poor and offering them (financial) services (Prahalad, 2004, Prahalad and Hammond, 2002). This proposition has been extensively criticized over the years however ${ }^{16}$. Some have argued that potential profits to be reaped from emerging economies have been greatly overstated (Karnani, 2009). Moreover, previous attempts frequently involved nonessential consumer goods which yield limited societal benefits, and in effect might do more harm than good (Karnani, 2007b; 2007c). Consequently, the original articulation of the BoP proposition has undergone reorientations.

Later views, referred to as $B o P 2.0$, began to emphasize the poor in their role as potential producers and co-creators. Further studies also included important issues surrounding impoverished and vulnerable communities such as identity and related biases (cf. Arora and Romijn, 2011). Discussions around ways to serve the BoP have thus gradually expanded to the role of smaller entrepreneurial organizations who by virtue of their social embeddedness have been deemed more apt to address important issues surrounding vulnerable people (Kolk et al., 2014; Weerawardena and Mort, 2006). Nonetheless, the implementation of the BoP proposition remains challenging (Kistruck et al., 2012). Distinctive conditions underlie new venture creation in BoP contexts and have led some to argue that substantial adaptations of existing BM's are required (London et al., 2010; Olsen and Boxenbaum, 2009).

For one, BoP contexts are characterized by extreme resource scarcity (Sutter et al., 2014). Resource scarcity implies that BoP consumers possess limited or nonexistent disposable income, and

\footnotetext{
${ }^{15}$ Worldbank report from 2017, see http://iresearch.worldbank.org/PovcalNet/index. htm?1.

${ }^{16}$ see Landrum (2007) for a more complete overview of these criticisms.
} 
are thus unlikely to pay for anything outside the sphere of absolute necessity (Collins et al., 2009). Indeed, some have viewed non-consumption as a defining condition which significantly limits the scope and nature of a BoP business venture (Simanis, 2011; Chiliova and Ringov, 2017). Moreover, resource scarcity may also affect the productive potential of BoP contexts (Seelos and Mair, 2007). Unlike in developed contexts, organizations in BoP contexts cannot typically draw on existing access to required resources and capabilities. For example, in many poor contexts, opportunities for publicly funded education are limited and private education is costly, further exacerbating low levels of education, high illiteracy rates and limited employment choices (Sen, 1999; Zoogah et al., 2015). Since low levels of education prevent sufficient opportunities to engage in paid employment that reach beyond agricultural production (Karnani, 2007a; Kistruck et al., 2011). Moreover, it may be difficult to operate and produce locally due to a lack of productive facilities with relevant technology (Bhatti and Ventresca, 2013; Seelos and Mair, 2007). As a result, new ventures struggle to find productive resources due to a widespread lack of employment, experience, technical competencies, and especially of managerial competencies, required to run business operations.

A second defining condition of BoP markets is the lack of well-functioning institutions, commonly referred to as institutional voids (Khanna and Palepu, 1997; Mair et al., 2012). These voids encompass economic, political, governmental and socio-cultural dimensions. Economic constraints manifest in low cash flow, limited access to traditional venture capital markets, and higher susceptibility toward potential market shocks in developing economies (Upreti et al., 2015). Political and governmental constraints become salient in form of poor governance, corruption and weak legal systems (Kaufmann et al., 2009). Importantly, such constraints also involve infrastructure challenges such as weak physical infrastructure or lack of reliable electricity that constrain distribution channels in large and fragmented market environments (De Soto, 2000; Kistruck et al., 2013; Panapanaan et al. 2016). Finally, socio-cultural issues manifest not only in a lack of disposable income, but also in cultural and educational disparities, which have shown to produce purchasing decisions that may differ significantly from developed market contexts (Viswanathan et al., 2010; Viswanathan et al., 2014).

Market actors in BoP contexts thus cannot rely on institutions that in other contexts provide rules and routines to ensure efficiency, consistency and fairness across market actors (De Soto, 2003). Institutional voids result where there is a dearth of established rights, transparency and supervising that enforce intermediaries (Khanna and Palepu, 1997; Mair et al., 2012). Compounding this problem, BoP economic activity is frequently informal and unregistered by official authorities, limiting the extent to which regulations can be enforced in case of unethical behaviors (Hart, 2010, Webb et al., 2009). Such 
information asymmetries and enforcement of sound business practices produce disincentives towards entrepreneurial initiatives (Anokhin and Schulze, 2009). For example, financial institutions cannot rely on customer information to offer services, nor can they make use of guarantees in case of suspended loan repayments (Webb et al., 2013). Similarly, businesses often operate based on oral or symbolic contracts (Bucher et al., 2016; Godfrey, 2011). Consequently, individuals and organizations know that potential profits from entrepreneurship might not be protected (Mair and Marti, 2009). Organizations operating in these contexts hence need to bear substantial transaction costs, which can make their involvement in markets less attractive (Hand and Gold, 2014; Khanna and Palepu, 2000).

New business ventures thus face extreme resource scarcity in form of financial and human resources on the one hand (Seelos and Mair, 2007), and institutional voids on the other (Mair and Marti, 2009; Mair et al., 2012). Consequently, they are informed by managerial issues that differ from ones researched in ToP markets (Chiliova and Ringov, 2017; George et al., 2012). These distinct difficulties that pertain to BoP markets may explain why the development of financially sustainable businesses for BoP markets has been considered more challenging than expected (Kistruck et al., 2012). Such views are mirrored in practice, where only few examples of organizations targeting the BoP have managed to reach significant organizational scale and size, and consequently, large-scale social impact (Kayser and Budinich, 2015; London and Hart, 2004). As a result, recent BoP scholarship is increasingly calling for a more nuanced inquiry into the mechanisms under which the BoP proposition can be realized successfully (Chiliova and Ringov, 2017; George et al., 2012; Kistruck et al., 2012; London et al., 2012).

\subsubsection{Hybrid Organizing}

In another line of research, commercially informed ways of addressing social constraints has frequently been associated with Social Entrepreneurship (cf. Hart and Dowell, 2011; Tate and Bals, 2018). SE's cater to needs related to such issues through their business venture, thereby operating across well-established sectors (Battilana and Lee, 2014). Foremost due to the pursuit of revenue generation associated with organizations in the private sector and the achievement of social and environmental goals associated with nonprofit and governmental organizations (Di Domenico et al., 2010; Jay, 2013). Similar to corporate ventures, commercial objectives of SE's involve organizational routines ${ }^{17}$ of opportunity recognition, the creative application of minimal resources, and endurance of associated risks to create a successful business venture (Chell, 2007; Peredo and McLean, 2006).

\footnotetext{
${ }^{17}$ consider Cyert and March (1963), Feldman and Pentland (2003)
} 
Social objectives, in contrast, entail routines that create some form of primary social value, and in doing so, may also entail secondary forms of social value creation such as particular organizational motivations (e.g., hiring of disenfranchised people, empowerment activities), or environmentally sustainable attitudes (Santos, 2012).

The boundaries between business and charity have historically been considered distinct and often incompatible, yet both also viewed as quintessential to the functioning of a social enterprise (Besharov and Smith, 2014). In fact, studies suggest that excelling at both commercial and social mission and the underlying objectives is vital to successful long-term performance (e.g., Battilana et al., 2015; Dacin et al., 2011). This context has led some to suggest that SE's represent an "extreme case" of hybridization and consequently provide a setting uniquely suited to the study of hybrid organizing and the achievement of social development goals through market-based approaches (Battilana and Lee, 2014; Doherty et al., 2014).

Similar to Prahalad's (2009) assertions that concurrent social impact and commercial profits are realizable at the BoP imply that a hybrid motivation would form the basis of any business involvement at the BoP. Some have further theorized how such motivations may be beneficial to the development of a new business venture in the BoP context (Chiliova and Ringov, 2017). For example, Dacin and colleagues (2010) assert that SE's are good at managing resource dependence and use their community embeddedness and relational ties with stakeholders to secure external resources and leverage relationships to initiate mechanisms that help overcome market barriers. Strong relational ties with stakeholders become then the conduit for resources and cooperative working arrangements that seek to fill institutional voids (Doherty et al., 2014). In this vein, others have argued that the combination of commercial activity and social purpose in one organization might seem paradoxical, yet that by spanning categorical boundaries, organizations signal increased flexibility and gain wider access to resources and sources of legitimacy (Dart, 2004; Pontikes, 2012; Teasdale, 2010).

Yet, a growing body of research suggests that SE's are challenged by the pursuit of their dual mission. With only nascent regulatory regimes emerging (Defourny and Nyssens, 2006), SEs become resource dependent toward constituents that span different sectors and thus reify conflicting institutional logics (Pache and Santos, 2013). Such that SE's manage competing demands of multiple stakeholders, related to their commercial and social goals (Battilana and Dorado, 2010; Bridgstock et al., 2010). Organizations however find ease in organizational homogeneity, developing mindsets and routines, supporting one mission at the neglect of the other (Ebrahim and Rangan, 2010). A social bent 
that for example takes shape in strong social imprinting has shown to lead to immediate social performance, yet also eventual stagnation, due to the negative association that imprinting has with commercial productivity in the medium term (Battilana et al., 2015). By the same token, SE's are inherently at risk of losing sight of their social mission and giving priority to their commercial activities, because they are dependent on generated revenue to financially sustain their operations (Dacin et al., 2011). In turn, drifts can eventually threaten the organization's raison d'être and survival (Ebrahim et al., 2014; Pache and Santos, 2010). Hybridity tensions hence lay traps for mission drifts which are counterproductive and potentially destructive.

Further SE literature provides a more complex picture of how hybridity may impact business ventures in poverty contexts. For example, managers in SE's need to assess and decide upon how to divide already scarce resources between social and commercial objectives (Moizer and Tracey, 2010; Nicholls, 2010). Moreover, operating in an environment strongly characterized by its institutional voids, SE's may have to examine and make trade-offs as to which voids they want to or can address. Organizations that target higher-income segments in developing countries for example can be more profitable but less impactful than those targeting the BoP, vice versa. For example, microcredit organizations that target the poorest customers typically earn lower total profits than those targeting more affluent clients (Cull and Morduch, 2007; Hermes et al., 2011). The complexity of hybridity related motivations hence may also exacerbate issues of resource scarcity and institutional voids, thereby intensifying existing management challenges (Pache and Santos, 2013).

Extant theory and evidence however suggest that organizations interested in developing scalable solutions for poverty contexts may under certain circumstances also benefit from a hybrid motivation (Battilana and Dorado, 2010). Hence, the provision of relevant goods and services for poor consumers which is at the heart of a social enterprise adds hybrid organizing as a further condition to successfully develop a business venture in poverty contexts. Yet, although a growing body of literature has amassed to reify social entrepreneurship into a legitimate domain of academic inquiry (cf. Dacin et al., 2011; Doherty et al., 2014) with managerial issues that pertain to this domain (e.g., Battilana and Dorado, 2010; Ebrahim et al., 2014), there have been less systematic examinations into the mechanisms under which hybrid organizations can actively deal with hybridity (cf. Battilana and Lee, 2014).

A prominent perspective in such research is resource dependency theory (Pfeiffer, 1978). In this sense, scholars suggest that social businesses bond cross-sectorially to attain critical resources and 
capabilities, and thereby become resource dependent. These ties become problematic because while different stakeholders may express different motivations, such tensions manifold when stakeholders come from different sectors (Battilana et al., 2015; Ebrahim et al., 2014). In turn, scholars have proposed various means of cultivating hybridity, accounting for multiple objectives and dealing with different stakeholder groups by drawing on theories of bricolage (Battilana and Dorado, 2010). However, such views fail to take into consideration the highly dynamic nature, weak regimes of appropriability and the inability to enforce contractual agreements that BoP context bear. It remains unclear how sustainable such bricolage approaches are for resource appropriation and their ability to deal with institutional voids in general. Moreover, such theories shed limited light on how attained resources or capabilities are combined to form commercially viable ventures. Such a perspective may explain also the dearth of economically self-sufficient models of social businesses, studied and illustrated in the literature (see 2.2.3).

\subsubsection{BM Theory}

The social businesses examined in the scope of this dissertation however painted a more complex picture than the reviewed BoP and SE literature. Said themes would suggest that the social businesses primarily rely on strategic partnerships, whose resources and capabilities inform value generation. In addition, the observed organizations spent considerable time in designing and implementing viable value creation and appropriation mechanisms to devise BM's which could target social needs profitably. To further develop such a perspective, I thus define important constructs that guided this pursuit: BMs, $\mathrm{BM}$ design and BM design in socially constrained poverty contexts (see fig. 2-2).

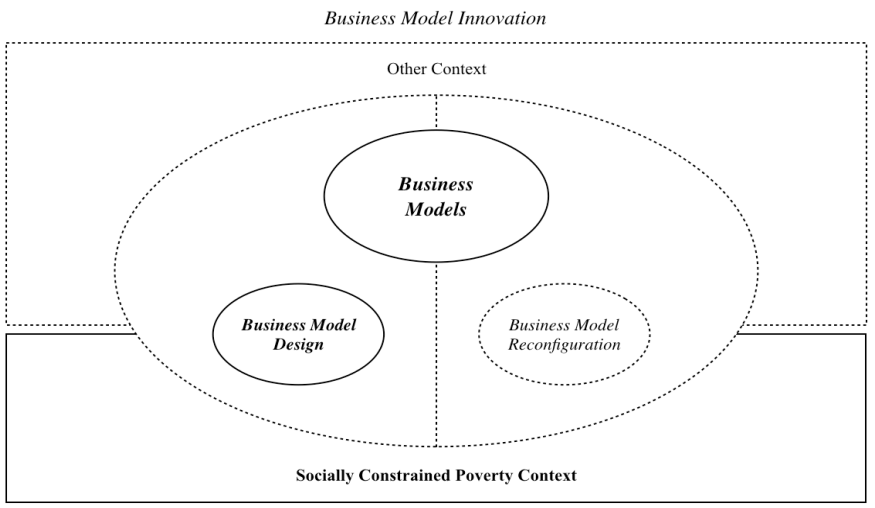

fig. 2-2. Overview of BM Literature 
The emergent working definitions are a result from three independent literature reviews ${ }^{18}$ (see fig 2-2). In a first review, I systematically reviewed seminal contributions that have shaped the conceptualization of BM's ${ }^{19}$. In doing so, I drew on an essentialist view of a BM to proffer key dimensions of a BM (see p. 28). Then, by considering BM's as a locus of innovation per se, the second review draws on a functionalist view of the BM. Such a view allows to explore the relevant topic of BM Design, which precisely occurs when BM's are devised and implemented (see p. 33).

\section{An essentialist View on BM's: the BM and its constituent elements}

A BM outlines "the manner, by which the enterprise delivers value to customers, entices customers to pay for value, and converts those payments to profit" (Teece, 2010, p. 172). In this sense, a BM is comprised of a set of interlocking activities, governed by organizational units that implement those activities both within and outside the focal firm. A BM is designed to create and deliver value through the production and delivery of its value proposition to a specific market segment (Santos et al., 2009; Teece, 2010). Due to the complex interactions between BM activities and organizational units, competitors find it difficult to discover and replicate such activities within their own organizational context. This pursuit helps differentiate the firm's offering and may ultimately lead to a competitive advantage.

In this sense, BM's build upon central ideas from Strategy (Casadesus-Masanell and Ricart, 2010; Zott and Amit, 2008). While Strategy puts greater emphasis on the competitive advantage aspects of the business, BM's reflect key value-generating activities and how these interlink (Demil et al., 2015). Amit und Zott's (2001) seminal contribution in Strategic Management Journal represents maybe one of the key, foundational works that marked the beginning of BM theory ${ }^{20}$, in which they precisely discuss elements and drivers for economic success of young Internet companies. They contend that central features important for economic value creation are best explained through BM's and thus suggest that BM's should be attributed the status of a unit of analysis.

Despite its perceived importance since pre-classical times, the BM however represents a relatively young concept in Management research (Teece, 2010). Previous reviews show that the large majority of extant literature was not published before the mid-1990's (Ghaziani and Ventresca, 2005;

\footnotetext{
${ }^{18}$ the reviews are presented separately in detail under Appendix I.

${ }^{19}$ based on the standard assumption that citation counts are a valid measure of influence (cf. Peteraf et al., 2013), limitations related to such an approach are detailed under Literature Review I, in Appendix I.

${ }^{20}$ theory pertaining to business models and business modelling (e.g., Foss and Saebi, 2017).
} 
Zott et al., 2011) ${ }^{21}$. Two self-conducted key word searches with the terms "business model" and "dynamic capabilities", of which the latter emerged around the same time, extend this observation. Compared to the total of 400 articles published on dynamic capabilities, roughly another 900 articles alone were published on BM's between 2016-2018, the time in which this dissertation was written (see fig. 2-3).

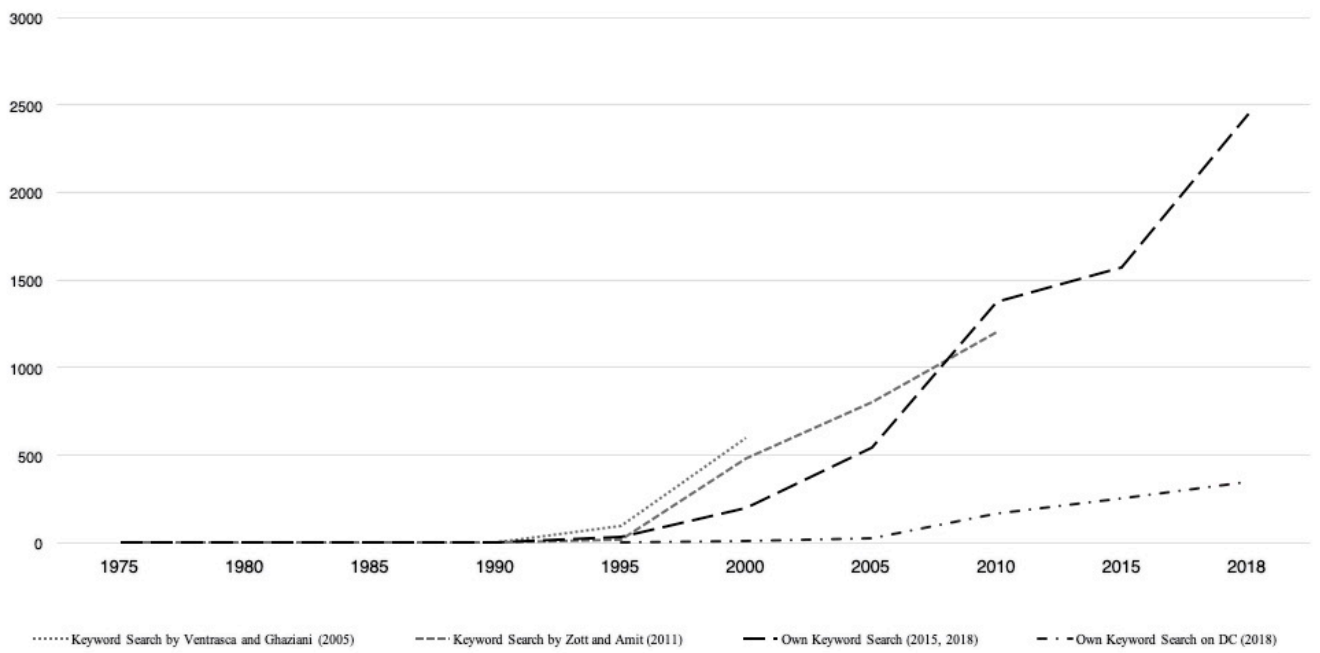

fig. 2-3. No. of Publications on BM's and Dynamic Capabilities ${ }^{22}$

The exponential increase of contributions after the mid 1990's is often associated with the new commercial opportunities that were fostered by the proliferation of the Internet (e.g., Amit and Zott, 2001; Teece, 2010) and the globalization of industries, dependent on post-industrial technologies (Perkman and Spicer, 2010). Since then, it has been widely adopted by scholars and practitioners alike, as evidenced by the growing number of publications that address the construct, including articles, books, and book chapters in the business press and academic journals (see fig. 2-3). It appears that two

\footnotetext{
${ }^{21}$ these findings result from a frame analysis based on ABI/INFORMS by Ghaziani and Ventresca (2005), in which articles between 1975 to 2000 were considered; and a literature review by Zott and colleagues (2011) who corroborate these results in a EBSCOhost search, showing another 700 articles had been published between 2000-2010 on the topic.

${ }^{22}$ the additional search strings applied: "TITLE (dynamic PRE/0 capabilities) AND ( LIMIT-TO ( SUBJAREA, "BUSI") AND ( LIMIT-TO ( LANGUAGE , "English") )"; "TITLE(business PRE/0 model) AND ( LIMIT-TO ( SUBJAREA , "BUSI" ) AND ( LIMIT-TO ( LANGUAGE , "English" ) )"(October, 2018). Counts were cumulated for each 5-year bin.
} 
decades later, the concepts of BM's and, closely related, BM innovation (BMI) have indeed both gained considerable traction in macro-management research (e.g., Foss and Saebi, 2017; Massa et al., 2017).

While the first assertions of Amit and Zott (2001) were primarily embedded in the context of the Internet Economy, the review of seminal contributions (see table 2-1, p.29) shows that a growing body of works extended BM research to other domains such as Strategic Management, Innovation, Technology Management and Entrepreneurship. This may explain the high variation in conceptualizations initially rendered to describe what a BM may consist of. This initial stream of BM research appeared not only to be characterized by high conceptual proliferation, but also by criticism regarding a lack of conceptual clarity and theoretical footing. For example, in one of the earliest contributions already, Margretta (2002) states BM's together with strategy may be the „most sloppily used terms in business [...] stretched to mean everything - and end up meaning nothing”. Similarly, Chesbrough and Rosenbloom (2002) argue that while the term is often used, "it is seldom defined explicitly" (p. 532).

In reviewing early contributions with more recent ones ${ }^{23}$, conceptual similarities can be observed despite divergent semantics. The BM is frequently understood as system levelled construct that goes beyond the matters of organizational design (e.g., Amit and Zott, 2001; Teece, 2010). For example, the BM has inter alia been referred to as a model (Baden-Fuller and Morgan, 2010), an architecture (Chesbrough and Rosenblom, 2002; Teece, 2010), a logic (Casadesus-Masanell and Ricart, 2010), or a set of decisions (Casadesus-Massanell and Ricart, 2010). These illustrations highlight thus an essentialist view of a BM (cf. Doganova and Eyquiem-Renault, 2009). Since essentialism is the view that every entity possesses a set of attributes that are necessary to its identity and function (Cartwright, 1986). The BM in this sense then represents the unit or entity of interest.

By adopting such a view, scholars have also suggested various attributes or elements (Johnson et al., 2008) that then imbue meaning to the construct. As a result, the BM is viewed as a configuration of multiple components, which involve interdependent strategic decisions in regard to their combination (Shafer et al., 2005; Casadesus-Massanell and Ricart, 2010). Similarly, Magretta (2002, p.6) argues that "business models describe, as a system, how the pieces of a business fit together." As a configuration of components, the reviewed literature suggests that a BM can comprehensively segmented into three mutually exclusive dimensions, which further highlight their descriptive nature.

\footnotetext{
${ }^{23}$ Results from a self-conducted, systematic literature review considering seminal contributions, see Appendix I.
} 
Tab. 2-1. Seminal BM Definitions

\begin{tabular}{|c|c|c|c|}
\hline Works & $\begin{array}{l}\text { Citation } \\
\text { p.a., (total) }\end{array}$ & BM Conceptualization & Components \\
\hline $\begin{array}{l}\text { Chesbrough } \\
\text { and } \\
\text { Rosenbloom } \\
\text { (2002) }\end{array}$ & $\begin{array}{l}304 \\
\left(4^{\prime} 864\right)\end{array}$ & $\begin{array}{l}\text { "The functions of a business model are to articulate the value } \\
\text { proposition, }[\ldots] \text { identify a market segment, }[. . .] \text { define the } \\
\text { structure of the value chain, }[. . .] \text { estimate the cost structure and } \\
\text { profit potential, }[\ldots] \text { describe the position of the firm within the } \\
\text { value network, }[\ldots] \text { and formulate the competitive strategy" (p. } \\
533)\end{array}$ & $\begin{array}{l}\text { Value proposition } \\
\text { Market Segment } \\
\text { Value Chain } \\
\text { Value Network } \\
\text { Cost and Profit Structure }\end{array}$ \\
\hline $\begin{array}{l}\text { Morris et al., } \\
(2005)\end{array}$ & $\begin{array}{l}208 \\
\left(2^{\prime} 705\right)\end{array}$ & $\begin{array}{l}\text { "A business model is a concise representation of how an } \\
\text { interrelated set of decision variable in the areas of venture } \\
\text { strategy, architecture, and economics are addressed to create } \\
\text { sustainable competitive advantage in defined markets" (p. 727) }\end{array}$ & $\begin{array}{l}\text { Value creation } \\
\text { Target customer } \\
\text { Value capture } \\
\text { Strategy }\end{array}$ \\
\hline $\begin{array}{l}\text { Teece } \\
(2010)\end{array}$ & $\begin{array}{l}198 \\
(1 ’ 585)\end{array}$ & $\begin{array}{l}\text { "A business model articulates the logic and provides data and } \\
\text { other evidence that demonstrates how a business creates and } \\
\text { delivers value to customers. It also outlines the architecture of } \\
\text { revenues, costs, and profits associated with the business } \\
\text { enterprise delivering that value." (p. 173) }\end{array}$ & $\begin{array}{l}\text { Customer benefits } \\
\text { Revenue streams } \\
\text { Technologies }\end{array}$ \\
\hline $\begin{array}{l}\text { Zott et al. } \\
(2011)\end{array}$ & $\begin{array}{l}141 \\
(988)\end{array}$ & $\begin{array}{l}\text { "The core logic of a business model, instead, revolves around a } \\
\text { firm's revenues and costs, its value proposition to the customer, } \\
\text { and the mechanisms to capture value" (p. 22) }\end{array}$ & $\begin{array}{l}\text { Value proposition } \\
\text { Value capture }\end{array}$ \\
\hline $\begin{array}{l}\text { Amit and } \\
\text { Zott (2001) }\end{array}$ & $\begin{array}{l}95 \\
\left(1^{\prime} 600\right)\end{array}$ & $\begin{array}{l}\text { "A business model depicts the content, structure, and } \\
\text { governance of transactions designed so as to create value } \\
\text { through the exploitation of business opportunities" (p. 511). }\end{array}$ & $\begin{array}{l}\text { Content } \\
\text { Structure } \\
\text { Governance } \\
\text { Revenue Model }\end{array}$ \\
\hline $\begin{array}{l}\text { Margretta } \\
(2002)\end{array}$ & $\begin{array}{l}58 \\
(906)\end{array}$ & $\begin{array}{l}\text { "The business model tells a logical story explaining who your } \\
\text { customers are, what they value, and how you will make money in } \\
\text { providing them that value" (p. 4) }\end{array}$ & $\begin{array}{l}\text { Value proposition } \\
\text { Customer definition } \\
\text { Revenue logic }\end{array}$ \\
\hline $\begin{array}{l}\text { Johnson et } \\
\text { al. (2008) }\end{array}$ & $\begin{array}{l}91 \\
(508)\end{array}$ & $\begin{array}{l}\text { "A business model consists of four interlocking elements that } \\
\text { taken together create and deliver value" (p. 52) }\end{array}$ & $\begin{array}{l}\text { Customer value } \\
\text { proposition } \\
\text { Key resources } \\
\text { Key processes } \\
\text { Profit formula }\end{array}$ \\
\hline $\begin{array}{l}\text { Zott and } \\
\text { Amit (2010) }\end{array}$ & $\begin{array}{l}82 \\
(657)\end{array}$ & $\begin{array}{l}\text { A business model depicts the content, structure, and } \\
\text { governance of transactions designed so as to create value } \\
\text { through the exploitation of business opportunities. }\end{array}$ & $\begin{array}{l}\text { Content } \\
\text { Structure } \\
\text { Governance, }\end{array}$ \\
\hline $\begin{array}{l}\text { Casadesus- } \\
\text { Masanell and } \\
\text { Ricart (2010) } \\
\end{array}$ & $\begin{array}{l}64 \\
(508)\end{array}$ & $\begin{array}{l}\text { "Business model is a reflection of a firm's realized strategy" } \\
\text { (p.205) }\end{array}$ & $\begin{array}{l}\text { Choices } \\
\text { Tactics }\end{array}$ \\
\hline $\begin{array}{l}\text { Zott and } \\
\text { Amit (2008) }\end{array}$ & $\begin{array}{l}47 \\
(469)\end{array}$ & $\begin{array}{l}\text { "The business model is a structural template of how a focal firm } \\
\text { transacts with customers, partners, and vendors; that is, how it } \\
\text { chooses to connect with factor and product markets" (p. 3) }\end{array}$ & $\begin{array}{l}\text { Content } \\
\text { Structure } \\
\text { Governance }\end{array}$ \\
\hline $\begin{array}{l}\text { Baden-Fuller } \\
\text { and Morgan } \\
(2010)\end{array}$ & $\begin{array}{l}46 \\
(372)\end{array}$ & $\begin{array}{l}\text { "One role of business models is to provide a set of generic level } \\
\text { descriptors of how a firm organizes itself to create and distribute } \\
\text { value in a profitable manner" (p. 157) }\end{array}$ & $\begin{array}{l}\text { Value creation } \\
\text { Value distribution } \\
\text { Profit Equation }\end{array}$ \\
\hline $\begin{array}{l}\text { Shafer et al. } \\
(2005)\end{array}$ & $\begin{array}{l}38 \\
(498)\end{array}$ & $\begin{array}{l}\text { "We define a business model as a representation of a firm's } \\
\text { underlying core logic and strategic choices for creating and } \\
\text { capturing value within a value network" (p. 202) }\end{array}$ & $\begin{array}{l}\text { Value creation } \\
\text { Value capture } \\
\text { Strategic choices }\end{array}$ \\
\hline
\end{tabular}

source: own table, ordered by citation count, see Appendix 8.1 for review process

The first aspect relates to the value proposition which translates salient or latent customer needs 
into a business opportunity (e.g., Zott and Amit, 2008; 2010). The design of such propositions requires thus a preliminary definition of what the offering consists of and which market segment it will appeal to (Chesbrough and Rosenbloom, 2002). To this end, firms include hypotheses about customers and the market environment (Margretta, 2002). Consequently, the value proposition can be understood as the element that subsumes relevant features of a business' offering (e.g., products, services) and describes how these may provide value for customers (Morris et al., 2005; Teece, 2010). Value in this sense is then considered by what a buyer may ay for a product or service (Chesbrough and Rosenbloom, 2002).

The value generating characteristic of BM's emerges as another key dimension of BM's (Baden-Fuller and Morgan, 2010). Value creation mechanisms thereby depict the quintessential resources, capabilities and processes to realize the proposed value (Morris et al., 2005; Johnson, 2008), as well as the involvement of external actors in these mechanisms (Shafer et al., 2005; Demil and Lecocq, 2010). In this context, some have especially emphasized the importance of the "value network" (Shafer et al., 2005). The value network created around a given business can shape the supply of complementary goods, and the demand through the creation of network effects (Chesbrough and Rosenbloom, 2002). This aspect makes the BM construct also externally oriented and may illuminate relationships that facilitate value creation for firms in their market environment.

Further, the way in which organizations appropriate value from their BM represents another salient theme across BM literature. The value capture that has sometimes also been depicted as a profit equation (Johnson et al., 2008) explains how the firm generates revenues based on costs associated with the realization of the value proposition and the pricing logics (Magretta 2002, Teece, 2010). It acts as the bottom line of the BM, translating the previous elements in costs and revenue flows (Magretta, 2002). Further, Chesbrough and Rosenbloom argue that target margins provide the justification for the real and financial assets required to realize the value proposition. These assertions suggest that BM's provide also an earnings logic that details how firms appropriate value generated from their operations.

As a configuration of components, several authors highlight the centrality of optimally matching BM components to maximize the joint performance (Johnson et al., 2008; Margretta, 2002). When components achieve fit firm-internally (Morris et al., 2005) as well as externally with the business environment (Zott and Amit, 2008), it consists of a coherent set of reinforcing strategic choices. Mismatches however occur when components have adverse or conflicting implications for one another (Demil and Lecocq, 2010), and seriatim threaten firm performance or survival (Magretta, 2002; Teece, 2010). Particularly, these developments point toward BM's capacity to explain management issues that 
may have not yet substantially figured in previous Strategy research (McGrath, 2010; Markides, 2013).

To conclude this section; although the BM has been viewed as an elusive concept allowing for considerable flexibility, it is growingly understood as a unit of analysis with the ability to depict an organization's strategy. Scholars describe it as a system leveled construct that focuses on value. As a result, the $\mathrm{BM}$ is viewed as a configuration of multiple components, which involve interdependent strategic decisions (Shafer et al., 2005; Casadesus-Massanell and Ricart, 2010). The premise of such an essentialist definition being that a BM can sensibly be segmented into mutually exclusive components, which in turn are amenable to analysis in its components or their configuration. The BM from an essentialist perspective then explains both the elements as well as the interplay between a business' value proposition, creation and capture mechanisms ${ }^{24}$.

\section{A functionalist View on BM's: designing BM's}

Over the past 15 years, the BM field has expanded from conceptualizing the BM at a given point in time to applying a more dynamic perspective in which BM changes are studied over time (Saebi and Foss, 2016). In this context, BMs have been discussed as a separate source of innovation "that complements the traditional subjects of process, product and organizational innovations" (Zott et al., 2011, p.1032). BMI has come into prominence, as drivers such as globalization, deregulation and technological change have profoundly altered dominant logics in established industries, which have forced organizations to develop new BM's or reconfigure existing ones (Massa and Tucci, 2013; Mitchell and Coles, 2003). BM design refers to the former process, in which managers or entrepreneurs are confronted with the design of novel internal organizational structures. That is, grouping activities, roles, or positions within the organizations that may span organizational boundaries (Amit and Zott, 2015; Zott and Amit, 2010).

Such a view adopts a functionalist view of the BM, as suggested by Doganova and EyquemRenault (2009). Thereby understanding the BM as a boundary object which helps coordinate a set of actors (Star and Griesemer, 1989). In this sense, the BM works as both a calculative and a narrative device addressed to members of the organization and third parties that allows to jointly explore and assess a market and to bring the business venture and necessary network that supports it into existence. The authors argue that the flexible mix of narratives and calculations within the BM in turn enables it to circulate across actors, which, consequently endows it with a performative role.

\footnotetext{
${ }^{24}$ This particular understanding also aligns with more recent reviews that point to definitional convergence in the BM literature (cf. Foss and Saebi, 2017).
} 
These assertions point to the difficulty in identifying BM elements and their configuration that fit a given market opportunity, technology, and other conditions (Andries and Debackere, 2013; O'Conor and Rice, 2013). To optimally enact a BM, scholars argue that firms thus must engage in ongoing experimentation (Athreye, 2005; Sabatier et al., 2010) and trial-and-error learning (Demil and Lecocq, 2010; Sosna et al., 2010) to reduce high levels of information asymmetry and uncertainty (Thomson and MacMillan, 2010). These circumstances may demand the development of new processes for experimentation, evaluation and learning from early failures (Chesbrough, 2007; Sosna et al., 2010). In turn, such processes can foster knowledge and expertise that acts as an important strategic resource, since it is valuable, rare and difficult to imitate or substitute (Barney, 1991) with the ability to improve the BM in regard to superior performance (Amit and Schoemaker, 1993; McGrath, 2010).

Zott and Amit (2010) have shown that the design of a BM can be characterized by design themes which detail the system's dominant value creation drivers. Design themes are configurations of $\mathrm{BM}$ elements, or the degree to which they are orchestrated and connected by distinct themes; such as the adoption of novel BM elements (Novelty), the lock-in of stakeholders (Lock-In), complementarities between activities or partner (Complementarities), and increased efficiency (Efficiency) in BM's (Zott and Amit, 2007).

In this vein, some studies have reported positive effects of Novelty and Lock-in themes on performance or innovation outcomes (e.g., Gerdoçi et al., 2018; Gronum et al., 2016; Kulins et al., 2016; Wei et al., 2014). For example, in a recent article, Gerdoçi and colleagues (2018) find that novelty-centred BM design significantly affects firm performance while efficiency-centred design do not. Instead, as the authors find, efficiency-centred designs appear to positively moderate the relationship between novelty-centred BM design and firm performance. Some work in this area has also expanded these concepts to specific industries. For example, Hahn et al. (2018) examined different sustainability driven start-ups and identified four clusters of design themes: niche novelty, integrated novelty, intermediary approaches, and platform approaches.

Another important concept in this line or research examines design antecedents. Amit and Zott's (2010) study suggests that founders of new business ventures must pay attention to goals, templates, collaboration, and constraints during the design phase to achieve value-creating BM's. When founders balance the goals of value creation (for all stakeholders) and capture (for their focal 
firms), they consider, and likely strengthen, the incentives of other stakeholders to participate in the firm's BM (Amit and Zott, 2001). By subconsciously or actively drawing inspiration from templates, i.e. BMs that become working examples in an industry (Doganova and Eyquem-Renault, 2009), templates may affect BM design outcomes. Further, BM design may be affected by collaboration, in form of cooperation with partners during the design process, or the cooperation as a defining characteristic of the resulting BM design. Constraints then represent the final antecedent identified, which include environmental constraints, such as economic or regulatory conditions, as well as internal constraints that concern the availability of activity-enabling assets of the firm.

Recent research on the creation of novel BM's also suggests that such design processes may be moderated by different capabilities. For example, a study by Pucci and colleagues (2017) finds that different capabilities spur the adoption of different BM's, and that different BM designs in turn show variable impacts on firm performance. However, this type of research remains rather nascent and fragmented. Some articles for example examine the importance of co-creation with different stakeholders (de Oliveira and Cortimiglia, 2014; Nenonen and Storbacka, 2010; Tolkamp et al., 2018), or manufacturing flexibility (Wei et al., 2014). While others explore the utility of decision-making support systems and frameworks in the BM design process, especially in the area of high tech (Cosenz, 2017; Daas et al., 2013; D'Souza et al., 2018; Kajanus et al. 2014; Pfisterer et al., 2016).

BM design can thus be understood as the process, by which businesses engage in developing a novel BM. The generation of devising and implementing a novel BM can be guided by design themes, which suggest the degree to which BM elements are orchestrated and connected by distinct themes. Moreover, BM design can be largely affected by design antecedents and moderated by managerial capabilities that appear relevant for reducing information asymmetries and other market uncertainties. In this process the BM itself may act as a boundary object that fulfils calculative and narrative functions. As a device, it supports managers in devising and developing their BM and eventually imbues it with performative value.

\subsection{Research Gap: Social BM's}

The theory outline highlights the emergence of social businesses which are emblematic of increases in activity at the interface between business and charity (Battilana et al., 2012). These theoretical developments have been underpinned by the extensions of traditional Management theories. Specifically, the SRBV brings into focus the social objectives and resources, social businesses may employ to achieve commercial as well as social performance (Hart, 2015; Hart and Dowell, 2010). 
These developments however also raise import questions as to how social business venture creation takes place where hybridity may compound existing managerial challenges, new ventures typically face. These issues are then further complicated in the context of the BoP, where organizations operate under extreme resource scarcity and various institutional voids. By exploring these matters, more can be learnt about managerial issues, hybrid organizations face as they pursue potentially conflicting objectives.

In this context, BM design has been proposed as a means to address conditions of poverty and hybridity with the potential to guide the assembly of resource and capability combinations that lead to commercial and social value generation (e.g. Sanchez and Ricart, 2010). Already the early BoP literature spoke of radically new or reshaped BM's as a way to succeed in the dynamic and uncertain environment of BoP markets (Prahalad and Hammond, 2002; Prahalad, 2004; 2009). In a recent review on BM's and their innovation, Foss and Saebi (2017) note that the need to target low-income consumers can result in significant BM innovations. Similarly, attempts to studying efficient scaling of social businesses has also sparked interest in BM's and their design (Demil et al., 2015; Seelos and Mair, 2007; Yunus et al., 2010).

However, both theory and practice have lagged this rhetoric. Multiple scholars have observed that few examples of organizations targeting the BoP have actually managed to grow into large organizations by developing successful business ventures at a larger scale (Chiliova and Ringov, 2017; Kayser and Budinich, 2015; Kistruck et al., 2012, other). Successful examplars such as Aravind Eye Hopitals and Grameen Bank in India have fueled enthusiasm for the creation of scalable BM's at the BoP (cf. Rosenberg, 2013; Yunus et al., 2010), yet have often received donations. As a result, it remains unclear how social businesses can design financially viable and sustainable BM's that can be scaled without large third-party donations.

Similarly, a careful reading of works at the intersection of BM, BoP and SE literatures shows that while BM's for social and commercial value generation are indeed more frequently invoked, it appears that relatively few studies offer theoretical explanations that explore the nature of BM's and their underlying conditions or related capabilities to enact them (cf. Dohrmann et al., 2015; Hlady and Servantie, 2010; Mair and Schoen, 2007; Margiono et al., 2014; Mason and Chakrabati, 2017; Ortega et al., 2014; Seelos and Mair, 2005; Sinkovics et al., 2014; Yunus et al., 2010) ${ }^{25}$. This thesis focusses on two specific gaps that arise from this line of work.

\footnotetext{
${ }^{25}$ Based on a self-conducted literature review considering 'social business model design', see Appendix I.
} 


\section{Gap 1: Constituent Elements of Social BM's and their Configuration}

Wilson and Post (2013, p. 728) write "the tight coupling of all three elements - the social mission, the market-based approach, and the BM inherent in the implementation - is integral to the creation of social value". More generally, BM design has been considered detrimental in defining and refining a firm's strategy (e.g., Porter, 2001; Chesbrough and Rosenbloom, 2002; Osterwalder et al., 2005), and has also shown to affect the initial performance of entrepreneurial organizations (cf. Amit and Zott, 2015). Social businesses will hence make strategic choices and weave together a set of interdependent activities, which in turn shape the BM (Casadesus-Masanell and Ricart, 2010; Amit and Zott, 2010). It is thus likely that some design choices in regards to individual BM elements or the entire configuration may lead to better outcomes than others. How are these models then devised?

The current literature offers mixed and limited theory on this matter. On the one hand, some scholars have refrained from defining what a social BM may consist of (cf. Seelos and Mair, 2005; Ortega et al., 2014), or have built on generic BM definitions whose elements have not been conceptually redefined to include social resources or capabilities (Dohrmann et al., 2015; Sinkovics et al., 2014). On the other hand, some have offered differing taxonomies of social BMs. For example, Yunus and colleagues (2010) highlighted the importance of devising novel value propositions and constellations that together can create a positive profit equation. Yet others also highlight aspects such as the customer interface, enabling technologies or social value capture as an especially important BM element to succeed in BoP markets (Ausrod et al., 2017; Mason and Chakrabarti, 2017; Sabatier et al., 2017). A review of such taxonomies (see Appendix I) shows that the concept of social BM remains emergent and that there still exists a lack of conceptual clarity in this field, which is further evidenced in the varying language adopted to describe these models and their elements. These differing conceptualizations in turn may thwart a more cohesive understanding of social BM design in regards to the elements that constitute a social BM and their configuration as a whole.

Further, a key issue in previous conceptualizations of social BM's is that value appropriation is often overlooked. Yet, successful exploitation of social needs requires the translation of said needs into a financially viable BM's. Especially in the context of poverty, one would assume that value appropriation would be paid particular scholarly attention to. As discussed earlier, customers may not only be extremely poor and vulnerable but as a result may also display distinct purchasing behaviours. Previous research however has for the most part focused on design challenges, such as access to critical production resources or social legitimacy, which relate mainly to value creation activities (e.g., 
Seelos and Mair, 2005; Mair and Schoen, 2007). This is problematic because a social mission does not negate nor diminish a focus on commercial value appropriation. Instead, appropriation is crucial for the sustainability of such ventures and the continued creation of social value (Dacin et al., 2011). Especially in the context of social goods and services that otherwise would not be available, value capture allows for the reallocation of benefits to multiple stakeholders, not only toward customers (Wilson and Post, 2013). Thus, more research is required to better understand value appropriation activities and commercial performance in social BM's.

\section{Gap 2: Social BM Design and Dynamic Capabilities}

Another implicit assumption found in this line of work is that social BM's are plannable. A typical impression rendered is that BM's once ideally devised (e.g., Yunus et al., 2010; Seelos and Mair, 2007), are then ready to be scaled by the social business and/or involved stakeholders (e.g., Ortega et al., 2014). This impression appears in line with a bulk of studies that has concentrated on individual factors or events that have led to innovative BM's or elements thereof. Such a view is also particularly prominent in the recent work of Chiliova and Ringov (2017) who have built on template replication work (Winter and Szulanski, 2001; Winter et al., 2012) to identify factors that promote template development and replication. By adopting such a static view, current research however largely ignores theoretical developments related to BM design in TOP markets and stands in stark contrast to BM scholars who have been vocal about the role of uncertainty in the development of a successful BM.

Successful exploitation of an entrepreneurial opportunity requires the translation of that opportunity into a viable BM (Amit and Zott, 2001). However, for many ventures, this is not straightforward, given the considerable levels of uncertainty they are confronted with, both in terms of technical and market feasibility (Anderson and Tushman, 1990). This is especially true in remote rural areas where what the market will become depends on multiple decisions by various stakeholders and market developments can be highly dynamic (Sachez and Ricart, 2010). As a consequence, the set of feasible opportunities and viable BM's is not predictable in advance (Alvarez and Barney, 2007), and BM's cannot be fully planned ex ante (Massa and Tucci, 2013). Therefore, organizations aim to discover and exploit new models through experimentation and learning (McGrath, 2010). BM's then take shape through a discovery-driven process (Sosna et al., 2010). Consequently, such a process places a significant premium on capabilities that enable experimentation and learning. 
However, current research offers little insight into the mechanisms that foster such discoverydriven processes that can ultimately lead to social $\mathrm{BM}$ innovation ${ }^{26}$. As a result, we know less about managerial capabilities ${ }^{27}$ that can influence social BM design and implementation, nor how these can be organized effectively. By adopting a such a functionalist view of the BM, it is possible to better focus on the intra-organizational mechanisms but also the individuals involved in such processes which social business employ to develop social BM's. Thus, more longitudinal research is necessary to study such mechanisms that lead to scalable BM's.

\section{Synthesis}

There exists thus a shared view that BM's employed by SE's in poverty contexts manifest distinct elements and design, and that SE's require different resources and capabilities to scale them effectively. As such, these models have been coined as social BM's (Yunus et al., 2010) and can be understood as a BM archetype. However, it remains less clear as to what constitutes such an archetype and how these are effectively designed and developed in poverty settings. A careful reading across the $\mathrm{BM}$, BoP and SE literatures show that while BM's for social (and commercial) value generation are frequently invoked, theoretical developments remain fragmented (Dohrmann et al., 2015; Hlady and Servantie, 2010; Mair and Schoen, 2007; Margiono et al., 2014; Mason and Chakrabati, 2017; Ortega et al., 2014; Seelos and Mair, 2005; Sinkovics et al., 2014; Yunus et al., 2010) ${ }^{28}$.

By addressing the two aforementioned gaps of devising and developing such models, the aim of this dissertation is then to contribute to these two gaps in practice and theory. First, by exploring how the context of socially constrained, low-income markets influences the nature of social BM's, by asking the question of how social businesses devise them (see MRQ1). To do so, I study how social businesses have emerged in the context of the unfolding pro-poor informal water market which have developed scalable BM's in market environments highly prone to resource scarcity and institutional voids. Then, I adopt a more dynamic perspective to explore different capabilities that appeared to have positively affected the BM design process. In turn, addressing the question of how social BM's are implemented (see MRQ2). In the following chapter, I elaborate on how the related research was conducted.

\footnotetext{
${ }^{26}$ same been said about BM theory in general

${ }^{27}$ treated synonymously to mechanisms

${ }^{28}$ based on a self-conducted literature review considering 'social business model design', see Appendix I.
} 


\section{Research Strategy}

Due to the high novelty associated with the study context, the research in this dissertation subscribed to an exploratory, critical realist perspective. Section 3.1 provides a brief description of the ontological, epistemological and axiological views that are positioned within said philosophical tradition. I the following sections, I then describe the methodological aspects associated with the research strategy. These manifested in a retroductive and pragmatist research approach informed by multiple case studies to infer mechanisms that may facilitate successful social BM design. These methodological aspects are thus extensively described in terms of the research approach (see 3.2), process (see 3.3), and embedded research design (see 3.4). Figure 6 provides a schematic overview of these dimensions and their relation to one another. Finally, I complement the chapter with details about the dissemination of the research throughout the research process.

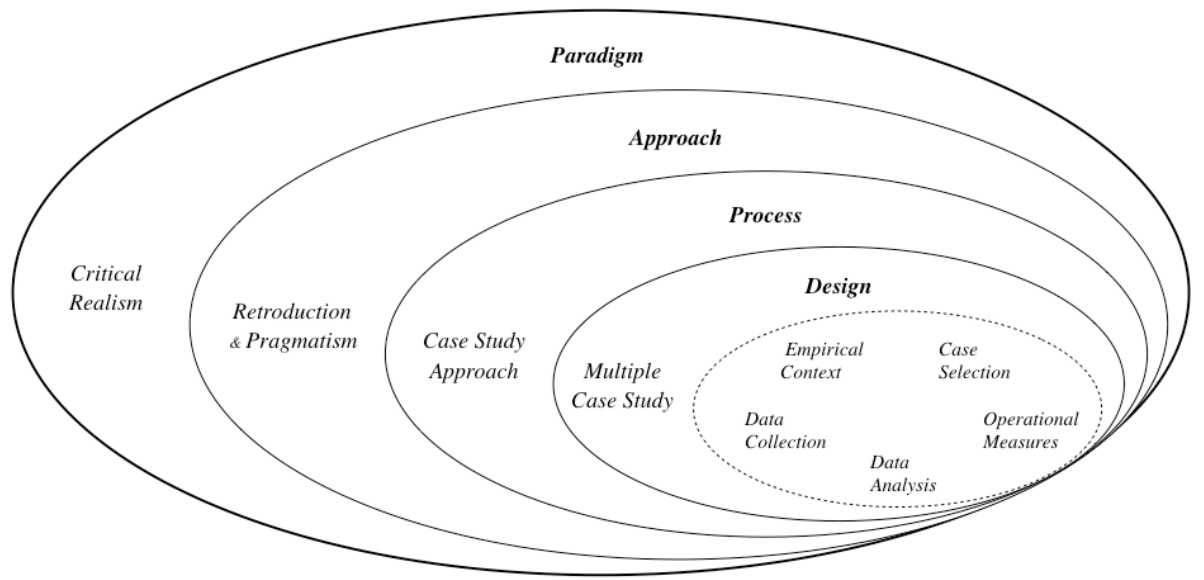

fig. 3-1. Overview of Methodology (adapted from Saunders et al., 2015) 


\subsection{Research Paradigm}

The five studies adopted a critical realist science of philosophy (cf. Sayer, 1992) ${ }^{29}$. Such a view implies a realist ontology, a subjective epistemology (and methodology), as well as a value-laden axiology (Easton, 2010). Since the study of managerial issues in poverty contexts has traditionally led to the adoption of other paradigms ${ }^{30,31}$, I provide a brief account of the ontological, epistemological, and axiological characteristics of critical realism (see tab. 3-1). Specifically, with a focus as to how they informed the interpretation of data throughout the dissertation.

Tab. 3-1. Major Concepts of Critical Realism

\begin{tabular}{lll}
\hline Dimensions & Key & Description \\
& Aspects & \\
\hline
\end{tabular}

Ontology

Open

reality that exists at a given point in time, independent of our knowledge

Complex

Reality consists of open systems and causality can only be understood as tendencies, because events are the result of contingent combinations of many underlying structures ${ }^{\star}$ and mechanisms ${ }^{\star \star}$. Thus, empirical regularities are rare.

Reality contains structures and mechanisms that provide very different causal potential. Potential may or may not result in actual events depending on the interaction with other conditions and mechanisms. Conversely, the same type of event may have different causes

$\begin{array}{lll}\begin{array}{l}\text { Epistemology } \\ \text { knowledge (gain) at a }\end{array} & \text { Fallible } & \begin{array}{l}\text { Knowledge is never certain, absolute, or definitive due to biases. Critical realism relies } \\ \text { on further data collection to distinguish among alternative explanations. }\end{array}\end{array}$
given point in time

Social Science is a human activity and occurs in social contexts. It is concerned with gaining new knowledge. Critical realists believe in rational judgment through pluralism.

\begin{tabular}{|c|c|c|}
\hline $\begin{array}{l}\text { Axiology } \\
\text { values that inform } \\
\text { world views }\end{array}$ & $\begin{array}{l}\text { Value- } \\
\text { laden }\end{array}$ & $\begin{array}{l}\text { Researcher acknowledges bias by world views. Researcher trie } \\
\text { errors to increase objectiveness as much as possible. }\end{array}$ \\
\hline
\end{tabular}

The conducted studies were guided by a realist ontology in the sense that I assumed a physical world - in this context, primarily the business venture and its immediate environment, - to exist despite being socially constructed (Weick, 1979). This world exists independent from human perception of it

\footnotetext{
${ }^{29}$ Critical Realism is associated with the philosophical approaches by Bhaskar (1978) and Sayer(1992). It combines a general philosophy of science with a philosophy of social science to describe an interface between the natural and social worlds.

${ }^{30}$ referring to the world view (Kuhn, 1962) that an individual researcher or research community adopts in the research process, consisting of a set of key assumptions, beliefs, norms and values, commonly characterized in terms of ontology, epistemology, methodology and axiology respectively (Guba and Lincoln, 1994).

${ }^{31}$ notably, interpretivism or positivism in consideration of the reviewed literature in chapter 2.
} 
(Blackburn, 2005). In the critical realist tradition, the physical world is made up of real objects, structures, and mechanisms that science attempts to create knowledge about. They exist independently from human cognition thus, because they remain unaffected by changes in knowledge about them (Bhaskar, 1978).

Realists however contend that whatever is known or believed - such as informant's opinions can lead to an approximation of reality (Sayer, 1992). Yet that improved accuracy about it will depend on sufficient pluralism (Blackburn, 2005). In particular, since individual cognition bases on different cultures, social norms, and mental biases (Van de Ven, 2009). Consequently, I embraced pluralism in form of multiple theoretical perspectives (discussed in Chapter 2), as well as triangulation at the researcher, data collection and informant level. Additionally, I aimed at cumulating perceived realities of managers especially knowledgeable about their BM design through human and digital interactions, which in turn constituted the inputs for the scientific process. These interactions were thus geared toward the collection of authoritative knowledge (cf. Slavin, 1984) ${ }^{32}$.

Further, much attention was paid to the axiology of the research pursuit. The axiology adopted can be characterized as value-laden (Kivunja and Kuyini, 2017), because a strong emphasis was laid on acknowledging and reducing biases in the research process (see 3.3.5). Furthermore, ethical considerations were also included in the research process, because I aimed to produce research outcomes that were beneficial to participants and related stakeholders. During the case selection period (see 3.3.2), I ensured that participating case organizations saw value in participating in the studies. I did this by providing information about the study purpose and the value of their contribution to potential respondents prior to participation in a non-technical manner (i.e. no jargon). Moreover, I also aimed at reducing the response burden of participants in consideration of their available time through extensive use of archival data. Finally, to ensure confidentiality, I guaranteed that data would only be presented in anonymized form to ensure anonymity as much as possible prior to data collection at the managerial and employee level ${ }^{3334}$. This arrangement meant that managers felt less hesitant to provide access to data and respondents could answer more freely throughout interviews.

\footnotetext{
${ }^{32}$ Slavin (1984) identifies three further types of knowledge: intuitive, logical and empirical.

${ }^{33}$ prior to data collection, respondents were also guaranteed that data would only be presented in anonymized form to protect the anonymity of informants within the organizations.

${ }^{34}$ the detailed arrangements of confidentiality were considered highly important by the participating case organizations. Consequently, non-disclosure agreements were established for the data collection and dissemination process.
} 


\subsection{Research Approach}

The engaged research approach became salient as an iterative and pluralist learning process through the continuous synthesis and division of gained data from field studies, practice and the underlying literature. That is, based on theoretical and empirical preconceptions, research questions were developed which created the foundation for the empirical data collection. The then gained empirical insights led to critical reflections of the observed reality and to distinctions, abstractions and potentially changes in perspectives on the theoretical counterpart. These series of steps were run through iteratively and eventually influenced the final knowledge gain in form of theoretical framing as well as the final contributions to theory and practice in each study and the dissertation overall (cf. Easton, 2010).

Specifically, theory building occurred retroductively. Retroduction means moving backwards and is a mode of inference in which events are explained by postulating mechanisms that are capable of producing them, considering what must be true in order to make an event possible (Sayer, 1992). Unlike inferences drawn from induction and deduction, it involves moving from a conception of some phenomenon of interest to a conception of different mechanisms that could have generated the given phenomenon (Lawson, 1997). As such, the process is comparable to abduction, which has also been suggested as appropriate for case research and other pragmatist approaches (Dubois and Gadde, 2002).

Consequently, a causal explanation was sought that identifies social businesses as structured entities and the mechanisms that connect them to cause an event to occur under conjunctures, which may be unique (Sayer, 1992, p.116). To achieve methodological fit (Edmonson and McManus, 2007) with this research aim and related questions prior state of knowledge (McGrath, 1964), research context and consistency with paradigmatic views (Gephart, 2004) were considered. Such that the studies in this thesis eventually drew on a critical realist multiple case study (Easton, 2010) to explore those mechanisms that may produce successful social BM's (see research design 3.3). Hereby, understanding a case study as an ideal type which allows for a detailed examination of single examples of a class of phenomena through an iterative research process (Gerring, 2004). Even though it may not provide reliable information about a broader class, it may still be useful in the preliminary stages of an investigation, as is the case for social BM's. 
Indeed, one reason for the case based research approach was sought because of the nascent theory state ${ }^{35}$ in regard to BM's in the context of poverty and hybrid organizing (cf. McGrath, 1964; von Krogh et al., 2012). Although conceptual clarity about BM's as a unit of analysis is increasing, theories about social BM's have not yet attracted formal theorizing ${ }^{36}$. Case study methodology is especially conducive to theory development, in which data collection techniques in the field can strongly shape the researcher's understanding of the phenomenon (Lee et al., 1999; Siggelkov, 2007). These considerations are further mirrored in the open-ended nature of the MRQ's that consisted of why and how questions, traditionally associated with qualitative methodologies (Yin, 2017).

Since business in low-income markets are considered a complex social phenomenon with multiple players involved, yet no clearly evident boundaries (Sanchez and Ricart, 2010), the research setting further advocated a case based approach sought after. It lent itself to study BM design activities in their natural environment, emphasizing the qualities of related structures and mechanisms as actors experience them (Denzin and Lincoln, 1994). Such emic ${ }^{37}$ views are deemed especially important in poverty related research settings to illuminate and adequately represent potentially neglected dimensions of poverty in the empirical context (Chambers, 2007).

Finally, the case based approach eventually reified in the form of multiple case studies (Gerring, 2004; Yin, 2017) that was consistent with the paradigmatic view adopted throughout the research process (cf. Gephart, 2004). Since critical realist case research allows the researcher the opportunity to tease out and disentangle a complex set of factors and relationships, inducing a process of iterative-parallel and retroductive research (Easton, 2010; Verschuren, 2003). This aspect meant that I continuously moved back and forth between diverse steps in the research process and related research projects (see fig. 3-2). This flexibility that case research allowed for was considered a major advantage to theoretically make sense of the considered empirical context and facilitated data collection, aside from other benefits traditionally associated with case based research ${ }^{38}$. Moreover, the longitudinal application of this method rendered deeper insights into the managerial mechanisms, and the consequences of said actions over time (cf. Bluhm et al., 2011; van de Ven and Poole, 2005).

\footnotetext{
${ }^{35}$ considering prior knowledge states among mature, intermediate or nascent (Edmonson and MacManus, 2007).

${ }^{36}$ comparing multiple, recent reviews that produce significantly varied categorizations and themes which ought to illustrate the field and state of research (cf. Spieth et al., 2014; Foss and Saebi, 2017); and scholars who advocate a more functionalist perspective to develop the research domain (e.g., Doganova and Renault-Eyquiem, 2009).

${ }^{37}$ expressing the views, concepts, categories and values of insiders.

${ }^{38}$ consider the works of Gephart (2004), Eisenhardt (1989), Flyjvberg (2006), Yin (2009).
} 


\subsection{Research Process}

Three major phases characterize the research process, in which the case-based research design was embedded. Figure 3-2 visualizes the research process and key steps taken throughout it. In the first phase, I familiarized myself with the empirical context by beginning relevant literature reviews, suitable research methods and settings. During this phase, study I and II were conducted and greatly supported the above stated aims, especially in terms of familiarizing myself with potential cases. In these studies, 20 and 12 cases respectively were studied, and led subsequently to further case selection criteria and the case selection of three performant cases for the remaining studies (see case selection 3.4.2). Consequently, the first phase led to the 'definition and design' of the research pursuit.
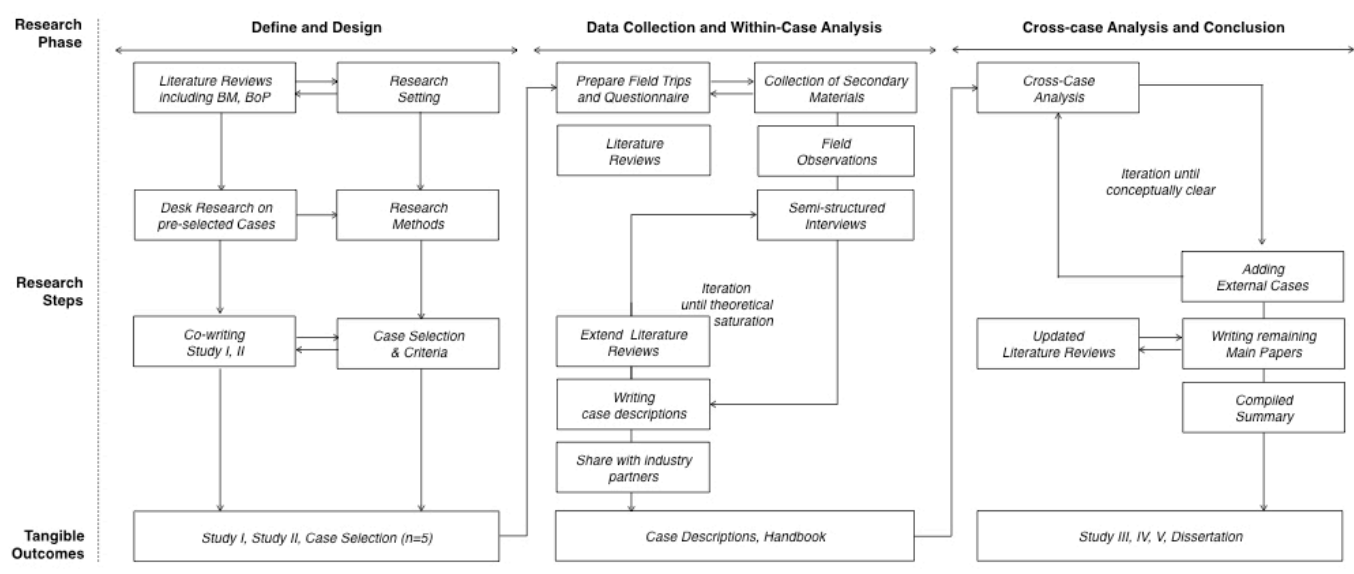

fig. 3-2. Key Steps taken in Research Process (adapted from Yin, 2009, p.57)

In the second phase, the actual fieldwork in the subset of case organizations took place. Data was collected and analysed iteratively, strongly characterizing the retroductive research approach highlighted so far. Moving back and forth between theory and the observed, the process resulted in individual case descriptions for each case (Miles and Huberman, 1994). The second phase thus was characterized by the 'data collection and within-case analysis'. In the final stage, themes observed across cases became salient and were translated into theoretical concepts that guided the production of the final studies and the overall dissertation. The third phase hence concluded the research process through the 'cross-case analysis and conclusion' making. 


\subsection{Research Design}

The case-based research design embodied in this investigation can be described in five major choices that were planned at the outset of the research process. The first choice consisted in selecting and familiarizing myself with a useful research setting (see 3.3.1). The water market in developing economies proved to not only be a pragmatic and relevant context, but also a theoretically suitable setting, in which to study social business modelling. This choice then informed eventually the case selection procedure (see 3.3.2) and the necessary data collection methods (see 3.3.3), both of which evolved throughout the research process. Further, I applied within and across case comparisons to infer relevant theoretical themes that relate to social BM's (see 3.3.4), and implemented multiple operational measures (Lincoln and Guba, 1985) throughout the implementation of the former choices to ensure trustworthy results based on the emergent themes (see 3.3.5).

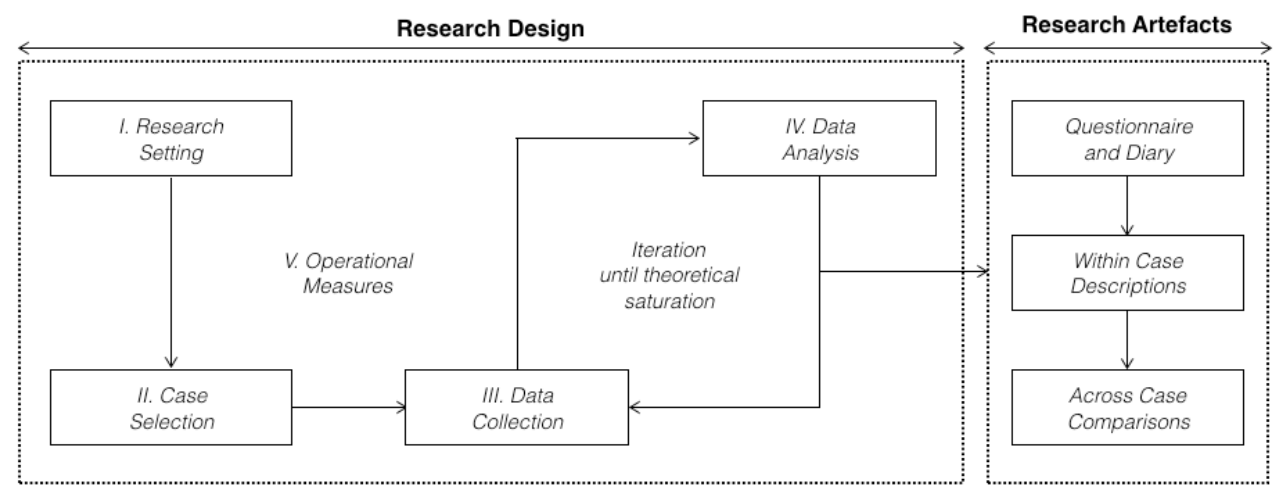

fig. 3-3. Key Methodological Choices in Research Design (own image)

\subsubsection{Research Setting}

I chose the informal water market in low-income markets as our empirical context for pragmatic (see Van de Ven, 2009) and theoretical (Patton, 2002) reasons. In broad terms, the research setting of this study encompasses the water sector of currently still developing countries. Developing countries are associated with a lack of industrial base and reflect lower rates of life expectancy, education and income in comparison to developed countries (O'Sullivan and Sheffrin, 2003) ${ }^{39}$. Currently it is

\footnotetext{
${ }^{39}$ as commonly compounded by the UN into the normalized Human Development Index measure, where nations with medium to low human development exhibit values roughly from 0.7 down to 0.3 respectively (UN, 2015).
} 
estimated that half a billion people in such areas lack access to improved drinking water sources (e.g., Kostyla et al., 2015; WHO, 2015). Yet, even improved sources commonly refer only to water sources, kept separate from use by animals and fecal contamination. As such, they are not deemed safe for human consumption. Various commissioned studies thus suggest that safe drinking water, free from feces and other toxins, may well exceed a population well beyond two billion people (e.g., Bain et al., 2014).

Developing countries hence suffer from a lack of governed water management systems and experience innovation deficits in urban water management (Potts, 2009). The previous absence of governmental initiatives has led philanthropic institutions to address such issues. These traditional approaches however often have limited geographical and temporary reach ${ }^{40}$. Moreover, studies have shown that market-based approaches are proven to lead to more long-term adoption of potable water in lesser developed contexts, compared to traditional, philanthropic give-away strategies (JonesChristensen et al., 2015). As such, philanthropic projects often come with an expiry date and cannot ensure long lasting access to affordable safe drinking water. To illustrate such views, a quote from a prominent practitioner in this sector:

"The fact is, few understand markets, and fewer still really truly care about market distortions; Africa, Asia and Latin America are littered with crappy filters, unused or in disrepair from improper use. The real revolution in water treatment will only occur when inventors and filter promoters take the time to understand customers, markets, and products." - Ned Breslin, CEO Water for People, 2014

This absence of governmental initiatives and inadequacy of philanthropic approaches has led to the emergence of informal ${ }^{41}$ water markets, which private actors have begun to tap into - particularly, the more rural the region at hand. Here, multiple organizations, both profit and/or socially oriented, have successfully begun to adopt market-based approaches that embrace BM thinking and design to commercialize different water purification technologies on a household or community level. This situation hence represented an ideal setting for the research pursuit, because it allowed to study unusual organizations that persevered despite the market barriers frequently associated with BoP markets, and despite mission related tensions that are often associated with hybrid organizations. Consequently, the setting provided initial processes of social business 'modelling' in light of this unfolding pro-poor

\footnotetext{
${ }^{40}$ consider a series of case examples studied by Hystra (2011).

${ }^{41}$ implying a situation where water quality is not ensured, nor monitored by a regulatory body.
} 
informal water market in developing economies that may be extendable to other industries that operate in low-income markets, targeting disfranchised customer segments with social value propositions.

\subsubsection{Case Selection}

The aim of the case selection was then to identify viable BM designs of organizations in our research setting. The twofold process is illustrated in fig. 3-4 which depicts the evolution of the case selection strategy in terms of selection criteria and selected cases. In the first part, we began to screen programs and reach out to international agencies ${ }^{42}$ for referrals. Since, from the outset, it was clear that not many social businesses existed that have attained a larger scale, which would suggest the design and implementation of viable BM's.

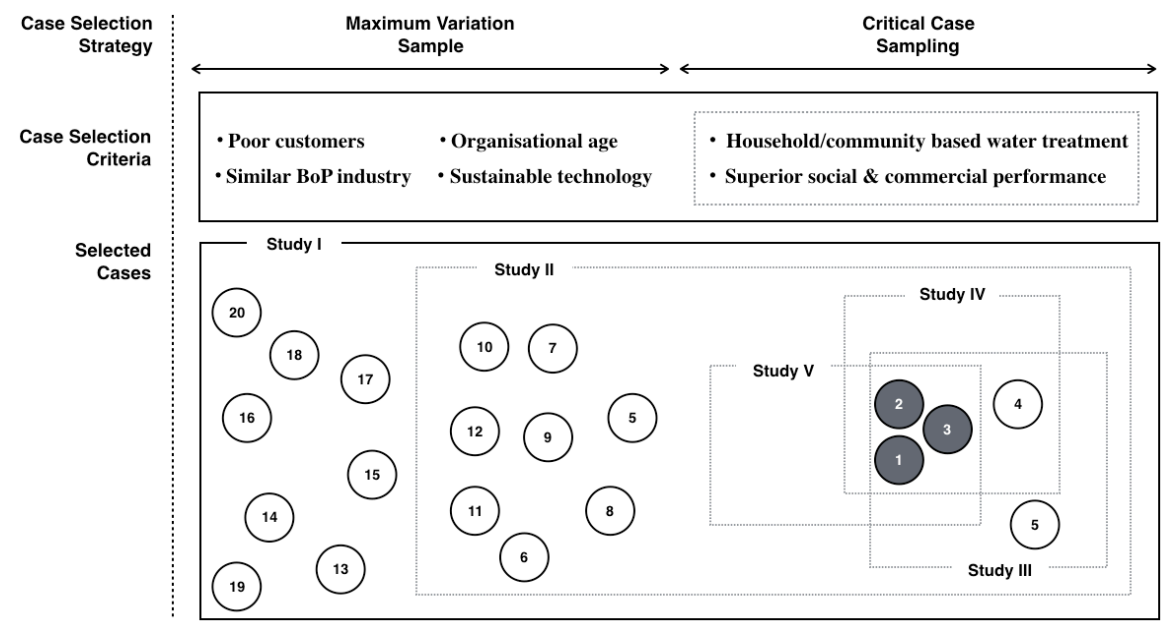

fig. 3-4. Schematic Overview of Case Selection Process

This approach resulted in considering around 30 notable programs to identify promising organizations in the water sector, in which 20 organizations were identified suitable. As heterogeneity in cases was embraced, a balance was struck with factors that had to apply to all cases to eventually produce sensible insights (Eisenhardt, 1989). We thus selected organizations that i) catered to severely poor customers, ii) operated in the same industry, iii) had operated for at least five years in their market

\footnotetext{
${ }^{42}$ for example, national development agencies such as the Swiss Federal Development Agency to international organizations such as the World Health Organization.
} 
environment, iv) and operated resource efficiently ${ }^{43}$. These factors to some degree could ensure comparability among cases despite the sought heterogeneity, the provision of archival data (iii), and consistency with our research aims and ethics (i, iv).

In the first study, we thus selected 20 organizations that met these selection criteria. Heterogeneity then manifested primarily in terms of organizational type, geography, and organizational size. In the second study, we drew on a subset of these cases. We re-selected 12 organizations from the original sample, because those permitted continued access to case information and had continued their business venture. This approach allowed to investigate the particularities of each case individually, as well as patterns shared despite variation (cf. Patton, 2002)

Tab. 3-2. Overview of Case Organizations

\begin{tabular}{llllllll}
\hline $\begin{array}{l}\text { Case } \\
\text { Pseudonym }\end{array}$ & $\begin{array}{l}\text { Products } \\
\text { \& Services }\end{array}$ & $\begin{array}{l}\text { Year } \\
\text { founded }\end{array}$ & $\begin{array}{l}\text { No. of core } \\
\text { employees }\end{array}$ & $\begin{array}{l}\text { No. of } \\
\text { offices }\end{array}$ & $\begin{array}{l}\text { No. of key } \\
\text { partners }\end{array}$ & $\begin{array}{l}\text { No. of } \\
\text { awards }\end{array}$ & $\begin{array}{l}\text { Households } \\
\text { catered to }^{\text {b }}\end{array}$ \\
\hline Aqua & Purifier & 2010 & 20 & $2(1)$ & 3 & 2 & $0.1 \mathrm{M}$ \\
2 Pani & Water Delivery & 2011 & 80 & $1(5)$ & 8 & 3 & $0.3 \mathrm{M}$ \\
3 Hydro & Purifier & 2008 & 110 & $1(2)$ & 15 & 16 & $0.9 \mathrm{M}$ \\
\hline 4 Fonto & Purified Water & 2017 & 20 & 2 & 6 & 0 & $0.1 \mathrm{M}$ \\
5 Eau & Water Delivery & 2009 & 50 & 2 & 12 & 1 & $0.3 \mathrm{M}$ \\
\hline
\end{tabular}

\footnotetext{
${ }^{a}$ Pseudonyms are used to protect anonymity of case enterprises and their members

${ }^{b}$ Figures from January, 31, 2018

source: own image
}

The involvement in the first two studies as a co-researcher allowed me to further narrow down the case selection criteria. For the remaining three studies, three cases were subsetted that not only met the selection criteria from above, but also v) shared a similar value proposition in form of household or community based water treatments; and vi) had outperformed other cases in terms of social and financial performance compared to other organizations in their respective industry. These factors improved comparability between cases and could help explain relevant conditions and mechanisms related to BM design. Informed by previous studies, more homogenous case organizations ${ }^{44}$ were

\footnotetext{
${ }^{43}$ by WHO standards regarding Household Water Treatment Technologies (WHO, 2016).

${ }^{44}$ further case descriptions can be found under Appendix II.
} 
consequently theoretically sampled in study III, IV, and V. Table 3-2 provides some relevant information on these cases and shortened case descriptions are appended (see Appendix II). In the study III and IV, it was possible to additionally select further theoretically relevant cases that adhered to the afore-mentioned selection criteria (case $4 \& 5$, in fig. 3-3). These represent thus opportunistically sampled cases that emerged through the co-authorships in the respective studies ${ }^{45}$.

\subsubsection{Data Collection}

The data collection for the first two studies were primarily based on semi-structured interviews. The corpus of data was complemented with secondary data, in the form of company material including strategic plans, organizational charts, technical papers, internal training material, reports and website content. The interviewees were divided into two categories: the first was comprised of individuals from multi-functional areas (e.g., marketing, manufacturing and quality management) and the second of individuals who were present at critical points in the company's history. In many cases, the latter involved interviewing the CEO or Vice President of the organization. Some individuals were contacted multiple times as the iterative process of data collection and theory development progressed.

Each interview lasted between 30 and $90 \mathrm{~min}$ and were semi-structured to discover more about the initial and current BM's and their respective components, past changes made to the BM and the managerial decisions and practices that guided those changes. The questions posed in the interviews were phrased in an unobtrusive and non-direct manner (McCracken, 1988), asking participants for specific examples (Mishler and Mishler, 2009), and were verified by other employees. Moreover, we aimed at using the interviewee's native language rather than using pre-defined constructs from the literature to avoid linguistic, cultural and cognitive dissonance. After conducting 20 and 38 interviews respectively, in addition to less formal exchanges, new answers to our questions subdued, thus indicating theoretical saturation (Glaser and Strauss, 2017).

The collection for the remaining studies due to their focus was more concentrated and took place over two years, including several visits and meetings to the case organizations and key strategic partners. This approach allowed for the retrieval of longitudinal data that spanned years of organizational history. I used several data sources, which included not only (1) archival data, (2) semistructured interviews, but also (3) observations, see table 6. Archival data helped me to gain an understanding of the organizational history and relevant key actors. The semi-structured interviews allowed me to develop a deep understanding of the key changes in the organizations, and the different

\footnotetext{
${ }^{45}$ these were also marked white in fig 3-4 (p. 49), since I did not engage in the data collection process.
} 
mechanisms that led to those changes. Finally, the observations enriched the data collection and analysis process by creating deeper relationships with the case organizations, access to further archival data, and led to impressions that helped reinforce or refute interview findings. Hence, all three sources of information were important in the research process and played a key role to expand my understanding of each case context and allowed for triangulation (Yin, 2017).

Tab. 3-3. Overview of Data Corpus and Collection Methods

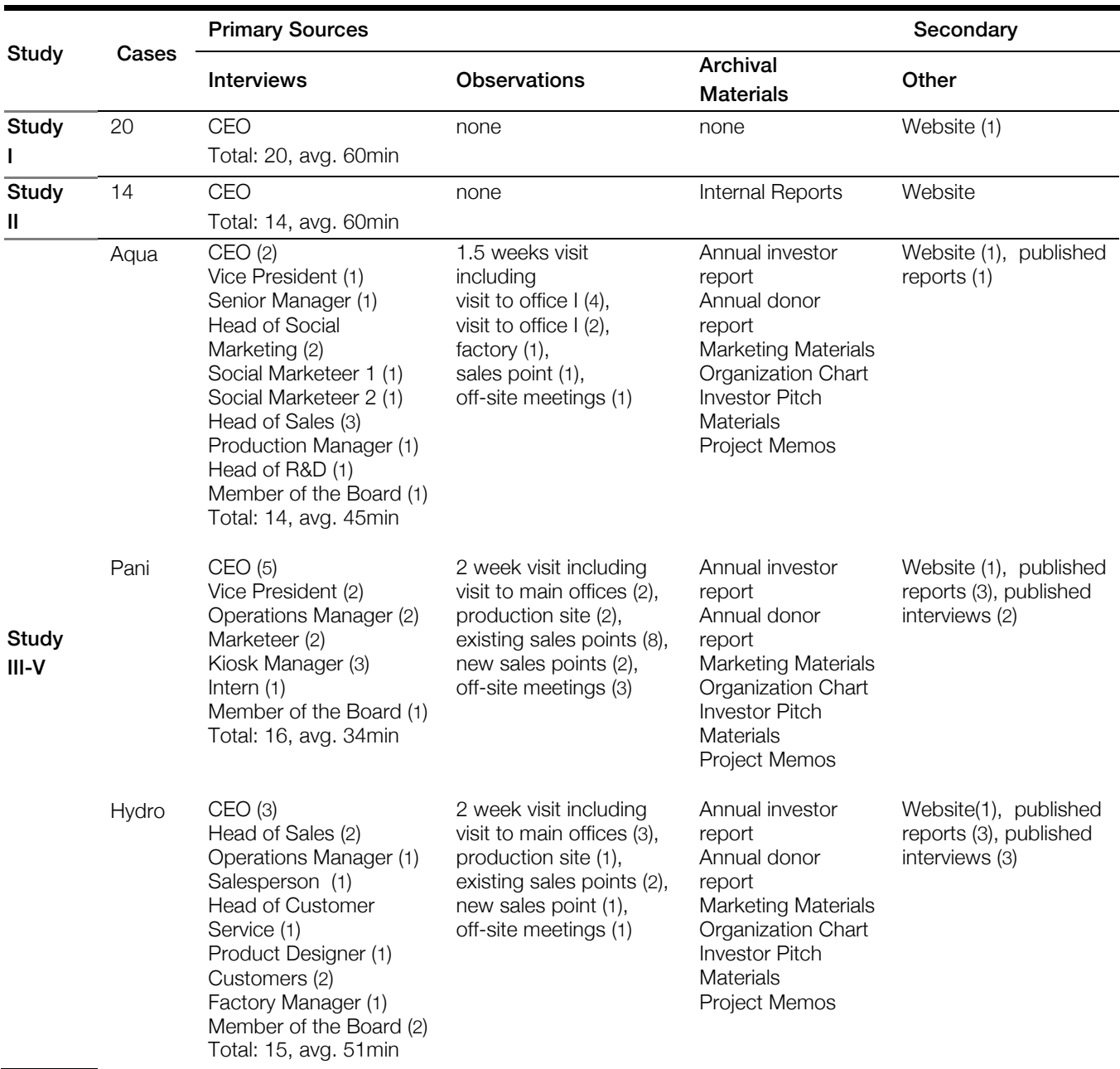

\footnotetext{
${ }^{a}$ Column summarises the role of the informants and the number of interviews held with him or her

${ }^{b}$ Column summarises the time spent at each organization, and the sites visited

${ }^{\mathrm{C}}$ This column summarises the forms of secondary materials collected for each case firm source: own table, adapted from study $\mathrm{V}$
} 
Prior to each visit, I collected archival data on each case organization. This involved desk research consisting of a website review, and related articles, as well as annual performance reports from initial funders and investors who provided useful overviews, impressions and suggestions regarding potential informants. Archival data was complemented during research visits with internal documents such as company reports, material on important projects, project outcomes, details of key collaborators, updated organizational charts, marketing materials, or extension plans. These materials clarified the business context of the organization, important milestones as well as their indicators for social and economic performance ${ }^{46}$. Moreover, they informed interview guidelines and were used for the individual case descriptions.

Informal and non-participant observations were made during site visits. In-between interviews, I was welcomed to examine and take notes of the work environment at all organizations within the office as well as in the field to meet front employees and customers. These observations allowed me to observe organizational members in their daily routines (e.g., distributing the sold water, opening new sales points, handling complaints) and in social interactions (e.g., weekly team meetings, impromptu discussions). Each visit lasted on average two weeks, and enabled to build the trust relationship for follow-up interviews and written exchanges. When employees face challenging issues, organization members make sense of them and can display emotional, cognitive and behavioral dimensions, with which they process such issues (Weick et al., 2005). The observations at the case firms rendered especially current issues salient.

Throughout these observations, I began to pay increased attention to the origin and nature of managerial struggles raised that mostly pertained to the interactions organizations' strategic dualities and the demanding nature of maintaining relations with customers and other relevant stakeholders. I held a total of 45 relevant in-depth interviews across the enterprises ${ }^{47}$. Informants varied across hierarchy and functional domains. I encouraged informants to wander freely in their answers through open-ended questions and probed whenever possible. All interviews were recorded and transcribed verbatim to ensure reliability, and were discussed post interview with local research assistants. Research assistants were present in each interview and spoke the local language, took notes, and helped clarify language and situations that were prone to cultural misunderstandings.

\footnotetext{
${ }^{46}$ usually reported in households served and saved medical expense per person for the social impact measure; and reported in expenses and profits.

${ }^{47} 52$ interviews were held across the selected case organizations, but seven of them did not provide relevant data, because the interviewees were either not knowledgeable or redirected the interview to a topic out of scope (possibilities for engagements, novel projects).
} 
As data collection and analysis unfolded, our interviews became increasingly focused on reoccurring struggles, and ways of dealing with the latter throughout the organizational levels. Within each firm, I re-interviewed knowledgeable informants about ongoing issues and the ways, in which they addressed them, until I felt that themes began to crystalize and I had sufficiently understood them. Overall, the interviews complemented the archival data and observations, by further articulating the kinds and manifestations of apparent managerial challenges throughout the organization's history. These insights hence complemented made observations and helped illustrate the case narratives.

\subsubsection{Data Analysis}

We found that informants were very deliberate in the choices they made that defined the design of their BM's, and that they also were acutely aware of managerial issues in implementing these designs. Through careful reading, re-reading of the data and deliberations among researchers, we transitioned from raw data toward identification of BM design choices as well as capabilities they required to implement the envisioned BM. This process in all studies involved thematic analysis, which was informed by Gioia and colleagues (2013). In this analysis, no computer software for structuring or identifying categories was used. Since I was very familiar with the material, the traditional pen-andpaper approach worked well. However, in retrospect, I would have complemented this method by using computer software, because it can facilitate the structuring and labelling of texts. Especially, since more novel software allows for word identification or even direct transcription.

The collected data was coded according to classifications, in order to facilitate the identification of different themes. This was done manually, by reading the case description and the transcriptions from the interviews and identifying the relevant units of comparison. These were then transformed into a code. To categorize, I structured text, mostly transcripts from interviews, to make it easier to manage the material. Thus, the large data content was reduced. Categories were developed from both the empirical material and from theory. Theory was thus an important part of the interpretation of the data, because I used several constructs from theory in my analysis (especially study III \& V). This was useful during rounds of coding work, since I could share interpretations with co-authors until consensus of the data and interpretation set in.

The objective of a thematic analysis was to provide interpretations which investigate possible categories and themes (Gioia et al., 2012). Examples of themes would be: forking, conflating and frequencing (see study V). Thematic analysis is a process that allows for the systematic analysis of textual information from interviews (Duriau et al., 2007). My transcripts were classified into content 
categories in order to structure the data. As an example, the data from Hydro was structured into (i) founding of the organization, (ii) initial BM design t_0, (iii) issues and BM t_1 (iv) issues and BM t_2, and so on, in study V. This facilitated the analysis of the data which had been gathered over a period of 2.5 years, but in terms of content often spanned a decade of organizational history. To facilitate comparison between cases, for example, I then structured the cases from study V in terms of (i) initial $\mathrm{BMl}$ design, (ii) type of issues, and (iii) type of ambidextrous responses.

\subsubsection{Rigor}

Strategy scholars increasingly conduct research in non-traditional contexts (Christensen et al., 2017). This development may hold especially true for research on hybrid organizations such as social enterprises that operate across different institutional sectors, and in markets where consumers face social inequalities. While such contexts enrich our understanding of existing theoretical concepts, they also bear methodological challenges.

Tab. 3-4. Overview of Rigor Criteria considered

\begin{tabular}{|c|c|c|c|}
\hline Rigor Criteria & Rigor Criteria & Implementation & Advantage \\
\hline \multirow{3}{*}{ Credibility } & Triangulation & $\begin{array}{l}\text { At theory, method, investigator and } \\
\text { data source type, and informant } \\
\text { level }\end{array}$ & $\begin{array}{l}\text { Avoid understandings and biases } \\
\text { from researcher side }\end{array}$ \\
\hline & Prolonged Engagement & $\begin{array}{l}\text { Observations at the social } \\
\text { businesses, follow-up calls every } 6 \\
\text { months }\end{array}$ & $\begin{array}{l}\text { Improved access to data, } \\
\text { avoidance of biases from } \\
\text { informant side }\end{array}$ \\
\hline & $\begin{array}{l}\text { Review by external } \\
\text { informants }\end{array}$ & $\begin{array}{l}\text { Interviews with closely tied } \\
\text { stakeholders who know the } \\
\text { organization, from same cultural } \\
\text { context }\end{array}$ & $\begin{array}{l}\text { Improved credibility through } \\
\text { verification of retrieved data or } \\
\text { alternative evidence }\end{array}$ \\
\hline \multirow[t]{2}{*}{ Dependability } & Explanation building & $\begin{array}{l}\text { Throughout introduction and theory } \\
\text { chapters of papers }\end{array}$ & $\begin{array}{l}\text { Development of relevant questions; } \\
\text { and follow-up questions for } \\
\text { retroduction }\end{array}$ \\
\hline & Address rival explanations & Throughout studies III-V & $\begin{array}{l}\text { Further substantiation of made } \\
\text { conclusions }\end{array}$ \\
\hline \multirow{2}{*}{ Confirmability } & Case study protocols & $\begin{array}{l}\text { Use of same questionnaire across } \\
\text { cases in studies I-II and III-V } \\
\text { respectively; and related case } \\
\text { descriptions }\end{array}$ & $\begin{array}{l}\text { Coherence and comparability of } \\
\text { case data }\end{array}$ \\
\hline & Review by key informants & $\begin{array}{l}\text { Case descriptions shared with } \\
\text { executives from case organizations }\end{array}$ & $\begin{array}{l}\text { Further specifications and details, } \\
\text { and consent for publishing case } \\
\text { vignettes and non-identifiable case } \\
\text { descriptions }\end{array}$ \\
\hline Transferability & $\begin{array}{l}\text { Replication logic (study I, } \\
\text { II); } \\
\text { Theory and Descriptions } \\
\text { (III-V) }\end{array}$ & $\begin{array}{l}\text { Throughout data analysis in study I- } \\
\text { II; and through description in studies } \\
\text { III-V }\end{array}$ & $\begin{array}{l}\text { Theoretical generalizations that } \\
\text { allow for generation of theoretical } \\
\text { propositions }\end{array}$ \\
\hline
\end{tabular}


For example, Christensen and colleagues $(2015 ; 2017)$ describe the difficulties with data reliability, when third-party intermediaries are engaged to retrieve data. Third-parties allow to better understand local culture, norms, and language, but may also represent a source of intermediary bias. Through the naturalistic approach that involved a direct relationship to the organization and visits, and drawing both on an emic and etic perspective through the integration of local and independent third parties in interviews and observations (Boyle 1994), I aimed to mitigate these forms of bias throughout my research. Table 3-5 summarizes the criteria that were considered and integrated into the research design (cf. Lincoln and Guba, 1985; Yin, 2014).

\subsection{Dissemination}

Another important aspect of the research design included the dissemination of preliminary findings with researchers and practitioners beyond traditional academic conferences. This engaged exchange supported the iterative process of sense-making between theory and obtained data. It also fostered transfer of relevant knowledge across relevant stakeholders (Van de Ven, 2007). For example, preliminary findings were shared at multiple internally held research seminars at the Environmental Social Science Department at the Swiss Federal Institute of Aquatic Sciences and Technology, which invited researchers who work in similar empirical contexts. Likewise, different stages of the research pursuit and made findings were shared at the Marketing Faculty of Texas State University and the Department of Management and Engineering of Linköping University during research visits.

\begin{tabular}{|c|c|c|}
\hline Orientation $\begin{array}{r}\text { Study } \\
\text { Aim }\end{array}$ & $\begin{array}{l}\text { Description } \\
\text { \& Explain }\end{array}$ & $\begin{array}{l}\text { Design } \\
\text { \& Control }\end{array}$ \\
\hline $\begin{array}{l}\text { Extension } \\
\text { \& Outside }\end{array}$ & $\begin{array}{l}\text { Basic Science with } \\
\text { Stakeholder Advice (1) }\end{array}$ & $\begin{array}{l}\text { Policy/Design science, } \\
\text { Evaluation research for } \\
\text { professional Practice (3) }\end{array}$ \\
\hline $\begin{array}{l}\text { Intension } \\
\text { \& Inside }\end{array}$ & $\begin{array}{l}\text { Co-production of } \\
\text { knowledge with } \\
\text { Collaborators (2) }\end{array}$ & $\begin{array}{c}\text { Action/Intervention } \\
\text { Research for a Client (4) }\end{array}$ \\
\hline
\end{tabular}

fig. 3-5. Forms of Engaged Scholarship (adapted from Van de Ven, 2007, p.271) 
Additionally, the findings were annually disseminated among interested practitioners through a self-organized practitioner conference Discovery Day. Finally, the overall findings were compiled into a guide for social entrepreneurs and related investment groups with key 'industry partners', and presented at the World Water Week in Stockholm in $2018^{48}$. The research process thus also entailed an element of engaged scholarship (Van de Ven, 2007), in form of knowledge co-production with collaborators.

\footnotetext{
${ }^{48}$ Link: https://sswm.info/perspective/safe-water-business-perspective
} 


\section{Summarized Findings}

In this chapter, I explore the topic of BM design for social goods and services in low-income markets. Five studies were conducted to explore this phenomenon (see table 4-1). The first three studies address the matter of design from an essentialist view (MRQ 1). Study I focuses on design themes that may guide such models. Study II looks into novel BM elements. While Study III provides a model of a social BM. Moreover, study III also discusses important cognitive and behavioral dynamics taken by social ventures to implement their BM, and thus provides a transition to the functional view of BM (MRQ 2). Study IV explores co-creation practices in regards to institutional voids and resource scarcity, and study $\mathrm{V}$ focuses on ambidextrous responses to hybridity related issues that arise with the dual mission of appropriating social and commercial value. I proceed with summaries of each study $^{49,50}$.

Tab. 4-1. Overview of Studies in the Scope of Research

\begin{tabular}{|c|c|c|c|c|}
\hline Study & Area & Focus & Personal Contributions & MRQ \\
\hline I & $\begin{array}{l}\text { Social BM } \\
\text { Design }\end{array}$ & $\begin{array}{l}\text { Design Themes of } \\
\text { Social BM's }\end{array}$ & $\begin{array}{l}\text { As a third author, my major contribution came in terms of } \\
\text { the literature review. The authors contributed equally to } \\
\text { the introduction, theoretical section, and conclusions. The } \\
\text { other authors conducted the analysis, and wrote the } \\
\text { analysis section. }\end{array}$ & 1 \\
\hline II & $\begin{array}{l}\text { Social BM } \\
\text { Design }\end{array}$ & $\begin{array}{l}\text { Innovative value } \\
\text { creation and capture } \\
\text { mechanisms }\end{array}$ & $\begin{array}{l}\text { As a second author, my major contribution came in terms } \\
\text { of literature review and the conceptual developments that } \\
\text { arose from the cross-case analysis. I made major } \\
\text { contributions to the methodological and empirical sections. } \\
\text { We contributed equally to the writing of the other parts of } \\
\text { the paper. }\end{array}$ & 1 \\
\hline III & $\begin{array}{l}\text { Social BM } \\
\text { Development }\end{array}$ & $\begin{array}{l}\text { Social BM \& related } \\
\text { design approaches }\end{array}$ & I was the main author of Paper 3. & $1 / 2$ \\
\hline IV & $\begin{array}{l}\text { Social BM } \\
\text { Development }\end{array}$ & $\begin{array}{l}\text { Co-creation in BoP } \\
\text { markets }\end{array}$ & $\begin{array}{l}\text { I was the main author of Paper } 4 \text {. The second-author } \\
\text { provided additional case material (case 5). I could draw } \\
\text { on valuable feedback from both co-authors regarding the } \\
\text { theoretical and empirical developments, as well as } \\
\text { support throughout the manuscript revision. }\end{array}$ & 2 \\
\hline v & $\begin{array}{l}\text { Social BM } \\
\text { Development }\end{array}$ & $\begin{array}{l}\text { Ambidexterity and } \\
\text { Paradoxes in SE }\end{array}$ & $\begin{array}{l}\text { I was the main author of Paper } 5 \text {. I was able to draw on } \\
\text { valuable feedback from my co-author as the synthesis of } \\
\text { multiple theoretical themes proved challenging, and } \\
\text { support throughout the manuscript revision. }\end{array}$ & 2 \\
\hline
\end{tabular}

Source: own table

\footnotetext{
${ }^{49}$ the studies are available in their complete versions in Appendix III.

${ }^{50}$ due to the co-authorships, I refer to the collective rather than to myself throughout the summaries.
} 


\subsection{Exploring Design Themes for Social BM's}

Study I focuses on design themes of social BM's. Specifically, it inquires into important design principles or 'templates' that guide social entrepreneurs in the design process of the BM (Amit and Zott, 2015). These design themes are important on a descriptive level, where they may inform the design process of new ventures, but also on a normative level, which help determine important characteristics of social BM's. The body of literature exploring these themes however remains scant and fragmented. The study hence sets out to synthesize design themes relevant to the empirical context, and describes how these were embedded in socially oriented organizations.

The study begins with a review of previously discussed design principles for social BM's, resulting in four design themes: inclusivity (George et al., 2010), collaboration (Seelos and Mair, 2007), complexity (Smith et al., 2010), and scalability (Anderson and Billou, 2007). The study then reports on a multiple case study of successfully considered social BM implementations. We sampled a larger set of case organizations $(n=20)$ that differed in terms of geography and scale, as well as activities that were important in the BM. We then juxtaposed the emerging heterogeneity in BM designs and scale with the previously identified design themes. Through semi-structured interviews (avg. $120 \mathrm{~min}$ ), we asked each organization to provide us with a detailed account of how the organization was founded and had devised their BM. Our expectation was that a comparison of case organizations would allow us to describe the independently suggested design themes, but also provide first insights as to what may prevent or limit the success of effective BM design themes.

While previous studies have proposed individual design themes in isolation, the findings suggest that BM's that had attained larger scale relied on a combination of all four design themes. Further, these case organizations applied different design approaches to realize them. For example, the BM became more inclusive through fostering value-in-context rather than merely addressing poverty penalties $^{51}$. In the study, successful organizations departed from poverty penalties as a starting point for the design of the value proposition, and imbued it further with the rich local knowledge of the BoP population. Next, the findings suggest that organizations realize collaborative value creation and complex value capture mechanisms by embracing ambidexterity. Ambidexterity arose as a salient theme with which organizations partnered up with stakeholders with potentially conflicting motivations; or with the introduction of new revenue or funding mechanisms that increased the

\footnotetext{
${ }^{51}$ such penalties are surpluses BoP consumers pay compared to non-BoP consumers to attain similar products and services (Mendoza, 2011).
} 
complexity in their value capture. Finally, more successful organizations allowed for sufficient flexibility in the BM design process, which manifested in continuous modifications and co-evolution of BM elements (value proposition, value capture and value creation). Here, organizations experimented with different BM modifications to analyze which may allow for organizational growth.

Tab. 4-2. Design Themes and identified Approaches

\begin{tabular}{llll}
\hline $\begin{array}{l}\text { Design } \\
\text { Theme }\end{array}$ & Definition & $\begin{array}{l}\text { Related } \\
\text { Approach }\end{array}$ & Case Examples \\
\hline Inclusivity & $\begin{array}{l}\text { Incorporation of rich } \\
\text { indigenous knowledge; } \\
\text { inclusion of BoP people } \\
\text { (George et al., 2010) }\end{array}$ & $\begin{array}{l}\text { Fostering Value- } \\
\text { in-Context }\end{array}$ & $\begin{array}{l}\text { Manila Water observed that water trucks create } \\
\text { inconveniences for customers, such as queuing, } \\
\text { waiting, adapting daily routines around the water } \\
\text { fetching and carrying heavy water canisters to } \\
\text { households. Manila Water thus began to offer the } \\
\text { convenience of 24-hour access to water that } \\
\text { remained affordable. Manila Water recovered the } \\
\text { additional costs by transferring the responsibility for } \\
\text { monitoring and payment collection to the } \\
\text { communities, leading to higher sales per village. }\end{array}$ \\
& &
\end{tabular}

\begin{tabular}{llll}
\hline Collaboration & $\begin{array}{l}\text { Leveraging capabilities and } \\
\text { resource access of other } \\
\text { actors in the eco-system } \\
\text { (Seelos and Mair, 2007) }\end{array}$ & $\begin{array}{l}\text { Embracing } \\
\text { Ambidexterity }\end{array}$ & $\begin{array}{l}\text { GrameenVeolia initiated an exploration effort into the } \\
\text { "20 liter jar business". This effort was set-up as an } \\
\text { outside team from the organization managing the } \\
\text { water distribution in rural areas. The team analyzed }\end{array}$ \\
$\begin{array}{l}\text { the water distribution market and collaborated with } \\
\text { distributors to deliver the } 20 \text { liter jars to offices, } \\
\text { schools and other non-base of the pyramid } \\
\text { customers. }\end{array}$
\end{tabular}

\begin{tabular}{|c|c|c|c|}
\hline Complexity & $\begin{array}{l}\text { Attending to tensions of } \\
\text { paradoxical strategies } \\
\text { which, may emanate from } \\
\text { inconsistencies or } \\
\text { contradictions (Smith et al., } \\
\text { 2010) }\end{array}$ & $\begin{array}{l}\text { Embracing } \\
\text { Ambidexterity }\end{array}$ & $\begin{array}{l}\text { Hydrologic secured additional income through } \\
\text { voluntary carbon credits. Hydrologic recognized the } \\
\text { fact that its filters replace the need to burn firewood } \\
\text { for boiling water. The saved emission could be } \\
\text { converted into carbon credits. Sales staff visit } \\
\text { customers frequently to obtain data on how much } \\
\text { water is treated to make emission estimations. }\end{array}$ \\
\hline
\end{tabular}

\begin{tabular}{|c|c|c|c|}
\hline $\begin{array}{l}\text { Scalability/ } \\
\text { Flexibility }\end{array}$ & $\begin{array}{l}\text { Considering profitability } \\
\text { when addressing unmet } \\
\text { needs of BoP people } \\
\text { (Anderson and Bilou, 2007) }\end{array}$ & $\begin{array}{l}\text { Allowing for } \\
\text { Modifications }\end{array}$ & $\begin{array}{l}\text { Purefresh started out with a BM for operating water } \\
\text { shops that treat and sell safe water. The scaling } \\
\text { began with the Purefresh founder relying on grants } \\
\text { and loans to build more shops. The founder paid } \\
\text { back the loan with the revenues from sales. Since } \\
\text { repayment took time, it limited the scaling process. } \\
\text { Purefresh's then altered to a model relying on water } \\
\text { vending machines in other local shops. Such vending } \\
\text { machines are cheaper than a shop, and more } \\
\text { machines promise customers a closer, continuously } \\
\text { access to water. }\end{array}$ \\
\hline
\end{tabular}


It is also interesting to note that while we observed a number of 'scaled' BM's, very few successful initiatives in the data corpus were actually financially self-sufficient. This particular finding corroborates previous research that underscores the difficulty in replicating BM templates due to limited purchasing power of poor communities (Karnani, 2009), limited financial resources (Yunus et al., 2010), limited organizational know-how (Dahan et al., 2010), diverse cultural attitudes and relationships in BoP markets (Viswanathan et al., 2010), and a lack of customer awareness about benefits of basic goods and services (London et al., 2010). As such, we found that sufficient flexibility appeared all the more pertinent. Since previous design guidance provides a view in which BM designs are conceived, "frozen", and then scaled, our findings suggest that increased flexibility allows to continuously incorporate solutions to the variety of issues social businesses learn of.

Based on our study, presented in Study I (Gebauer et al., 2017a), we propose that viable BM designs for social goods and services in low-income environments may require multiple design themes and dynamic approaches to embed these design principles. Moreover, despite receiving relatively less acknowledgement in the literature compared to the other examined themes, considering scalability as a design theme in the initial BM design process allows for the identification and integration of key market conditions. These findings are in line with more current literature on BoP markets that discusses a series of market conditions that can affect the replication of a viable model. Scalability as a design theme provides guidance to better determine such viability, and in our cases became salient as an attitude that eventually allowed for continuous modifications to BM elements.

The findings in this study primarily contribute to the BoP literature with a synthesis of relevant design themes for social BM's. Since previous literature suggest the design of reshaped models yet provides little and fragmented guidance as to what ought to be considered. Specifically, the findings suggest that the studied design themes are more useful in combination, although discussed separately so far in the literature. Further, the related approaches and cases examples also provide further illustration and evidence of BM design themes that so far have remained conceptually broad or based on single case studies respectively. 


\subsection{Overcoming Constraints in BoP Markets}

BM's are increasingly understood as an object of innovation per se. Study II explores the phenomena of social BMI in poverty contexts (Gebauer et al., 2017b). The study thereby focuses on how BM elements alter throughout the BM evolution. The study hence takes on a process view of social BM design. Adopting such a view is important since it renders insights that may lead to a more systematic approach for BM design and related innovation that must occur despite a series of challenges associated with the BoP market environment and the hybrid nature of the social business. The study identifies prominent managerial challenges and illustrates how social businesses respond with patterns of BM innovations to overcome said market constraints.

In this study, we began by providing working definitions of relevant BM concepts, mainly focusing on the BM elements that determine the design of a BM. These elements were then used to study twelve social businesses. To learn more about their BM evolution and the BM innovations realized, we adopted a longitudinal approach. This approach allowed us to parse and assemble sequences of key events (Langley, 1999) that eventually underpinned the BM design at different stages of the BM evolution. These evolutions were informed by company materials and multiple in-depth interviews with key members of and across the case organizations. After conducting 38 interviews (avg. $60 \mathrm{~min}$ ), the amount of challenges and related BMinnovations that could be considered relatively novel subdued, pointing towards theoretical saturation. When examining the BM designs over time, we began to associate certain managerial issues with key changes in BM elements and overall patterns of BM innovation.

Indeed, we identified a series of prominent issues that social businesses experienced. Lack of financial resources manifested in form of low and volatile income levels as well as lack of access to financial services or traditional capital markets. Some businesses were challenged by the low margin business and the heterogeneous customer needs (e.g. amount of water) associated with it. In other instances, the low profitability threatened the survival of the organization at a stage in the BM evolution. This problem was then further compounded by a pro-poor branding that some poor customer groups did not want to be associated with. Moreover, case organizations also struggled with high levels of risk associated with the business venture and the slower than expected growth developments. These managerial challenges acted as the impetus for substantial changes in their BM design. 
Tab. 4-3. Patterns of Social BM Innovation and related Managerial Challenges

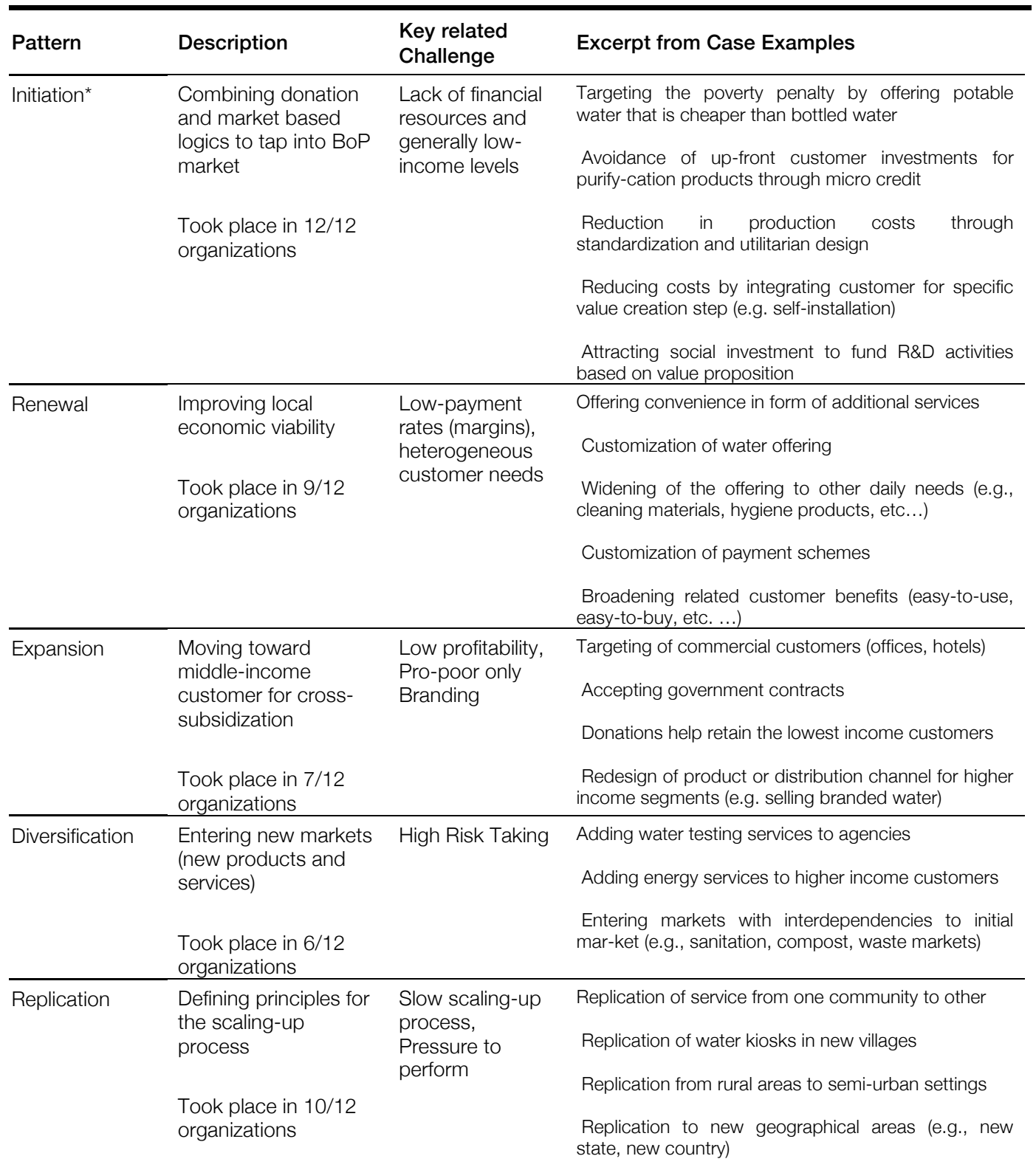

${ }^{*}$ Referred to as Initiation in the initial research process, then as Design. I adapt it here accordingly for conceptual coherence Source: own table adapted from study II 
We identified five common patterns of social BM innovation, which occurred in light of the afore-mentioned challenges. We labelled these emerging themes 'launch',52, 'renewal', 'expansion', and diversification', and 'replication'. As noted, common to all these patterns is that they were sought as a response to managerial issues and entailed substantial changes in the entire BM. That is, managers revised activities in a specific BM element, which in turn lead to consecutive changes in other BM elements. The timely occurrence of these patterns in the BM evolution differed however from case to case. Such that they sometimes co-evolved or occurred sequentially, and did so in different sequences. Table 4-3 provides an overview of the emergent patterns, the underlying managerial challenges, and some case example excerpts.

In the first pattern, social businesses designed BM's that were affordable for BoP people and considered ways of achieving affordability through alternative value creation (e.g., cost reduction, new payment schemes) and value capture meachanisms (e.g., attract social impact investments). In the second pattern, the social businesses renewed the BM by customizing products and services to make the offering more appealing to customers. Consequently, these changes led again to the adoption or alteration of value creation and capture mechanisms. In turn, the social businesses were able to better address related needs of customers that were important to them (e.g., convenience, customization, other daily necessities). BM expansion involved the addition of higher income customer segments to deal with matters of low profitability. In this specific pattern, organizations had to pay additional attention to adapting the branding to the different segments and the creation of separate revenue streams. BM diversification dealt with the entering of new markets or the development of offerings that often relied on existing organizational capabilities (e.g., water testing services to agencies). Diversification added components to all BM elements and allowed for risk diversification, inherent to the creation of social business ventures. In the final pattern, social businesses replicated the BM often while engaging in the above-mentioned patterns. Replication took shape in form of principle-based replication, in which core BM activities remained, yet other were modified to the new locations.

Our findings contribute to the literature on $\mathrm{BoP}$ and $\mathrm{BM}$ in three meaningful ways. A key insight from our study is that BM designs require more than collaborations among firms and non-profit oriented organizations to fund or cross-subsidies activities, as frequently highlighted in BoP literature (e.g., Dahan et al., 2010; Thompson and MacMillan, 2010). Since each of the identified patterns

\footnotetext{
${ }^{52}$ Initially, labelled as ,initiation' and not to be treated synonymously with business model design, as treated throughout the dissertation.
} 
underscore the attention paid by social businesses in the generation of viable value appropriation mechanisms, as well as attempts to reduce the operating risks associated with the business venture (e.g., customer segments, new products, new geographical markets, ...). Moreover, the examined cases also show that the design of BM's and related BM innovations during said process require reconfiguration of all $\mathrm{BM}$ elements rather than critical changes in single elements, as often portrayed in the wider BoP literature; such as the inclusion of shared distribution channels or joint production (Karamchandani et al., 2009; Kayser and Budinich, 2015). Finally, the study also renders interesting insights for BM related literature. Our study is in line with scholars who have pointed toward reshaped BM's that allow for the commercialization of technologies which achieve poverty alleviation outcomes (Massa and Tucci, 2013; Prahalad, 2004). Specifically, the findings suggest the need to pay further attention to the particular conditions and associated managerial challenges that BoP markets and hybrid strategies entail (cf. Chiliova and Ringov, 2017). The identification of such conditions allows to examine how such 'reshaping' can take place.

\subsection{Design of Social BM's}

The purpose of the third study was to build on the previous articles and to further explore the design of BM's in poverty contexts for social goods and services. To this end, we addressed two limitations, we identified earlier. Previous BoP literature stresses the need for reshaped models due to the dynamic and uncertainties inherent to BoP markets, yet simultaneously more recent studies i) provide a myriad of market conditions, ii) remain conceptually broad about adequate design approaches, and iii) rely mostly on single case studies of organizations that are not financially self-sustainable. As such, the aim of this study was to explore how successful social businesses designed their BM's to circumnavigate conditions imposed by poverty contexts. By drawing on a cognitive perspective, we sampled and investigated four case studies to better understand their design process and the implications these had on the resulting BM.

Regarding the above-mentioned gap, our empirical investigation aims to address the question of how does managerial cognition affect the design of BMs for socially beneficial goods and services in low-income markets. As a conceptual framework we relied on two literature streams that inform this study. We first review relevant literature on BM design with a focus on streams that have discussed BM's in poverty contexts. Then, we draw on managerial cognition literature and conceptual contributions that discuss the close link between cognition and BM's, which in turn have guided the study. This approach allowed us to parse and assemble important concepts that eventually became 
salient in the BM design processes observed. With little theoretical precedent, we followed a case study approach (Eisenhardt, 1989) to explore how businesses devise social BMs, and theoretically analyze these insights in the light of the contextual factors (Yin, 2009).

Based on the reviewed literature, the research question led to the examination of cognitive and behavioral dynamics that support the design process of social BM and the reifying model elements. As previous literature suggests (Tracey et al., 2011; Yunus et al., 2010), the process is guided by particular problem framing and counterfactual thinking strategies and affects the design of different BM dimensions (value proposition, creation and appropriation mechanisms). Drawing on these concepts, we centered the analysis on the initial design stage of a social business, where we examined these dynamics and resulting strategies and BM elements at the initial design stage.

By drawing on a cognitive perspective, we identified a series of challenging market conditions that social businesses faced when developing their BM's. We suggest that frames shaped their actions and summarize these relationships in six design approaches, which we labelled solving social issues, transforming BoP people into active consumers, socially embedding the venture, establishing a resource network, identifying new funding sources, and developing novel revenue mechanisms. Further, we illustrate how these themes affect the final BM design, by proposing a model of social BM's, consisting of a social value proposition, embedded value creation mechanisms, and customized value capture mechanisms (see fig. 4-1).

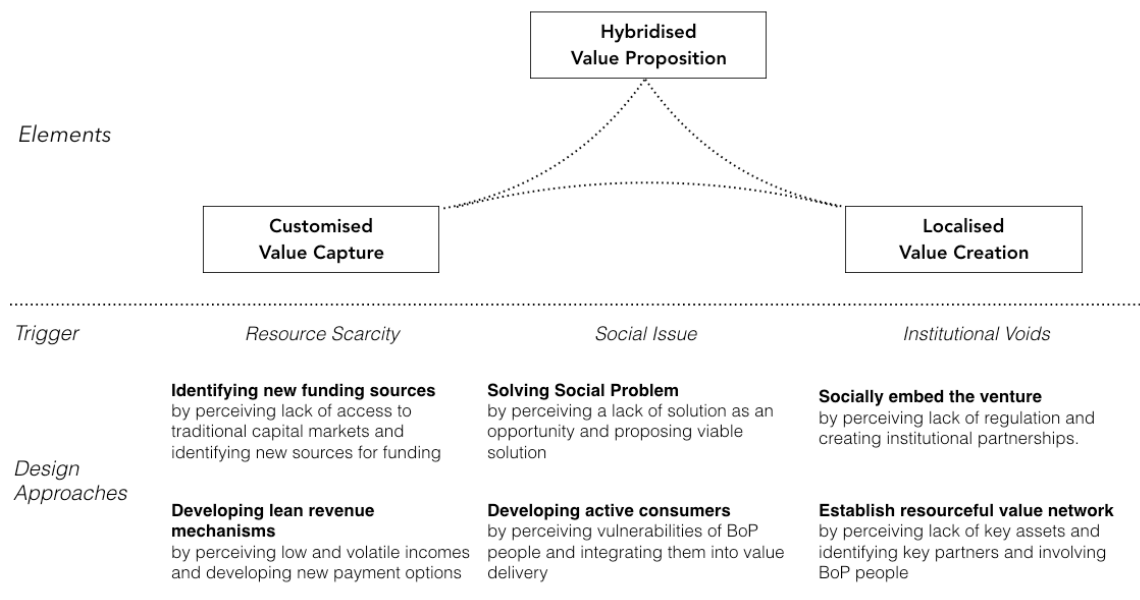

fig. 4-1. A model of Social BM Design (adapted from Haldimann, n.d., p. 38) 
Although the presented model does not prescribe how the design process should take place, it helps to understand a wide range of cognitive and behavioral dynamics that organizations adopt in dealing with matters of hybridity, institutional voids and resource scarcity, common to BoP market contexts. The findings of this study stress the importance of studying BM design in various market contexts, but also how significant the role of cognition is in the process of social venture creation, where widely held frames across globalized industries do not uphold. This article contributes to the literature streams on BoP markets (e.g., Kolk et al., 2014; London and Hart, 2004), BMs (e.g., Foss and Saebi, 2017; Massa et al., 2017) and Social Entrepreneurship (e.g., Dacin et al. 2010; 2011) by advancing our understanding of the potential of designing organizational templates to promote social and economic development in poverty environments.

Hence, the theory elaboration approach rendered interesting insights that contribute to the BoP and BM literature by advancing our current understanding of how social BMs emerge and how they can be developed to promote social and economic development at the BoP. Specifically, our framework improves the understanding of the emerging yet fragmented area of designing viable BMs at the BoP by (a) synthesizing influential BoP context-related conditions that affect the development of $\mathrm{BMs}$ at the BoP, and (b) delineating cognitive mechanisms that translate these conditions into effective BM designs. Thus, our integration of these two relatively disparate literatures promotes the advancement of theoretical developments on BoP model replications and provides propositions amenable to future research. Moreover, the findings also contribute to Social Entrepreneurship literature by delineating distinctive conditions and cognitive mechanisms that may further distinguish social from commercial entrepreneurship.

\subsection{Social BM Development through Co-creation}

The fourth study focuses on the topic of co-creation. It is well established that such models rely on cocreation with a wide array of stakeholders from companies (Mair and Seelos, 2007) to non-profits Dahan and colleagues (2010), and the customer him or herself (Karnani, 2007a). However, less attention has been paid as to how such co-creation practices affect the BM development of such organizations. In particular, how social business then organize various value creation mechanisms. To address this gap, we hence apply an open innovation perspective to the matter of BM development to more systematically and holistically illustrate different value co-creation practices and examine how these affect initial stages of BM development. 
To this end, we sampled and contrasted four cases of social businesses and their BM developments with external stakeholders. In a next step, we explored the co-creation practices through semi-structured interviews with the management teams. Our open-ended questions aimed at understanding the founding and growth of the organization, the initial BM design process and required changes. We were particularly interested in uncovering the managerial decisions, practices and involvement of external stakeholders that supported these changes. That allowed us to explore which co-creation activities underpinned their successful BM development, how they affected the BM development and what types of stakeholder interactions these co-creation activities necessitated. Our expectation was that a multiple case study including successful social BM would help internally validate previously suggested design approaches regarding value creation mechanisms.

Tab. 4-4. Themes of Co-creation in Social BM Design

\begin{tabular}{|c|c|c|c|c|c|}
\hline Themes & $\begin{array}{l}\text { Identifying core } \\
\text { need }\end{array}$ & $\begin{array}{l}\text { Developing } \\
\text { novel payment } \\
\text { methods }\end{array}$ & $\begin{array}{l}\text { Integrating BoP } \\
\text { customers as } \\
\text { co-producers }\end{array}$ & $\begin{array}{l}\text { Identifying } \\
\text { nested needs }\end{array}$ & $\begin{array}{l}\text { Assessing } \\
\text { Willingness- to-pay }\end{array}$ \\
\hline Challenges & $\begin{array}{l}\text { - Managers find } \\
\text { customers are } \\
\text { unaware or } \\
\text { unable to express } \\
\text { latent needs } \\
\text { - Managers find it } \\
\text { difficult to } \\
\text { convince } \\
\text { skeptical } \\
\text { customers who } \\
\text { suffer from a } \\
\text { poverty penalty }\end{array}$ & $\begin{array}{l}\text { - Managers } \\
\text { struggle to } \\
\text { receive steady } \\
\text { payments } \\
\text { - Managers find it } \\
\text { difficult to } \\
\text { implement } \\
\text { processes to } \\
\text { collect small } \\
\text { payments } \\
\text { continuously }\end{array}$ & $\begin{array}{l}\text { - Managers are } \\
\text { challenged in } \\
\text { finding good staff } \\
\text { and build capacity } \\
\text { - Managers find it } \\
\text { difficult to } \\
\text { incentivize staff } \\
\text { - Micromanagement } \\
\text { is not appreciated } \\
\text { by staff }\end{array}$ & $\begin{array}{l}\text { - Customers } \\
\text { refrain from } \\
\text { purchasing due } \\
\text { to other poverty } \\
\text { related issues } \\
\text { - Customers } \\
\text { often do not } \\
\text { want to share } \\
\text { these issues } \\
\text { openly (shame, } \\
\text { conflict } \\
\text { avoiding) }\end{array}$ & $\begin{array}{l}\text { - Managers set prices too } \\
\text { low and risk further } \\
\text { operations } \\
\text { - Managers set prices too } \\
\text { high and risk losing } \\
\text { customer adoption } \\
\text { - Managers cannot easily } \\
\text { identify viable price } \\
\text { ranges for their offering }\end{array}$ \\
\hline Activities & $\begin{array}{l}\text { Involve the } \\
\text { customers and } \\
\text { groups that know } \\
\text { them: } \\
\text { - Infer customer } \\
\text { pain points } \\
\text { through } \\
\text { speaking to } \\
\text { communities or } \\
\text { NGO's } \\
\text { - Speak to } \\
\text { customers to } \\
\text { describe pain } \\
\text { points that } \\
\text { inform the value } \\
\text { proposition }\end{array}$ & $\begin{array}{l}\text { Involve } \\
\text { organizations that } \\
\text { operate in the } \\
\text { same regions: } \\
\text { - Integrate } \\
\text { NGO's such as } \\
\text { MFl's into } \\
\text { payment } \\
\text { process to deal } \\
\text { with high } \\
\text { upfront costs } \\
\text { of customers } \\
\text { - Integrate } \\
\text { companies that } \\
\text { have existing } \\
\text { distribution } \\
\text { channels for } \\
\text { payment } \\
\text { collection }\end{array}$ & $\begin{array}{l}\text { Involve lead } \\
\text { customers: } \\
\text { - Integrate lead } \\
\text { customers as } \\
\text { employees } \\
\text { - Integrate local } \\
\text { companies for the } \\
\text { production of key } \\
\text { materials }\end{array}$ & $\begin{array}{l}\text { Involve people } \\
\text { 'in the field' and } \\
\text { 'on the ground': } \\
\text { - Observe } \\
\text { customers } \\
\text { through fresh } \\
\text { eyes } \\
\text { - Connect with } \\
\text { customers } \\
\text { through } \\
\text { trusted } \\
\text { platforms }\end{array}$ & $\begin{array}{l}\text { Involve different types of } \\
\text { customers: } \\
\text { - Involve vendors for } \\
\text { rapid baseline } \\
\text { comparisons } \\
\text { - Involve research } \\
\text { organizations to } \\
\text { conduct experiments } \\
\text { - Involve key villagers to } \\
\text { finalize and set pricing } \\
\text { jointly }\end{array}$ \\
\hline
\end{tabular}

Notes: $\mathrm{NGO}=$ Non-governmental Organization, MFI=Micro-Finance Institution

Source: adapted from Haldimann et al., n.d., p. 7 
Instead, the different relationships maintained with the social businesses indicated that social businesses engage with external stakeholders for multiple reasons that go well beyond the development of value creation mechanisms. In fact, co-creation processes featured in all components of the BM and were central in the development of teach BM component. We labelled these as (1) identifying latent needs, (2) addressing nested needs, (3) integrating BoP customers as co-producers, (4) optimizing value creation processes, (5) identifying willingness-to-pay, and (6) establishing novel payment options. These are summarized in table 4-4 (see p.67).

Our findings add to research on the BoP research in two relevant ways. Our findings suggest that successful social businesses continuously 'open up' their BM to a wide range of co-creation partners. These activities help them attain not only tangible resources and competencies (Seelos and Mair, 2007; Dahan et al., 2010), but also as a means to attain intangible resources in form of legitimacy and trust. Moreover, while multiple authors have stressed the importance of integrating BoP customers as co-producers (e.g., Kolk et al., 2014; Karnani, 2007a) only few studies to date have illustrated successful cases that have done so.

Finally, these findings also add interesting insights to literature on Open BM's. First, our findings confirm that different antecedents foster the openness of BM's. Frankenberger and colleagues (2013) identified five different antecedents in form of BM inconsistency, the need to create and capture new value, previous experiences with collaboration, open BM patterns, and industry convergence. Although our setting substantially differed from a high-tech industry, we observed all five antecedents in our cases. Our findings also highlight an additional antecedent in form of resource scarcity that motivated our cases organizations to not only exchange skills and knowledge, but to effectively open up their BM's. Although the chosen research setting is prone to resource scarcity, it is not implausible for other organizations in developed contexts to face resource constraints to some degree or throughout certain periods of the firm's evolution.

\subsection{Maintaining Hybridity during Social BM Development}

In the fourth study, the purpose of the study was to better understand how social businesses maintain a hybrid value proposition. As we have seen, social businesses strive to create value with the provision of solutions to social problems, while pursuing commercial objectives such as cost-recovery and profit. Hybrid value propositions hence imply hybrid organizing (Battilana and Lee, 2014). It is well 
established that social businesses struggle to excel at the simultaneous pursuit of their dual mission (Ebrahim et al., 2014), due to the emanating tensions of conflicting logics that hybridity may bear (Pache and Santos, 2010; 2013). While previous studies regarded these tensions as trade-offs, thereby oftentimes positing social value propositions above commercial ones (Austin et al., 2006); recent research has proposed ideas of managerially balancing hybridity tensions and 'productively harnessing' them (Dacin et al., 2011, Battilana et al., 2015). The concrete aim of the study was hence to explore such harnessing strategies (see Haldimann and Gebauer, n.d.).

For this study, we selected three case organization that appeared to deal well with their hybridity due to annually growing social impact and profitability figure increases. As we began to study each case individually, we observed different management forms employed to deal with hybridity. In turn, different hybridity related tensions and organizational responses elicited became salient throughout the research process. We thus growingly relied on established literature themes of Paradox and Ambidexterity theories - that have precisely guided previous studies challenged dual missions - to better understand the tensions and responses, our case observations provided.

The results propose an alternative framework for examining how hybrid organizations may embrace and sustain hybridity tensions productively, which we referred to as "embracing hybridity" (see fig. 4-2). Specifically, the framework details three paradox response paths that SEs used to embrace hybridity at different stages of their evolution. We conceptualized these robust paths as "forking", "conflating", and "frequencing". Each social business observed maintained balance between proposing social and commercial value. At an early stage of the BM design stage, the observed cases forked their business units in adherence to the social and commercial mission. At a later stage, the two of the observed cases began to conflate their dual mission at the employee level, such that employees were trained to conflate and allocate distinct periods of their schedule to either mission. At a final stage, in one case that had become the largest retailer of filters in the country had achieved to fulfilling its dual mission by frequencing. By doing so, the organization was able to switch between missions temporarily to cater to stakeholders who only took interest in one of the social businesses' missions (e.g., government bodies, loan providers). 


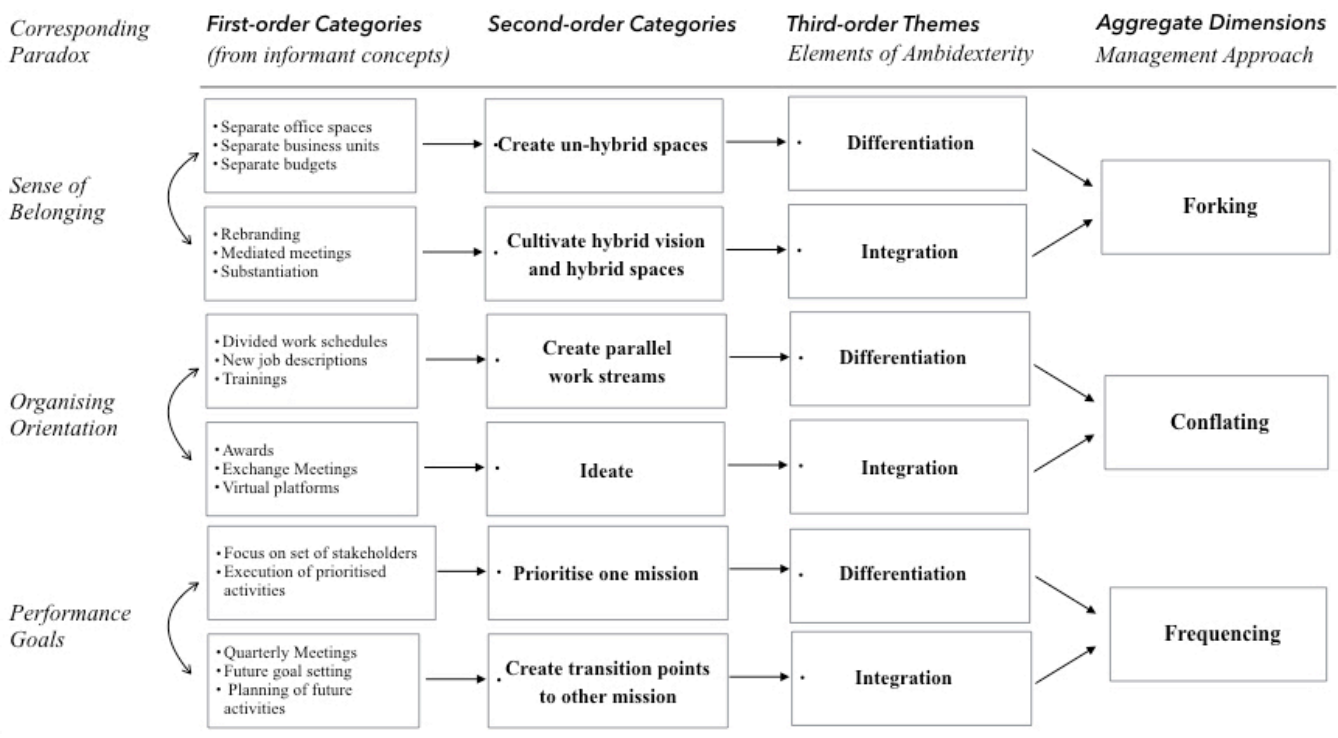

fig. 4-2. Ambidextrous Responses to Tensions in SE's

(adapted from Haldimann and Gebauer, n.d., p. 50)

These finding portray a view that is a departure from the way that hybridity and its management have been conceived in previous hybrid organization literature in three ways. First, instead of a contingency-based sense of balance, in which actors resort to top-down governance mechanisms (e.g. integrated performance metrics) that alleviate pressures to prioritize one goal over the other (Ebrahim et al., 2014, Ebrahim and Rangan, 2010), the model presented aims to harness rather than alleviate hybridity tensions. This perspective manifests in a multi-level actor engaging process of managerial balancing across the organizations. Second, rather than portraying and conceptualizing hybridity as a generic and static organizational issue, the model presented shows hybridity as a multi-faceted and continuous process, compared to a majority of social business studies. Hybridity tensions are then not the outcome of SEs mismanagement of hybridity, but rather represent antecedents to managing hybridism effectively, determined by the way in which organizational members experience them over time. By building from paradox and ambidexterity studies, we also gain a more micro-level and cognitive explanation as to what may prevent 'vicious cycles' (Sundaramurthy and Lewis, 2003) that lead to the favouring of one mission, and what may constitute 'virtuous cycles' (Andriopoulos and Lewis, 2009) of hybridity. In turn, these findings help better understand what makes social and commercial value propositions complex and hard to maintain. 


\section{Discussion}

The aim of this dissertation was to explore how social businesses design contextually adequate BM's for social goods in poverty-stricken contexts. While the design of a BM is clearly an emergent process that may not be completely predefined; I conceptualized BM design as a two-staged process where business models first devise a BM and then develop the BM. The first set of studies synthesized common challenges and themes related to devising BM's. The second set of studies explored managerial capabilities that supported the development of the BM. I identified cognition, ambidexterity and co-creation mechanisms that affect the likelihood of successful BM development given the distinctive conditions of hybrid organizing in a BoP market. These findings raise cogent implications for theory and practice. The aim of this chapter is to discuss these by embedding them in the relevant literatures. I then tend to the methodological limitations that must be considered in evaluating my findings. Based on these discussions, I conclude the chapter with implications for practice and suggestions for future research.

\subsection{Theoretical Contributions}

Beyond the previously mentioned individual contributions, the dissertation leads to interesting implications for related theory. By advancing our understanding of BM's to promote social and economic development in challenging environments, the studies directly contribute to the literature on BoP markets (e.g., Chiliova and Ringov, 2017; Kistruck et al., 2012; Kolk et al., 2014), Social Entrepreneurship (e.g., Battilana and Lee, 2014; Dacin et al., 2011), and Business Models (e.g., Teece, 2018; Foss and Saebi, 2018). This sub-chapter tries to discuss these contributions by research stream, illustrated in figure $5-1$.

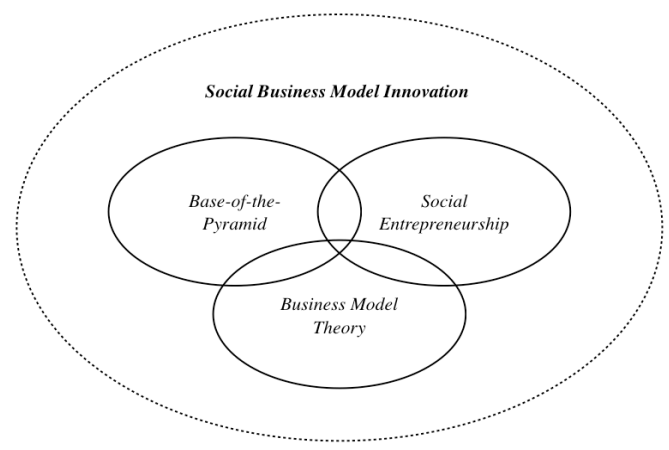

fig. 5-1. Related Research Streams 


\subsubsection{BoP Research}

Debates in the Strategy field about whether and how to serve people living in BoP conditions for socially considered goods motivated this research. The presented work is unique in that it simultaneously compares divergent BoP strategies within an industry to accomplish such a goal. A dominant position in BoP literature points to the inefficacy of for-profit BoP strategies in traditionally considered social development domains (e.g., Karnani, 2007b;2007c; 2009). In studying a wide variety of social organizations, and performant social businesses over time specifically, the findings provide a more positive perspective on BoP approaches for poverty alleviation, in which for-profit approaches over philanthropy were favoured.

This is particularly the case if success is defined in terms of repeat purchase/usage by the social business, and the usage directly implies social as well as commercial performance. In contrast, previous research shows little support for long-term adoption of social goods through philanthropic approaches (Christensen et al., 2014; Meierhofer et al., 2016). The in-depth cases provide deeper qualitative insights as to way this may be the case, such as the finity of give-away strategies, uncertainties or imposed demands related to donation-based funding, and the lack of behavior change associated with-free consumption (see study III, IV).

In efforts to address for-profit BoP strategies, researchers have further suggested that managers must "fundamentally rethink" their strategies (Seelos and Mair, 2007, p.49) and "reshape" BM's (Prahalad, 2009). By integrating BM theory with BoP research, our findings suggest that there may be a template (Baden-Fuller and Winter, 2007) for social BM's in poverty contexts. That is, a working example or template which supports imitation or comparison by entrepreneurs, investors, customers or partners, and thus serve as important input for the evaluation of a venture-specific BM (cf. Doganova and Eyquiem-Renault, 2009). The findings present the concept of social BM's which provides a deeper understanding about how BM elements of value proposition, creation and appropriation are devised, but also why such BM's emerge in the BoP context for social goods.

Contrary to early conceptualizations of social BM's (cf. Yunus et al., 2010), the findings suggest that social value propositions are not separate to their commercial counter-part. Such a view provides more insight into the challenging task of embedding dual objectives into the $\mathrm{BM}$, as illustrated in study V, and the importance of value appropriation, as shown in study I-III. Such a 
conceptualization may thus contribute to the development of a more convergent construct with the potential to reconcile empirical results from BoP and Social Entrepreneurship streams.

Studies rooted in the BoP literature, particularly those adopting a value creation lens, continue to place a large emphasis on value creation mechanisms in form of resource mobilizing partnerships (e.g., Hahn and Gold, 2014; Schuster and Holtbrügge, 2014). The made findings are in consistent with prior research that collaborations occur among business, non-business and institutional actors for sector specific resources and critical capabilities (Dahan et al., 2010; Seelos and Mair, 2007). However, I also find that social businesses extend value creation mechanisms to the BoP customer himself or herself. For example, the findings in study III and IV introduce new collaboration potentials by partnering with local BoP individuals (vendors, village chiefs, et cetera ...) for identifying latent needs and pricing BoP goods.

This form of integration is not entirely novel to the BoP literature. However, few studies report on the ways in which such collaborations can take place beyond distribution channels (Kolk et al., $2014)^{53}$. This is surprising given the growing importance in BoP scholarship to not treat the poor as recipients of aid, but to engage them as active consumers, co-producers or co-creators of BoP specific product and services (Karnani, 2009; Simanis and Hart, 2009). Our findings suggest that by integrating customers as value-conscious consumers, and socially-embedded co-producer or co-creators, social businesses can gain essential information that support the design and development of their BM's.

By adopting a BM lens, our findings also complement BoP research by highlighting and illustrating value appropriation mechanisms in poverty contexts. As noted, a large body of work has focused on value creation mechanisms to address distinct BoP market conditions, notably extreme resource scarcity (Kayser and Budinich, 2015; Seelos and Mair, 2007; Sutter et al., 2014) and institutional voids (De Soto, 2003; Khanna and Palepu, 1997; 2000; Mair and Marti, 2009). Our findings suggest however that successful organizations pay equal attention to value appropriation mechanisms. By designing and refining value propositions and appropriation mechanisms according to customers' pre-dispositions (value-adding product functions or services, adapted marketing approaches, installment-based payment systems, et cetera ...), the findings offer an alternative approach to addressing issues related to resource scarcity through collaborative partnerships. These

\footnotetext{
${ }^{53}$ In a review of 67 articles, Kolk and colleagues (2014) find that 38 articles consider alternative roles for the poor as employees and 34 articles consider the integration of consumers for significant product and service adaptations.
} 
dynamics may be all the more pertinent during the BM design phase, since during this time investors or larger organizations that may step in and leverage resources to help replicate, as suggested frequently across the BoP literature (e.g., Seelos and Mair, 2007), may actually be hesitant to do so with scant proof of viability.

An auxiliary finding in this regard is that BM design appears to be characterized by high levels of variation in which social businesses modify value creation and appropriation mechanisms. This finding ties in with recent studies that have adopted a template-based understanding of the scaling issues associated with new ventures at the BoP. Specifically, Chiliova and Ringov (2017) propose that large scale replication of BoP strategies occur in two stages, development and replication, which require different capabilities. Our findings are consistent with such a conceptualization and extend it in two ways at the development stage. First, our findings suggest that organizations rely on adaptation and principle based template replication during venture creation. Such an approach allows the organizations to adapt the $\mathrm{BM}$ to fit the salient characteristics of the $\mathrm{BoP}$ environment, and incorporate new knowledge (Winter and Szulanski, 2001). Moreover, our findings provide further insights into the capabilities that may guide effective template development (Winter, 2003), in form of managerial cognition, ambidexterity and co-creation.

\subsubsection{Social Entrepreneurship}

The findings made in this study contribute in two meaningful ways to the emerging literature of Social Entrepreneurship (Battilana and Lee, 2014; Dacin et al., 2011). A first contribution relates to the BoP market context. Prahalad's (2009) assertion that concurrent profits and social impact are possible at the BoP implies that hybrid motivation would form the very basis of business involvement at the BoP. Still, the argument that any type of organization can become successful in the BoP has been echoed in subsequent research (see e.g., Hart and Simanis, 2008; Simanis and Duncan, 2014). In the original articulation of the $\mathrm{BoP}$ proposition multinational corporations were considered the primary actors, as they were assumed to have sufficient resources and capabilities to scale poverty solutions (Prahalad, 2009; Prahalad and Hammond, 2002). Our findings however provide examples of the ability of smaller entrepreneurial organizations that may be able to develop scalable solutions for the BoP. This is in line with more recent $\mathrm{BoP}$ literature that has turned to examine the role of entrepreneurial organizations (see Kolk et al., 2014). 
By having selected a relatively rarer subset of organizations that successfully combine their social and commercial objectives in their respective industry, our findings also suggest that BoP strategies may be more effectively enacted by social enterprises. Studies III-V also provide insights why this may be the case. Study III demonstrates that social enterprises compared to legitimized organizational forms may perceive and make sense of difficult market conditions differently, which may further help explain how they devise new value capture and creation mechanisms. Study IV suggests that SE's by virtue of their dual nature are more capable to interact with a wide array of stakeholders that span different sectors including BoP communities. In turn, this multifariousness appears to allow them to draw on commercial as well as social capital. Finally, study V suggests that SE's achieve BoP strategies more effectively because they experience but also respond to tensions that relate to their dual mission. These implications thus add organizational form and alignment to the raised discussion of social embeddedness in poverty settings (e.g., Kitstruck et al., 2013; Webb et al., 2009).

Our findings also contribute to the growing body of work on hybrid organizing in SE's and the distinct challenges they experience (for a review, see Battilana and Lee, 2014). In organization theory, several streams of research have examined the nature of hybrid organizations that combine dissimilar aspects of different organizational forms (Haveman and Rao, 2006; Padgett and Powell, 2012). One stream of research has for example examined how hybrid organizations deal with internal identity challenges (e.g., Pratt and Foreman, 2000; Wry and York, 2017). Another stream has examined how hybrids deal with potentially conflicting institutional demands that stem from their environment (e.g., Battilana and Dorado, 2010; Pache and Santos, 2013). The conducted studies show how such issues manifest in social businesses that operate in BoP contexts. Specifically, study IV, theorizes how these issues relate to key paradoxes social businesses may experience when implementing their BM and that these may be contingent on the venture's organizational stage.

Moreover, previous studies on mechanisms that influence the organization's ability to address paradoxical tensions remain limited. Although notable exceptions exist, these have focused on detached SE's that cater to customers and beneficiaries separately (see Battilana et al., 2016). The findings extend this line of work to integrated SE's. Our findings suggest that the latter devise and implement value creation and appropriation mechanisms, and adopt ambidextrous responses to deal with tensions that may arise in light of these pursuits. Similarly to previous research on detached hybrids (Canales, 2014; Ebrahim et al., 2014), we find that a common understanding of binate goals 
and the awareness of mutual interdependencies represent critical conditions for effective responses to hybridity related tensions in integrated hybrids. These findings hence further contribute to a growing view that hybridity tensions can be harnessed productively (cf. Battilana et al., 2016), but also highlight the potential of managers to coordinate potentially contradictory sets of activities not only in firms (O’Reilly and Tushman, 2008; 2013), but also in hybrid organizations.

\subsubsection{BM Theory}

The made findings contribute to the evolving research on how to manage resources and capabilities in various contexts (Seelos and Mair, 2007; Sirmon et al., 2007). The studies provide insights to how resources and capabilities can be configured across separate organizational structures into an overall $\mathrm{BM}$ which achieves its social and commercial objectives, despite resource scarcity and institutional voids that BoP contexts induce. Understanding how value can be created from environments, poor in resources, can enable better informed decisions about the retrieval and allocations of resources and capabilities at the BoP.

However, our findings also draw particular attention toward value appropriation mechanisms. In this vein, Morris et al. (2005) for example state that "executives have a tendency to focus so much on the value creation part of the model that the value capture portion is ignored or at least downplayed. In this situation, organizations are unable to capture corresponding economic returns in relation to the value they create" (p. 205). Such a concern became particularly salient when studying BM design for social goods. The observed cases dealt with extremely low-income customers who previously assumed a more passive role as beneficiaries of aid. Studies I and III provide BM 'designers' interested in devising social BM's with relevant design themes as well as design approaches that can lead to delivering value creating BoP strategies. Moreover, study IV provides means of integrating BoP people into active customers and co-producers, in ways that may benefit the $\mathrm{BM}$ design process.

Further, the study of social BM's and BM's in general appears pertinent to Entrepreneurship research as often studies tend to examine new ventures (George and Bock, 2011). Social BM's may represent a special form of entrepreneurial opportunity creation explicitly initiated by market imperfections (Cohen and Winn, 2007), yet of societal relevance. The lack of a more consistent framework has resulted in fragmented conceptualizations and findings, especially within the $\mathrm{BoP}$ and Social Entrepreneurship literature. Studies have asked whether a BM can integrate donation-based 
resources (Tracey and Jarvis, 2007) or objectives (Tate and Bals, 2018), be adapted to environmental circumstances (Chiliova and Ringov, 2017), or may be specific to the entrepreneurial mode (Dacin et al., 2011). The made findings in regards to the essentialist and functionalist nature of social BM's may contribute to the development of more convergent construct that could reduce confusion and help reconcile conflicting empirical results.

Moreover, the findings also contribute to BM research that focuses on the importance of BM Design. Such research offers a distinct explanation of strategy making and strategic change by focusing on the idiosyncratic managerial frames that generate heterogeneity in strategy making and enactment (e.g., Eggers and Kaplan, 2013; Kaplan, 2011). Such a view also emphasizes managers as imaginative architects and system designers (Porac and Tschang, 2013), when managers imagine new possibilities based on exploration of problem spaces (Martins et al., 2015). The findings made take a step in this direction, highlighting organizations who perceive complex social problems in poverty contexts as business opportunities. Moreover, the findings also show how processes of cognition involving design themes and approaches then lead to the eventual BM and outcomes of a social businesses. By examining frames of social businesses, the resulting findings thus also contribute to a more refined understanding of the link between BM antecedents, design and outcomes (cf. Foss and Saebi, 2017).

Bridging BM literature with the BoP and Social Entrepreneurship literatures hence resulted in a number of contributions. While BM literature has a long history with well-established premises and increasingly more nuanced theoretical developments (Amit and Zott, 2001; Massa et al., 2017), it has generally focused theoretical and empirical attention on countries and populations at the ToP. I further extend the boundaries of this literature to the BoP and SE context by examining conditions and specific mechanisms, not present in current BM literature focused on the ToP, that affect BM design and consequently larger replication at the BoP. Thus, the studies can be viewed as contributing to a more nuanced view of the challenge of BM design toward the very challenging context of the BoP.

\subsection{Managerial Implications}

The made findings provide further insights into the distinctive conditions social businesses face in the BoP which affect the development and in turn the scalability of social BM's. However, by focusing on the process of BM design through a phenomenon-based and engaged research approach, the findings also evince useful implications for managers of social businesses, operating in these contexts. I proceed with key managerial implications by study. Since few business-driven BoP initiatives have 
progressed from a promising first BM to a larger-scale solution, organizations closely replicating them may yield performance benefits. These include the application of i) multiple design themes and ii) BM innovations, as well as the integration of routines that concern iii) managerial cognition, iv) co-creation with non-traditional market actors, and v) managerial ambidexterity.

Applying multiple design themes. Scholarship suggests that BM's for BoP markets require a revolution and change in the genetic code of an organization (Garrette and Karnani, 2010). The findings suggest that BM's in BoP markets should be designed with inclusivity, complexity, collaboration and scalability in mind. Synthesizing these building blocks with our lessons learned provides a promising means for managers to scale their BoP initiatives. Moreover, businesses may have to integrate new routines to establish them effectively. For example, fostering value-in-context may require a better systemization of knowledge within the organization about latent customer needs and competitive dynamics. Organizations may also need to rethink and reshape their organizational processes, responsibilities and competencies to be more ambidextrous. Finally, organizations may need to scout for specific business intelligence and learn to integrate these successfully to manage modifications in the scaling process of their BM's, thereby allowing value-in-context, modifiable scaling elements and ambidextrous management to convert promising BM designs into larger-scale solutions for tapping in the emerging BoP market.

Implementing BM innovation patterns. The second study shows that organizations when implementing their BM's are confronted with a series of market related challenges, such as a lack of financial resources, low-margin business, or high levels of risk. The identified BM innovations may serve as further guidance as to how to deal with these issues, based on successful experiences from the observed case studies. The findings thus can allow managers to take a closer look at their existing BM's and take strategic decisions for BM changes which can include the launch of a new BM, the renewal, extension or diversification of the existing offering, as well as template-based replication. The findings also highlight the importance of managers to consider consistency between components when pursuing such innovations.

Fostering managerial attention. Study III provides a more systematic categorization of managerial issues with further examples of key issues that managers may encounter in poverty contexts and how social businesses perceive and sequentially address them in the BM. Consequently, the findings suggest that businesses could benefit from actively reflecting or manipulating firm-held beliefs. Such a view fits into a still small, but growing series of works that advocate the use of external 
interpreters (Verganti, 2011) or framing contests (Kaplan, 2008) among employees to reflect on or counter managerial biases. Moreover, the resulting model provides also a holistic guide that may help managers to 'make sense' of the various design issues and corresponding approaches that are relevant in designing social BMs. In this context, the study also discuss cognitive traps - mission, growth and consistency traps - associated with BM design at the interface of BM elements, and potential strategies to overcome them.

Implementing co-creation practices. Study IV illustrates how co-creation practices with stakeholders can span several sectors with different types of interactions and jargon, but can be highly effective for BM design in BoP markets. Specifically, the study identified five major themes of cocreation potential: identifying core needs, developing novel payment methods, integrating BoP customers as co-producers, identifying nested needs, and assessing willingness-to-pay. As the experiences from the case organizations show, social businesses may benefit from integrating these practices during the BM design process. These findings however imply that managers may need to pay increased attention toward workforce selection and socialization as a way to enable such practices, especially when they involve BoP people.

Harnessing hybridity. The final study explicates a response framework for managers to better manage paradoxical tensions, social enterprises commonly experience. By applying such a paradox lens, managers can explore interdependence of contradictory demands when tensions are re-framed from either/or to both/and logics (Bartunek, 1988). The findings highlight that managers in these situations realize that a choice of one competing force is not possible due to the intensifying need for its opposite. The immersion in opposing forces thereby enables the ability to discover links and synergies, and in turn accept and manage paradoxical tensions ambidextrously. Hence, managers should continuously ensure that staff members' common understanding of the organization's dual goal, and awareness of their mutual interdependencies. Furthermore, managers can establish structures and processes to harness paradoxical tensions and further embed hybrid responses.

\subsection{Policy Implications}

The findings made in the scope of this dissertation have meaningful implications for policy making in regard to water provision and allocation in BoP contexts. The effective transitions from BM design to implementation I examined provide further evidence for the potential of market-based approaches for the provision of goods and services that address social issues. These findings add hence to a growing 
body of literature on SE's that make similar observations in other low-income sectors. In the context of water however, opposition still abounds to applying market mechanisms to allocate water resources, in particular due to its status of a human right (Barlow, 2007). The thrust of such arguments is that, at least in principle, water and markets are incompatible; in particular for the poor (Dosi and Easter, 2003). In pricing water affordably, the findings indicate that BoP people can be integrated in markets as active consumers when they experience social as well as economic benefits (e.g., lower health costs). In pricing water in general, the cases studied also provide a more sustainable solution to temporary give-away solutions by philanthropic approaches, pursued in the water sector. These findings suggest that NGO's may consider investments in similar for-profit social businesses rather than donation-based campaigns.

\subsection{Limitations}

Based on a limited knowledge base regarding the design and development of social BM's, the epistemological grounding of this dissertation was characterized by a strong explorative and phenomenon based research approach. The presented dissertation thus does not present claims about correlations, but rather provides a first in-depth inquiry into conceptual matters and potential causal relationships at play in social BM design that could allow for further theory elaboration. In the following, I discuss the limitations that relate to said pursuit and potential research that may arise in light of it.

Definitional choices. A first limitation deals with the fact that it was seldom possible to draw on established concepts due to the relative juvenility of the related theory streams. The latter required the development of a consistent set of theoretical underpinnings including relevant theory streams and concepts; and in some cases the development of own definitions. Much attention was paid to concepttual clarity (Suddaby, 2010), including relevant and seminal contributions. Nonetheless, the findings should not be considered isolated from the definitional scope of the thesis. It is for example plausible that a different conceptualization of the BM could have led to the identification of other contingencies or mechanisms. To rule such possibilities out further studies can examine in how far the results can be reproduced based on different definitional bases (e.g., George and Bock, 2011; Amit and Zott, 2011).

Unit of Analysis. The chosen unit of analysis implies other limitations. Due to the exploratory nature of the research it was not an easy pursuit to define and focus on the relevant concepts and stakeholders. As the research process unfolded, the unit of analysis in fact shifted from the BM per se 
to firm-level mechanisms. I employed dyadic approaches to understand these analytical units. In particular, as additional stakeholders became relevant (in study IV and V), alternatively, triads or larger group configurations could have been studied. This is especially apparent in the co-creation study (study V). Adopting higher analysis levels may provide further valuable insights.

Case selection. By first considering a large sample of relevant cases, and then studying three social enterprises in-depth, I aimed to imbue the conducted studies with qualitative rigor (Gioia et al., 2013). This approach involved mainly the theoretically purposive sampling among similar organizations, prolonged engagement, various and multiple forms triangulation, member checking, and producing detailed descriptions (Lincoln and Guba, 1985). These strategies helped to increase the trustworthiness of said studies. Nonetheless, the researched organizations may have had idiosyncratic characteristics that impacted their development.

Data collection methods. In addition, there exist limitations within the selected data collection methods. The studies are based mostly on in-depth interview materials. Of course, more observations could have complemented the collected data. However, that would have been time and cost consuming for this particular study setting. Moreover, the time spent at each case organization, on average 1.5 weeks) appeared also to exhaust the informant's available time. In some cases clearly preventing them in conducting their day-to-day business tasks. Considering the lack of infrastructure and technology, I experienced in most field trips, I suggest the application of more long-term ethnographic approaches, in form of conversation analysis for example, which in turn could allow for the longitudinal observation necessary to study everyday strategy enactment (cf. Bluhm et al., 2011). Such approaches could then be embedded in employment (e.g. internship), which potentially lessen research related burdens while providing the case organization with required human resource.

Theoretical generalizability. In this thesis, the case study method was appropriate since it inter alia allowed for the flexibility needed to adjust the scope and aim of the study over time. The method also inspired new ideas and was well suited for illustrative purposes (Siggelkow, 2007). In a positive tradition, further studies on individual or multiple cases may have helped verify or extend findings. With the limited amount of existent cases that met my research criteria and set cost constraints, further case sampling however were not an option. Hence, I opted for sampling additional cases through coauthorships (study III, IV). By considering other industries and collaborative research programs larger case samplings may be more easily attainable. 
Lack of contrasting cases. Alternatively, case studies deliberately investigating terminated BoP projects could have been valuable for understanding conditions that enable social BM designs. However, from experiences in the case selection process, it is likely that collecting primary data concerning such failures will be challenging, since managers and organizations prefer to speak of success stories (cf. Hahn and Gold, 2014). This became evident in multiple settings with case organizations who were seeking social impact investment in an area where the investor scene remains nascent. Nonetheless, deviant cases would allow for theory verification.

\subsection{Future Research}

Social businesses offer a promising way to create 'shared value' (Porter and Kramer, 2011). With an increasing market in social impact investing ${ }^{54}$, frequency of social businesses is anticipated to grow further. This development implies that hybrid organizations will need to establish organizational processes and systems that enable them to sustain their operations without compromising their social and commercial missions. Further research will need to provide more insights into the conditions under which hybrid organizations thrive in BoP contexts (cf., Chiliova and Ringov, 2017; Ebrahim et al, 2014). I thus conclude this chapter with a subset of three potential avenues which stem from the implications of the made studies.

Creation of Social BM's. In examining social businesses, an important unanswered question concerns workforce selection and socialization (Battilana and Lee, 2014; Campbell, 2012) as a complement to governance through behavioral or outcome-based controls (Eisenhardt, 1985; Ouchi, 1979). There exists a longstanding line of research which suggests that organizational membership decisions and socialization policies contribute to imbuing members with organizational values and associated working practices (Finegan, 2000). In turn, these affect organizational members that they may act based on moral reasoning and commitment to organizational goals rather than making decisions based primarily on adhering to rules or responding to incentives (Schwartz, 2011; Trevino, 1992).

A key concern that arose throughout the studies indeed was the inclusion of the BoP people, albeit in different forms as customers, co-producers or co-inventors. The case work conducted in this thesis points to the importance of such practices since it does not halt at the inclusion of BoP consumers as mere co-distributors, as reported in many BoP studies (cf. Kolk et al., 2014). Instead, interactions with consumers informed many decisions taken during the BM design process as well as the emergent model itself. These findings point to a research direction that centres on the examination

\footnotetext{
${ }^{54}$ The Economist, ““'Impact investing” inches from niche to mainstream“, 05.01.2017.
} 
of customer and community relationships at the BoP. Human resource practices necessary to turn potentially vulnerable people into active consumers, co-producers or even co-inventors (e.g., Malik et al., 2017) could render contributions of particular relevance. As an alternative starting point, scholars may also look for insights in the existing service-oriented literatures that have begun to expand to BoP contexts (cf. Fisk et al., 2016; Reynoso et al., 2015).

Social BM as Narrative Device. A notable feature of presentations of social businesses is the role of narratives that evoke heroic exploits performed under conditions of adversity (Trice and Beyer, 1993). Individuals identified as social entrepreneurs provide the raw material for rich and powerful narratives that tend to receive funding (Martens et al., 2007). More broadly, through their retelling, these narratives perpetuate and codify particular set of beliefs about the nature of social entrepreneurship, and they support a particular ideology about its role in society (Dacin et al., 2010). Although some have argued that such a focus has distorted academic work on social entrepreneurship (e.g., Dacin et al., 2011, Doherty et al., 2014), it also illustrates the power of narratives to carry cultural messages that support social value creation (Seelos and Mair, 2005; Yunus et al., 2010).

For example, one interesting feature of these narratives is that they appear to resonate with a very diverse group of actors; compared to corporate narratives that involve stories for locating organizations within relevant markets or legitimating products with investor and customer types (Martens et al., 2007). Creation of social value may thus require distinct types of narratives that resonate with basic notions of equity and social justice (Dacin et al., 2011). Although less considered in this dissertation, through the processes of data collection, it became clear that social BM's, as presented by social businesses, may indeed act as such narrative devices in the context of storytelling. Such a view may inform further agency potential of BM's (Ausrød et al., 2017; Doganova and Eyquiem-Renault, 2009), and in turn different forms of BM experimentation and design strategies (e.g., Andries and Debackere, 2013; Reymen et al., 2015), or alternatively provide important contributions to the area of social impact investing (e.g., Glänzel and Scheuerle, 2016; Louche et al., 2012).

Social BM Outcomes. Based on the made findings, further empirical studies into the antecedents and consequences of BM design in poverty contexts are especially encouraged. Further research is required to assess and verify the effects of design themes and the studied capabilities in regard to overall performance such as profitability or growth, as proposed in this dissertation. Moreover, it would be interesting to know whether certain strategies or activities may promote 
scalability also at different stages after the BM design phase. Such research could lead to the development of models for the impact of BM structures and in turn result in normative models for multiple outcome types, including the development of boundary-spanning networks, survival and performance in poverty contexts, as proposed by recent research in this context (Chiliova and Ringov, 2017). 


\section{Conclusion}

This thesis set out to shed light on the development of social BM's in poverty contexts. A growing body of BoP research advocates the application of market-based approaches for poverty alleviation outcomes in extreme low-income settings (e.g., Prahalad, 2004; 2009). Similarly, a growing tally of research on BM's that has examined mechanisms of value creation and appropriation in ToP markets suggests that BoP markets require different mechanisms (e.g., Foss and Saebi, 2017; Massa and Tucci, 2014). While SE research informs us about the emergence and difficulties hybrid organizations face when they combine these commercial objectives with social ones for their business venture. These themes in literature hence have the potential to dovetail and help explain matters of value creation and appropriation for social goods in poverty settings. It was thus the intention to synthesize these existing themes and explore their intersection, by inquiring into the design of social BM's. This intention manifested in two main research questions of how social BM's are devised and eventually developed.

To address these research questions, I examine how social businesses have emerged in the context of the unfolding pro-poor informal water market in developing economies. This sector addresses a prominent poverty related need concerning the access to safe and affordable drinking water in still severely poor and remote rural areas; to which adequate and sustainable solutions in profit, nonprofit or governmental form have not yet emerged. This setting thus lent itself to study BM design especially well, since successful social businesses have emerged that have managed to grow in market environments highly prone to resource scarcity, institutional voids, based on hybrid missions. Through two types of multiple case study approaches (cf. Gioia et al., 2012; Yin, 2017), I identify and elaborate on contingencies as well as mechanisms (cf. Easton, 2010) with which the social businesses produced viable BM designs, respectively.

With a focus on theory development, various propositions as to what may constitute and underpin successful BM design were developed. The first set of two studies synthesize common design challenges and themes related to social BM's, providing deep insights into the conditions that shape social BM's. The second set of three studies then identifies capabilities of managerial cognition, cocreation; and ambidexterity which supported the implementation of the BM. While the initial development of a BM is clearly an emergent process that may not be completely pre-definable, the studies strongly suggest that these contingencies and mechanisms positively affect the likelihood of successful BM development of social businesses in poverty-stricken markets. 
In considering the limitations of the research pursuit, the presented dissertation provides a first in-depth inquiry into conceptual matters and potential causal relationships at play in social BM innovation that could allow for further theory elaboration and verification. Specifically, these findings lead to various implications for related theory, managerial and institutional practices. Since the thesis advances our understanding of BM's that promote social and economic development in the challenging environment of the BoP, I present contributions relating to the literatures on BoP markets (e.g., Chiliova and Ringov, 2017; Kolk et al., 2014), Social Entrepreneurship (e.g., Battilana and Lee, 2014; Dacin et al., 2011), and BM's and their innovation (e.g., Teece, 2018; Foss and Saebi, 2018). Furthermore, the related findings provide useful insights for managerial and institutional practice by outlining a framework on social BM design, and detailing supportive activities and processes that may help implement such designs. Furthermore, I present avenues for further research that go beyond the limitations of the conducted studies that could allow for conceptual development regarding social BM's.

Clearly, social businesses and their BM's offer a promising way to create both economic and social or 'shared value' (Porter and Kramer, 2011). With an increasing market in social impact, frequency of social businesses is anticipated to grow further. This development implies that such hybrid organizations will need to establish organizational processes and systems that enable them to sustain their operations without compromising their missions, and further research will need to provide more insights into the conditions under which hybrid organizations thrive in poverty contexts. This dissertation hence makes a step toward extending the boundaries of BM research not only beyond the ToP, but toward the very challenging context of SE at the economic base of the pyramid. 


\section{References}

A

Acedo, F. J., Barroso, C., \& Galan, J. L. (2006). The Resource-Based Theory: dissemination and main trends. Strategic Management Journal, 27(7), 621-636.

Amit, R., \& Schoemaker, P. J. H. 1993. Strategic Assets and organizational Rent. Strategic Management Journal, 14(1), 33-46.

Amit, R., \& Zott, C. (2015). Crafting Business Architecture: The Antecedents of Business Model Design. Strategic Entrepreneurship Journal, 9(4), 331-350.

Amit, R., \& Zott, C. (2012). Creating Value Through Business Model Innovation. MIT Sloan Management Review, 53(53310), 41-49.

Amit, R., \& Zott, C. (2001). Value Creation in e-business. Strategic Management Journal, 22(6-7), 493-520.

Anderson, J., \& Billou, N. (2007). Serving the World's Poor: innovation at the Base of the economic Pyramid. Journal of Business Strategy, 28(2), 14-21.

Andries, P., \& Debackere, K. (2007). Adaptation and Performance in new Businesses: understanding the moderating Effects of Independence and Industry. Small Business Economics, 29(1), 81-99.

Andries, P., Debackere, K., \& Looy, B. (2013). Simultaneous Experimentation as a learning strategy: Business Model Development under Uncertainty. Strategic Entrepreneurship Journal, 7(4), 288-310.

Andriopoulos, C., \& Lewis, M. W. (2009). Exploitation-exploration Tensions and organizational Ambidexterity: managing Paradoxes of Innovation. Organization Science, 20(4), 696-717.

Anokhin, S., \& Schulze, W. S. (2009). Entrepreneurship, Innovation, and Corruption. Journal of Business Venturing, 24(5), 465-476.

Aspara, J., Hietanen, J., \& Tikkanen, H. (2010). Business Model Innovation vs. Replication: financial Performance Implications of Strategic Emphases. Journal of Strategic Marketing, 18, 39-56.

Athreye, S. (2005). The Indian Software Industry and its evolving Service Capability. Industrial \& Corporate Change, 14(3), 393-418.

Arora, S., \& Romijn, H. (2012). The empty Rhetoric of Poverty Reduction at the Base of the Pyramid. Organization, 19(4), 481-505.

Austin, J., Stevenson, H. \& Wei-Skillern, J. (2006). Social and Commercial Entrepreneurship: same, different or both? Entrepreneurship Theory and Practice, 30, pp. 1-22.

Aspara, J., Lamberg, J.-A., Laukia, A., \& Tikkanen, H. (2013). Corporate Business Model Transformation and interorganisational Cognition: The case of Nokia. Long Range Planning, 46, 459-474.

Ausrød, V. L., Sinha, V., \& Widding, Ø. (2017). Business Model Design at the Base of the Pyramid. Journal of Cleaner Production, 16(2), 982-996.

\section{B}

Baden-Fuller, C., \& Haefliger, S. (2013). Business Models and technological Innovation. Long Range Planning, 46(6), 419-426.

Baden-Fuller, C., \& Mangematin, V. (2013). Business Models: A challenging Agenda. Strategic Organization, 11(4), 418-427.

Baden-Fuller, C., \& Morgan, M. (2010). Business Models as Models. Long Range Planning, 43(2-3), 156171. 
Baden-Fuller, C., \& Winter, S. (2007). Replicating Knowledge Practices: Principles or Templates. Working paper. Cass Business School. City University, London, UK.

Barney, J. (1991). Firm Resources and Sustained Competitive Advantage. Journal of Management, 17(1), 99-120.

Barney, J. (2001a). Is the Resource Based View a Useful Perspective for Strategic Management Research? Yes. Academy of Management Review, 26(1), 41-56.

Barney, J. (2001b). Resource- Based Theories of Competitive Advantage: a Ten-Year Retrospective on the Resource-based View". Journal of Management, 27(16), 643-650.

Bartunek, J. M. (1988). The Dynamics of personal and organizational Reframing. In: Quinn, R. \& Cameron, K. (Eds.), Paradox and Transformation: toward a Theory of Change in Organization and Management. Cambridge MA, Ballinger.

Battilana, J. \& Dorado, S. (2010). Building Sustainable Hybrid Organizations: The Case of Commercial Microfinance Organizations. Academy of Management Journal, 53(6), 1419-1440.

Battilana, J., \& Lee, M. (2014). Social Enterprises as Hybrid Organizations: a Review and Roadmap for Organization Studies. Academy of Management Annals, 8(1), (397-441)

Battilana, J., Sengul, M., Pache, A. C., \& Model, J. (2015). Harnessing productive Tensions in Hybrid Organizations: the Case of Work Integration Social Enterprises. Academy of Management Journal, 58(6), 1658-1685.

Battilana, J., Lee, M., Walker, J., \& Dorsey, C. (2012). In Search of the Hybrid Ideal. Stanford Social Innovation Review, 10(3), 50-55.

Bechky, B. A. (2003). Sharing Meaning across occupational Communities: the Transformation of Understanding on a Production Floor. Organization Science, 14(3), 312-330.

Berends, H., Smits, A., Reymen, I., \& Podoynitsyna, K. (2016). Learning while (re)-configuring: Business Model Innovation Processes in established Firms. Strategic Organization, 14(3), 181-219.

Besharov, M. L., \& Smith, W. K. (2014). Multiple Institutional Logics in Organizations: explaining their varied Nature and Implications. Academy of Management Review, 39(3), 364-381.

Bhaskar, R. (2013). A Realist Theory of Science. London, Routledge.

Bhaskar, R. (1978). A Realist Theory of Science. Brighton, Harvester-Wheatsheaf.

Bloom, P. N., \& Chatterji, A. K. (2009). Scaling social entrepreneurial Impact. California Management Review, 51(3), 114-133.

Blowfield, M. (2004). CSR and Development: is Business appropriating Global Justice?. Development, 47(3), 61-68.

Bluhm, D. J., Harman, W., Lee, T. W., \& Mitchell, T. R. (2011). Qualitative Research in Management: A Decade of Progress. Journal of Management Studies, 48(8), 1866-1891.

Bock, A. J., Opsahl, T., George, G., \& Gann, D. M. (2012). The Effects of Culture and Structure on strategic Flexibility during Business Model Innovation. Journal of Management Studies, 49, 279-305.

Bohnsack, R., Pinkse, J., and Kolk, A. (2014). Business Models for Sustainable Technologies: exploring Business Model Evolution in the Case of electric Vehicles. Research Policy, 43(2),

Bourgeois, L. J., \& Eisenhardt, K. M. (1988). Strategic Decision Processes in high-velocity Environments: four Cases in the Microcomputer Industry. Management Science, 34(7), 816-835.

Boyle, J.S. (1994), Styles of Ethnography. In: Morse, J.M. (Ed.), Critical Issues in Qualitative Research Methods. Sage, Thousand Oaks, CA.

Bridgstock, R., Lettice, F.M., Özbilgin, M.F. \& Tatli, A. (2010). Diversity Management for Innovation in Social Enterprises in the UK. Entrepreneurship \& Regional Development, 22, pp. 557-574. 
Bucher, S., Jäger, U., \& Prado, A. M. (2016). Scaling private health care for the base of the pyramid: Expanding versus broadening service offerings in developing nations. Journal of Business Research, 69(2), 736-750.

\section{C}

Calvano, L. (2008). Multinational Corporations and local Communities: a critical Analysis of Conflict. Journal of Business Ethics, 82(4), 793-805.

Cavalcante, S., Kesting, P., \& Ulhøi, J. (2011). Business Model Dynamics and Innovation: (Re)-establishing the missing Linkages. Management Decision, 49(1), 1327-1342.

Casadesus-Masanell, R., \& Ricart, J. E. (2010). From Strategy to Business Models and onto Tactics. Long Range Planning, 43(2-3), 195-215.

Casadesus-Masanell, R., \& Zhu, F. (2013). Business Model Innovation and Competitive Imitation: the case of sponsor-based Business Models. Strategic Management Journal, 34(4), 464-482.

Cartwright, R. L. (1968). Some Remarks on Essentialism. The Journal of Philosophy, 65(20), 615-626.

Chambers, R. (2007). Poverty Research: Methodologies, mindsets and multidimensionality. Institute of Development Studies at the University of Sussex.

Chatterjee, S. (2013). Simple Rules for designing Business Models. California Management Review, 55(2), 97-124.

Chell, E. (2007). Social Enterprise and Entrepreneurship: towards a convergent Theory of the entrepreneurrial Process. International Small Business Journal, 25(1), 5-26.

Chesbrough, H. W., \& Rosenbloom, R. S. (2002). The Role of the Business Model in capturing Value from Innovation: evidence from Xerox Corporation's Technology Spin-off Companies. Industrial and Corporate Change, 11(3), 529-555.

Chesbrough, H. (2010). Business Model Innovation: Opportunities and Barriers. Long Range Planning, 43(2-3), 354-363.

Chliova, M., \& Ringov, D. (2017). Scaling Impact: Template Development and Replication at the Base of the Pyramid. Academy of Management Perspectives, 31(1), 44-62.

Christensen, L., Siemsen, E., \& Balasubramanian, S. (2015). Consumer Behavior Change at the Base of the Pyramid: Bridging the gap between for-profit and social responsibility strategies. Strategic Management Journal, 36(2), 307-317.

Christensen, L. J., Siemsen, E., Branzei, O., \& Viswanathan, M. (2017). Response Pattern Analysis: Assuring Data Integrity in extreme Research Settings. Strategic Management Journal, 38(2), 471-482.

Cohen, B., \& Winn, M. I. (2007). Market imperfections, opportunity and sustainable entrepreneurship. Journal of Business Venturing, 22(1), 29-49.

Collins, D., Morduch, J., Rutherford, S., \& Ruthven, O. (2009). Portfolios of the Poor: How the world's poor live on $\$ 2$ a day. Princeton NJ, Princeton University Press.

Cooney, K., \& Shanks, T. R. (2010). New Approaches to old Problems: Market-based strategies for Poverty Alleviation. Social Service Review, 84(1), 29-55.

Cosenz, F. (2017). Supporting Start-up Business Model Design through System Dynamics Modelling. Management Decision, 55(1), 57-80.

Cukier, W., Trenholm, S., Carl, D. \& Gekas, G. (2011). Social entrepreneurship: a content analysis. Journal of Strategic Innovation and Sustainability, 7(1), 99-119.

Cull, R., \& Morduch, J. (2007). Financial Performance and Outreach: A global Analysis of leading Microbanks. Economic Journal, 117(517), 107-133. 
Daas, D., Hurkmans, T., Overbeek, S., \& Bouwman, H. (2013). Developing a Decision Support System for Business Model Design. Electronic Markets, 23(3), 251-265.

Dacin, P.A., Dacin, M.T. and Matear, M. (2010). Social Entrepreneurship: why we don't need a new Theory and how we move forward from here. Academy of Management Perspectives, 24(3), 37-57.

Dacin, P.A., Dacin, M.T. and Tracey, P. (2011). Social Entrepreneurship: a Critique and future Directions. Organization Science, 22(5), 1203-1213.

Dacin, M. T. (1997). Isomorphism in context: The Power and Prescription of institutional Norms. Academy of Management Journal, 40(1), 46-81.

Dahan, N. M., Doh, J. P., Oetzel, J., \& Yaziji, M. 2010. Corporate-NGO Collaboration: Co-creating new Business Models for Developing Markets. Long Range Planning, 43(3), 326-342.

Dart, R. (2004). The Legitimacy of Social Enterprise. Non-profit Management and Leadership, 14(4), 411424.

D’Aveni, R. (1994). Hypercompetition: Managing the Dynamics of Strategic Management. New York, John Wiley.

Davidsson, P., \& Wiklund, J. (2007). Levels of Analysis in Entrepreneurship Research: Current research practice and suggestions for the future. In: Entrepreneurship. Berlin, Springer.

Davies, A.I. and Ryals, J.L. (2010). The Role of Social Capital in the Success of Fair Trade. Journal of Business Ethics, 96(2), 317-338.

Davies, I.A., Doherty, B. \& Knox, S. (2010). The Rise and Stall of a Fair Trade Pioneer: the Café Direct Story. Journal of Business Ethics, 92(1), 127-147.

de Oliveira, D. T., \& Cortimiglia, M. N. (2017). Value Co-creation in Web-based multisided Platforms: a conceptual Framework and Implications for Business Model Design. Business Horizons, 60(6), 747758.

Dees, J.G. (1998). Enterprising Non-profits. Harvard Business Review, 76(1), 54-69.

Defourny, J. \& Nyssens, M. (2006). Defining Social Enterprise. In Nyssens, M. (ed.), Social Enterprise at the Crossroads of Market, Public Policies and Civil Society. London, Routledge.

Defourny, J. \& Nyssens, M. (2010). Conceptions of Social Enterprise and Social Entrepreneurship in Europe and the United States: Convergences and Divergences. Journal of Social Entrepreneurship, 1(1), 32-53.

Demil, B., \& Lecocq, X. (2010). Business Model Evolution: In Search of Dynamic Consistency. Long Range Planning,43(2), 227-246.

Demil, B., Lecocq, X., Ricart, J. E., \& Zott, C. (2015). Special Issue on Business Models: Business Models within the Domain of Strategic Entrepreneurship. Strategic Entrepreneurship Journal, 9(1), 1-11.

Denyer, D., Tranfield, D., \& van Aken, J. E. (2008). Developing Design Propositions through Research Synthesis. Organization studies, 29(3), 393-413.

Denzin, N. K., \& Lincoln, Y. S. (1994). Handbook of qualitative research. Sage publications, inc.

De Soto, H. (2000). The Mystery of Capital: Why Capitalism Triumphs in the West and fails everywhere else. New York NY, Basic Books.

Di Domenico, M.L., Haugh, H. \& Tracey, P. (2010). Social Bricolage: theorising Social Value Creation in Social Enterprises. Entrepreneurship Theory and Practice, 34(4), 681-703.

Di Domenico, M.L., Tracey, P. \& Haugh, H. (2009). The Dialectic of Social Exchange: theorizing corporate-social enterprise collaboration. Organization Studies, 30(8), 887-907. 
Doganova, L., \& Eyquem-Renault, M. (2009). What do business models do?: Innovation devices in technology entrepreneurship. Research Policy, 38(10), 1559-1570.

Doherty, B., Haugh, H., \& Lyon, F. (2014). Social enterprises as hybrid organizations: A review and research agenda. International Journal of Management Reviews, 16(4), 417-436.

Dosi, C., \& Easter, K. W. (2003). Water Scarcity: Market Failure and the Implications for Markets and Privatization. International Journal of Public Administration, 26(3), 265-290.

D'Souza, A., Bouw, K., Velthuijsen, H., Huitema, G. B., \& Wortmann, J. C. (2018). Designing viable multi-commodity energy business ecosystems: Corroborating the business model design framework for viability. Journal of Cleaner Production, 182, 124-138.

Dubois, A., \& Gadde, L. E. (2002). Systematic combining: an abductive Approach to Case Research. Journal of Business Research, 55(7), 553-560.

Dunford, R., Palmer, I., \& Benveniste, J. (2010). Business Model Replication for early and rapid Internationalisation: The ING direct experience. Long Range Planning, 43(5), 655-674.

Duriau, V. J., Reger, R. K., \& Pfarrer, M. D. (2007). A Content Analysis of the Content Analysis Literature in Organization Studies: Research Themes, Data Sources, and Methodological Refinements. Organizational Research Methods, 10(1), 5-34.

\section{$\mathbf{E}$}

Easton, G. (2010). Critical Realism in Case Study Research. Industrial Marketing Management, 39(1), 118128.

Ebrahim, A., Battilana, J., \& Mair, J. (2014). The governance of social enterprises: Mission drift and accountability challenges in hybrid organizations. Research in Organizational Behavior, 34(1), 81-100.

Ebrahim, A., \& Rangan, V. K. (2010). Putting the Break on Impact: a Contingency Framework for measuring Social Performance. In: Academy of Management Proceedings (Vol. 2010, No. 1, pp. 1-6). Briarcliff Manor, NY 10510: Academy of Management.

Edmondson, A. C., \& McManus, S. E. (2007). Methodological Fit in Management Field Research. Academy of Management Review, 32(4), 1246-1264.

Eggers, J. P., \& Kaplan, S. (2013). Cognition and Capabilities: A multi-level Perspective. Academy of Management Annals, 7(1), 295-340.

Eisenhardt, K. M., \& Graebner, M. E. (2007). Theory Building from Cases: Opportunities and Challenges. Academy of Management Journal, 50(1), 25-32.

Eisenhardt, K. M., \& Martin, J. A. (2000). Dynamic Capabilities: what are they?. Strategic Management Journal, 21(10-11), 1105-1121.

Eisenhardt, K.M. (1989). Building Theories from Case Study Research. The Academy of Management Review, 14(4), 532.

Eisenhardt, K. M. (1985). Control: Organizational and economic Approaches. Management Science, 31(2), 134-149.

Elkington, J. (1998). Partnerships from Cannibals with Forks: The triple Bottom Line of 21st-century Business. Environmental Quality Management, 8(1), 37-51.

\section{$\mathbf{F}$}

Finegan, J. E. (2000). The Impact of Person and organizational Values on organizational Commitment. Journal of Occupational and Organizational Psychology, 73(2), 149-169. 
Fisk, R., Anderson, L., Bowen, D. E., Gruber, T., Ostrom, A., Patrício, L., \& Sebastiani, R. (2016). Billions of impoverished People deserve to be better served: A Call to Action for the Service Research Community. Journal of Service Management, 27(1), 43-55.

Flyvbjerg, B. (2006). Five Misunderstandings About Case-Study Research. Qualitative Inquiry, 12(2), 219245.

Foss, N. J. (1998). The resource-based Perspective: an Assessment and Diagnosis of Problems. Scandinavian Journal of Management, 14(3), 133-149.

Foss, N. J., \& Saebi, T. (2017). Fifteen Years of Research on Business Model Innovation how far have we come, and where should we go?. Journal of Management, 43(1), 200- 227.

Frankenberger, K., Weiblen, T., Csik, M., \& Gassmann, O. (2013). The 4I-framework of Business Model Innovation: an Analysis of the Process Phases and Challenges. International Journal of Product Development, 18(4), 1-18.

Furnari, S. (2015). A cognitive Mapping Approach to Business Models: Representing Causal Structures and Mechanisms. Advances in Strategic Management, 33(1), 207-239.

\section{G}

Gavetti, G., Levinthal, D., \& Ocasio, W. (2007). Perspective-Neo-Carnegie: The Carnegie school's past, present, and reconstructing for the future. Organization Science, 18(3), 523-536.

Gavetti, G., \& Levinthal, D. (2000). Looking forward and looking backward: Cognitive and experimental Search. Administrative Science Quarterly, 45(1), 113-137.

Gebauer, H., Saul, C. J., \& Haldimann, M. (2017a). Business Model Innovation in Base-of-the-Pyramid markets". Journal of Business Strategy, 38(4), pp.38-46.

Gebauer, H., Haldimann, M., \& Saul, C. J. (2017b). Business Model Innovations for overcoming Barriers in the base-of-the-pyramid markets. Industry \& Innovation, 24(5), 543-568.

George, G., \& Bock, A. J. (2011). The Business Model in Practice and its Implications for Entrepreneurship research. Journal of Entrepreneurship: Theory \& Practice, 35(1), 83-111.

George, G., McGahan, A. M. \& Prabhu, J. (2012). Innovation for inclusive Growth: towards a theoretical Framework and a Research Agenda. Journal of Management Studies, 49(4), 661-683.

Gephart, R. P. (2004). Qualitative Research and the Academy of Management Journal. Academy of Management Journal, 47(4), 454-462.

Gerdoçi, B., Bortoluzzi, G., \& Dibra, S. (2018). Business Model Design and Firm Performance: Evidence of interactive Effects from a Developing Economy. European Journal of Innovation Management, 21(2), 315-333.

Gerring, J. (2006). Case study research: Principles and Practices. Cambridge, Cambridge University Press.

Ghaziani, A., \& Ventresca, M. J. (2005). Keywords and cultural Change: Frame Analysis of Business Model public talk, 1975-2000. In Sociological Forum (Vol. 20, No. 4, pp. 523-559). Kluwer Academic Publishers-Plenum Publishers.

Giddens, A. (1984). The Constitution of Society. Berkeley, University of California Press.

Gioia, D. A., Corley, K. G., \& Hamilton, A. L. (2013). Seeking qualitative Rigor in inductive Research: Notes on the Gioia methodology. Organizational Research Methods, 16(1), 15-31.

Glänzel, G., \& Scheuerle, T. (2016). Social impact investing in Germany: Current impediments from investors' and social entrepreneurs' perspectives. International Journal of Voluntary and Nonprofit Organizations, 27(4), 1638-1668.

Glaser, B. G., \& Strauss, A. L. (2017). Discovery of Grounded Theory: Strategies for Qualitative Research. Routledge. 
Global Footprint Network (2018). Earth Overshoot Day.https://www.footprintnetwork.org/2017/06/27/eart h-overshoot-day-2017-2/. Accessed October 1, 2018.

Godfrey, P. C. (2011). Toward a Theory of the informal Economy. The Academy of Management Annals, 5(1), 231-277.

Gronum, S., Steen, J., \& Verreynne, M. L. (2016). Business model design and innovation: Unlocking the performance benefits of innovation. Australian Journal of Management, 41(3), 585-605.

Guba, E. G., \& Lincoln, Y. S. (1994). Competing Paradigms in Qualitative Research. Handbook of Qualitative Research, 2(163-194), 105.

\section{$\mathbf{H}$}

Hacklin, F., Björkdahl, J., \& Wallin, M. W. (2018). Strategies for Business Model Innovation: How Firms reel in migrating Value. Long Range Planning, 51(1), 82-110.

Hahn, R., \& Gold, S. (2014). Resources and Governance in "base of the pyramid"-partnerships: assessing Collaborations between Businesses and non-Business Actors. Journal of Business Research, 67(7), 1321-1333.

Hart, S. L., \& Dowell, G. (2011). Invited Editorial: a natural-resource-based View of the Firm: fifteen years after. Journal of Management, 37(5), 1464-1479.

Hart, S. L., \& Milstein, M. B. (2003). Creating Sustainable Value. Academy of Management Perspectives, 17(2), 56-67.

Hart, S. L. (1995). A natural-resource-based view of the firm. Academy of Management Review, 20(4), 9861014.

Haldimann, M., Gebauer H. (under submission). The Role of Cognition in Framing Social Issues: Business Model Design at the economic Base of the Pyramid. Working paper.

Haldimann, M., Moellers, T., Gebauer H. (under submission). 'Opening Up' of Social Business Models in BoP Markets. Working paper.

Haldimann, M., Gebauer H. (under submission). Embracing Hybridity: exploring Paradoxes and Response Strategies in ambidextrous Social Enterprises. Working Paper.

Halme, M., Lindeman, S., \& Linna, P. (2012). Innovation for inclusive Business: Intra-preneurial bricolage in multinational corporations. Journal of Management Studies, 49(4), 743-784.

Haveman, H. A., \& Rao, H. (2006). Hybrid Forms and the Evolution of Thrifts. American Behavioral Scientist, 49(7), 974-986.

Helfat, C. E. (2007). Stylized Facts, empirical Research and Theory Development in Management. Strategic Organization, 5(2), 185-192.

Hermes, N., Lensink, R., \& Meesters, A. (2011). Outreach and Efficiency of Microfinance Institutions. World Development, 39(6), 938-948.

Holcomb, T. R., Holmes Jr, R. M., \& Connelly, B. L. (2009). Making the most of what you have: Managerial ability as a source of resource value creation. Strategic Management Journal, 30(5), 457485.

Hurt, M. J., \& Hurt, S. (2005). Transfer of managerial Practices by French Food Retailers to Operations in Poland. Academy of Management Perspectives, 19(2), 36-49.

$\mathbf{J}$

Jay, J. (2013). Navigating Paradox as Mechanisms of change and Innovation in Hybrid Organizations. Academy of Management Journal, 56(1), 137-159. 
Jenkins, R. (2005). Globalization, Corporate Social Responsibility and Poverty. International Affairs, 81(3): $525-540$.

Johnson, M. W., Christensen, C., \& Kagermann, H. (2008). Reinventing your Business Model. Harvard Business Review, 86(12), 50-59.

$\mathbf{K}$

Kajanus, M., Iire, A., Eskelinen, T., Heinonen, M., \& Hansen, E. (2014). Business Model Design: new Tools for Business Systems Innovation. Scandinavian Journal of Forest Research, 29(6), 603-614.

Kaplan, S. (2011). Research in Gognition and Strategy: Reflections on two Decades of Progress and a Look to the Future. Journal of Management Studies, 48(3), 665-695.

Kaplan, S. (2008). Framing contests: Strategy Making under Uncertainty. Organization Science, 19(5), 729-752.

Karim, S., \& Mitchell, W. (2000). Path-dependent and path-breaking Change: reconfiguring Business Resources following Acquisitions in the US medical Sector, 1978-1995. Strategic Management Journal, 21(10-11), 1061-1081.

Karnani, A. (2007a). Doing well by doing good—Case study: 'Fair \& Lovely' whitening cream. Strategic Management Journal, 28(13), 1351-1357.

Karnani, A. (2007b). The Mirage of Marketing to the Bottom of the Pyramid: how the private Sector can alleviate Poverty. California Management Review, 49(4), 90-111.

Karnani, A. (2007c). Misfortune at the Bottom of the Pyramid. Greener Management Journal, 51(1), 99110.

Karnani, A. (2009). Romanticizing the Poor harms the Poor. Journal of International Development, 21(1), 76-86.

Kaufmann, D., Kraay, A., \& Mastruzzi, M. (2009). Governance matters VIII: Aggregate and individual Governance Indicators 1996-2008. The World Bank.

Kayser, O., \& Budinich, M. V. (2015). Scaling up Business Solutions to social Problems: A practical Guide for social and corporate Entrepreneurs. Basingstoke, Palgrave Macmillan.

Kerling, J. (2013). Defining Social Enterprise across different Contexts: a conceptual Framework based on institutional Factors. Nonprofit and Voluntary Sector Quarterly, 12(1), 84-108).

Kerlin, J. (2010). A Comparative Analysis of the Global Emergence of Social Enterprise. Voluntas, 21(1), $162-179$

Khanna, T., \& Palepu, K. (1997). Why focused Strategies may be wrong for Emerging Markets. Harvard Business Review, 75(2), 41-54.

Kistruck, G. M., Beamish, P. W., Qureshi, I., \& Sutter, C. J. (2013). Social Intermediation in base-of-the-pyramid Markets. Journal of Management Studies, 50(1), 31-66.

Kistruck, G. M., Sutter, C. J., Lount Jr, R. B., \& Smith, B. R. (2012). Mitigating principal-agent Problems in base-of-the-pyramid Markets: an Identity Spillover Perspective. Academy of Management Journal, 56(3), 659-682.

Kistruck, G. M., Webb, J. W., Sutter, C. J., \& Ireland, R. D. (2011). Micro-franchising in base-of-thepyramid Markets: Institutional Challenges and Adaptations to the Franchise Model. Entrepreneurship Theory \& Practice, 35(3), 503-531.

Kolk, A., Rivera-Santos, M., \& Rufín, C. (2014). Reviewing a Decade of Research on the "Base/Bottom of the Pyramid" (BOP) concept. Business \& Society, 53(3), 338-377.

Kostyla, C., Bain, R., Cronk, R., \& Bartram, J. (2015). Seasonal Variation of fecal Contamination in Drinking Water Sources in Developing Countries: a systematic Review. Science of the Total 
Environment, 514, 333-343.

Kuhn, T. S. (1962). The Structure of Scientific Revolutions. Chicago IL, University of Chicago Press.

Kulins, C., Leonardy, H., \& Weber, C. (2016). A configurational approach in business model design. Journal of Business Research, 69(4), 1437-1441.

$\mathbf{L}$

Lavrakas, P. J. (2008). Encyclopedia of Survey Research Methods. Thousand Oaks CA, Sage Publications.

Lawson, T. (1997). Economics and Reality. London: Routledge.

Leadbeater, C. (1997). The Rise of the Social Entrepreneur. London: Demos.

Lee, T. W., Mitchell, T. R., \& Sablynski, C. J. (1999). Qualitative Research in organizational and vocational Psychology, 1979-1999. Journal of Vocational Behavior, 55(2), 161-187.

London, T. (2009). Making better Investments at the Base of the Pyramid. Harvard Business Review, 87(5), 106-113.

London, T., \& Hart, S. L. (2011). Creating a Fortune with the Base of the Pyramid. In: London, T., Hart, S. (Eds.). Next Generation Business Strategies for the Base of the Pyramid. Upper Saddle River NJ, FT Press.

London, T., \& Hart, S. L. (2004). Reinventing strategies for Emerging Markets: beyond the transnational Model. Journal of International Business Studies, 35(5), 350-370.

Louche, C., Arenas, D., \& van Cranenburgh, K. (2012). From preaching to investing: Attitudes of religious Organisations towards responsible Investment. Journal of Business Ethics, 110(3), 301-320

Lincoln, Y. S., \& Guba, E. G. (1985). Naturalistic inquiry. Beverly Hills CA, Sage.

Lyons, K. (2006). Globalization and Social Work: international and local Implications. British Journal of Social Work, 36(3), 365-380.

M

Magretta, J. (2002). Why Business Models matter. Harvard Business Review, 80(5), 86-92.

Mair, J., \& Martí, I. (2006). Social Entrepreneurship Research: A Source of Explanation, Prediction, and Delight. Journal of World Business, 41(1), 36-44.

Mair, J., \& Martí, I. (2009). Entrepreneurship in and around Institutional Voids: A case study from Bangladesh. Journal of Business Venturing, 24(5), 419-435.

Mair, J., Martí, I., \& Ventresca, M. (2012). Building inclusive Markets in rural Bangladesh: How Intermediaries work Institutional Voids. Academy of Management Journal, 55(4), 819-850.

Mair, J., \& Schoen, O. (2007). Successful social entrepreneurial Business Models in the context of developing economies: An explorative Study. International Journal of Emerging Markets, 2(1), 54-68.

Malik, A., Boyle, B., \& Mitchell, R. (2017). Contextual Ambidexterity and Innovation in Healthcare in India: The role of HRM. Personnel Review, 46(7), 1358-1380.

Margolis, J. D., \& Walsh, J. P. (2003). Misery loves Companies: Whither social initiatives by Business? Administrative Science Quarterly, 48(2), 268-306.

Markides, C. (2013). Business Model Innovation: What can the Ambidexterity literature teach us?. The Academy of Management Perspectives, 27(4), 313-323.

Martins, L. L., Rindova, V. P., \& Greenbaum, B. E. (2015). Unlocking the Hidden Value of Concepts: A Cognitive Approach to Business Model Innovation. Strategic Entrepreneurship Journal, 9(1), 99-117. 
Martens, M. L., J. E. Jennings, P. D. Jennings. 2007. Do the stories they tell get them the money they need? The role of entrepreneurial narratives in resource acquisition. Academy of Management Journal. 50(5) $1107-1132$.

Mason, K., \& Chakrabarti, R. (2017). The role of proximity in business model design: Making business models work for those at the bottom of the pyramid. Industrial Marketing Management, 61, 67-80.

Mason, C., \& Doherty, B. (2016). A fair trade-off? Paradoxes in the governance of fair-trade social enterprises. Journal of Business Ethics, 136(3), 451-469.

Mason, K. J., \& Leek, S. 2008. Learning to build a supply network: An exploration of dynamic business models. Journal of Management Studies, 45(4): 774-799.

Massa, L., Tucci, C. L., \& Afuah, A. (2017). A critical assessment of business model research. Academy of Management Annals, 11(1), 73-104.

Massa, L. \& Tucci, C. (2014). Business model innovation. In: The Oxford Handbook of Innovation Management. Ed. by Mark Dodgson, David Gann and Nelson Philips, Oxford: Oxford University Press.

Massa, L., \& Tucci, C. (2013). Business Model Innovation. In: Dodgson, M., Gann, D., \& Philips, N. (Eds.). The Oxford Handbook of Innovation Management. Oxford, Oxford University Press.

McCracken, Grant (1988), The Long Interview. Qualitative Research Methods, Vol. 13, Newbury Park: Sage.

McGrath, J. E. (1964). Toward a "Theory of Method" for Research on Organizations. In: Cooper, W., Leavitt, H. \& Shelly, M. (Eds.). New Perspectives in Organization Research. New York, John Wiley.

McGrath, R. G. (2010). Business Models: A discovery-driven Approach. Long Range Planning, 43(2-3), 247-261.

McGrath, R. G., \& MacMillan, I. C. (2000). The entrepreneurial Mindset: Strategies for continuously creating Opportunity in an Age of Uncertainty (Vol. 284). Harvard Business Press.

Meierhofer, R., Flückiger, A. C., \& Gebauer, H. (2016). Do Sales Models influence the Purchase and Use of Ceramic Filters in rural Areas of Kenya and Bolivia?. Journal of Water Supply, 65(1), 87-102.

Miles, M. \& Huberman, M. (1994). Qualitative Data Analysis. Thousand Oaks CA, Sage.

Miller, D. (2003). An asymmetry-based view of advantage: towards an attainable sustainability. Strategic Management Journal, 24(10), 961-976.

Misher, E. G., \& Mishler, E. G. (2009). Research Interviewing: Context and Narrative. Boston, Harvard University Press.

Mitchell, D., \& Coles, C. (2003). The ultimate competitive advantage of continuing business model innovation. Journal of Business Strategy, 24(5), 15-21.

Moizer, J., \& Tracey, P. (2010). Strategy making in social enterprise: The role of resource allocation and its effects on organizational sustainability. Systems Research and Behavioral Science, 27(3), 252-266.

Moore, D., Cranston, G., Reed, A. \& Galli, A. (2012). Projecting future human demand on the Earth's regenerative capacity. Ecological Indicators. 16(1), 3-10.

Morris, M., Schindehutte, M., \& Allen, J. (2005). The entrepreneur's business model: Toward a unified perspective. Journal of Business Research, 58(6), 726-735.

Murphy, P. J., \& Coombes, S. M. (2009). A model of social entrepreneurial discovery. Journal of Business Ethics, 87(3), 325-336.

$\mathbf{N}$

Nag, R., Hambrick, D. C., \& Chen, M. J. (2007). What is Strategic Management, really? Inductive Derivation of a Consensus Definition of the Field. Strategic Management Journal, 28(9), 935-955. 
Nenonen, S., \& Storbacka, K. (2010). Business Model Design: conceptualizing networked Value Cocreation. International Journal of Quality and Service Sciences, 2(1), 43-59.

Newbert, S. L. (2007). Empirical Research on the Resource-based View of the Firm: an Assessment and Suggestions for future Research. Strategic Management Journal, 28(2), 121-146.

Newell, P., \& Frynas, J. G. (2007). Beyond CSR? Business, Poverty and Social Justice: an Introduction. Third World Quarterly, 28(4), 669-681.

Nicholls, A. (2010). The Legitimacy of Social Entrepreneurship: reflexive Isomorphism in a preparadigmatic Field. Entrepreneurship Theory and Practice, 34(4), 611-633.

$\mathbf{O}$

Olsen, M., \& Boxenbaum, E. (2009). Bottom-of-the- Pyramid: Organizational barriers to implementation. California Management Review, 51(4), 100-125.

O'Reilly III, C. A., \& Tushman, M. L. (2013). Organizational Ambidexterity: Past, Present, and Future. Academy of Management Perspectives, 27(4), 324-338.

O'Reilly III, C. A., \& Tushman, M. L. (2013). Ambidexterity as a Dynamic Capability: resolving the Innovator's Dilemma. Research in Organizational Behavior, 28(1), 185-206.

Ortega, S., Furr, N., Liman, E., \& Flint, C. (2014). The Science of Social Impact Innovation: how to deliver more Impact through innovative Business Models. International Journal of Innovation Science, 6(2), 73-82.

OECD, (2005). The Measurement of Scientific and Technological Activities: Oslo Manual: Guidelines for Collecting and Interpreting Innovation Data, 3rd ed., OECD and Statistical Office of the European Communities.

Osterwalder, A., Pigneur, Y., \& Tucci, C. L. (2005). Clarifying Business Models: Origins, Present, and Future of the Concept. Communications of the Association for Information Systems, 15(1), 1-43.

Osiyevskyy, O., \& Dewald, J. (2015). Explorative versus exploitative Business Model Change: the cognitive Antecedents of firm-level Responses to Disruptive Innovation. Strategic Entrepreneurship Journal, $9(1), 58-78$.

O'Sullivan, A., \& Sheffrin, S. M. (2003). Economics: Principles in Action. New Jersey, Pearson Prentice Hall.

\section{$\mathbf{P}$}

Pache, A.C. \& Santos, F. (2010). When Worlds collide: the internal Dynamics of organizational Responses to conflicting institutional Demands. Academy of Management Review, 35(3), 455-476.

Pache, A.C. \& Santos, F. (2013). Inside the hybrid Organization: Selective Coupling as a Response to competing institutional Logics. Academy of Management Journal, 56(4), 972-1001.

Padgett, J. F., \& Powell, W. W. (2012). The Emergence of Organizations and Markets. Princeton University Press.

Panapanaan, V., Bruce, T., Virkki-Hatakka, T., \& Linnanen, L. (2016). Analysis of shared and sustainable Value Creation of Companies providing Energy Eolutions at the Base of the Pyramid (BoP). Business Strategy and the Environment, 25(5), 293-309.

Patton, M. Q. (2002). Qualitative Research and Evaluation Methods (3rd ed.). Thousand Oaks, Sage.

Penrose, E. T. (1959). The Theory of the Growth of the Firm, 3rd ed. Oxford University Press, Oxford, UK.

Pentland, B. T. (1999). Building Process Theory with Narrative: from Description to Explanation. Academy of Management Review, 24(4), 711-724. 
Peredo, A. M., \& McLean, M. (2006). Social Entrepreneurship: A critical Review of the Concept. Journal of World Business, 41(1), 56-65.

Perkmann, M., \& Spicer, A. (2010). What are Business Models: towards a Theory of Performative Representations. Research in the Sociology of Organization, 29(10), 265-275.

Pfisterer, D., Radonjic-Simic, M., \& Reichwald, J. (2016). Business Model Design and Architecture for the internet of everything. Journal of Sensor and Actuator Networks, 5(2), 7.

Poole, M. S., van de Ven, A. H., Dooley, K., \& Holmes, M. E. (2000). Organizational change and Innovation Processes: Theory and Methods for research. Oxford University Press.

Pontikes, E.G. (2012). Two Sides of the same Coin: how ambiguous Classification affects multiple Audiences' Evaluations. Administrative Science Quarterly, 57(1), 81-118.

Porac, J., \& Tschang, F. T. (2013). Unbounding the managerial Mind: It's time to abandon the Image of Managers as "Small Brains". Journal of Management Inquiry, 22(2), 250-254.

Porter, M. E. (2001). Strategy and the Internet. Harvard Business Review, 79(3), 64 -78.

Porter, M. and Kramer, M. (2006) "Strategy and Society: The Link Between Competitive Advantage and Corporate Social Entrepreneurship," Harvard Business Review, December 2006.

Porter, M. \& Kramer, M. (2011) “Creating Shared Value,” Harvard Business Review, 111(3), 335-351.

Prahalad, C. K., \& Hammond, A. (2002). Serving the World's Poor, profitably. Harvard Business Review, 80(9), 48-59.

Prahalad, C. K., \& Mashelkar, R. A. (2010). Innovation's holy Grail. Harvard Business Review, 88(7-8), 132-141.

Prahalad, C. K. (2009). The Fortune at the Bottom of the Pyramid, revised and updated 5th anniversary edition: Eradicating poverty through profits. FT Press.

Prahalad, C.K. (2004) The Fortune at the Bottom of the Pyramid, Wharton School Publishing.

Pratt, M. G., \& Foreman, P. O. (2000). Classifying managerial Responses to multiple organizational Identities. Academy of Management Review, 25(1), 18-42.

Pucci, T., Nosi, C., \& Zanni, L. (2017). Firm Capabilities, Business Model Design and Performance of SMEs. Journal of Small Business and Enterprise Development, 24(2), 222-241.

\section{$\mathbf{R}$}

Remane, G., Hanelt, A., Tesch, J. F., \& Kolbe, L. M. (2017). The Business Model Pattern Database—a Tool for systematic Business Model Innovation. International Journal of Innovation Management, 21(1), 161.

Reymen, I. M., Andries, P., Berends, H., Mauer, R., Stephan, U., \& Van Burg, E. (2015). Understanding Dynamics of Strategic Decision Making in Venture Creation: a Process Study of Effectuation and Causation. Strategic Entrepreneurship Journal, 9(4), 351-379.

Reynoso, J., Valdés, A., \& Cabrera, K. (2015). Breaking new Ground: Base-of-Pyramid Service Research. The Service Industries Journal, 35(13), 695-709.

Ritter, T., \& Lettl, C. (2018). The wider implications of business-model research. Long Range Planning.

Rivera-Santos, M., Holt, D., Littlewood, D., \& Kolk, A. (2015). Social Entrepreneurship in Sub-Saharan Africa. Academy of Management Perspectives, 29(1), 72-91.

Rivera-Santos, M., \& Rufin, C. (2010). Global village vs. small town: Understanding networks at the base of the pyramid. International Business Review, 19(2), 126- 139.

Rumelt, R. P. (1984). Toward a strategic Theory of the Firm. In: R. Lamb (Ed.), Competitive Strategic Management (pp. 139-158). Cambridge MA, Ballinger. 
Sabatier, V., Mangematin, V., \& Rousselle, T. (2010). From recipe to dinner: business model portfolios in the European biopharmaceutical industry. Long Range Planning, 43(2), 431-447.

Sabatier, V., Medah, I., Augsdorfer, P., \& Maduekwe, A. (2017). Social business model design and implementation in developing countries: Learning from an affordable medicine developed in Burkina Faso. Journal of Management Development, 36(1), 48-57.

Saebi, T., Lien, L., \& Foss, N. J. (2017). What drives business model adaptation? The impact of opportunities, threats and strategic orientation. Long Range Planning, 50(5), 567- 581.

Saebi, T., \& Foss, N. J. (2015). Business models for open innovation: Matching heterogeneous open innovation strategies with business model dimensions. European Management Journal, 33, 201-213.

Sánchez, P., \& Ricart, J. E. (2010). Business model innovation and sources of value creation in low-income markets. European Management Review, 7, 138-154.

Santos, F. (2012). A Positive Theory of Social Entrepreneurship. Journal of Business Ethics, 111(3), 335351.

Saunders, M., Lewis, P., Thornhill, A. \& Bristow, A. (2015). Understanding Research Philosophy and Approaches to Theory Development. In: Saunders, M., Lewis, P., \& Thornhill, A (Eds.). Research Methods for Business Students. Harlow, Pearson Education.

Sayer, A. (1992). Method in Social Science: A realist Approach, (2nd ed.) London: Routledge.

Schneider, S., \& Spieth, P. (2013). Business Model Innovation: towards an integrated future Research Agenda. International Journal of Innovation Management, 17(1), 134-164

Schwarz, G., \& Stensaker, I. (2014). Time to take off the theoretical Straightjacket and (re-)introduce phenomenon-driven Research. The Journal of Applied Behavioral Science, 50(4), 478-501.

Schuster, T., \& Holtbrügge, D. (2014). Resource Dependency, innovative Strategies, and Firm Performance in BOP Markets. Journal of Product Innovation Management, 31, 43-59.

Scott, W. R. (1987). The adolescence of institutional theory. Administrative Science Quarterly, 493-511.

Seelos, C., \& Mair, J. (2007). Profitable business models and market creation in the context of deep poverty: A strategic view. Academy of Management Perspectives, 21(4), 49-63.

Seelos, C. \& Mair, J. (2005). Social entrepreneurship: cre- ating new business models to serve the poor. Business Horizons, 48, pp. 241-246.

Shafer, S. M., Smith, H. J., \& Linder, J. C. (2005). The power of business models. Business Horizons, 48(3), $199-207$.

Simanis E. 2012. Reality check at the bottom of the pyramid. Harvard Business Review 90(6): 120-125.

Simanis, E., \& S. L. Hart. 2006. "Expanding the Possibilities at the Base of the Pyramid." Innovations: Technology, Governance, Globalization 1 (1): 43-51.

Simanis, E., Hart, S., \& Duke, D. (2008). The Base of the Pyramid Protocol: Beyond "Basic Needs" business strategies. Innovations: Technology, Governance, Globalization, 3(1), 57-84.

Simanis, E., \& Hart., S. (2009). "Innovation from the Inside Out.” MIT Sloan Management Review 50 (4): $77-86$.

Sirmon, D. G., Hitt, M. A., \& Ireland, R. D. (2007). Managing firm resources in dynamic Environments to create Value: Looking inside the Black Box. Academy of Management Review, 32(1), 273-292.

Sirmon, D. G., Hitt, M. A., Ireland, R. D., \& Gilbert, B. A. (2011). Resource orchestration to create competitive advantage: Breadth, depth, and life cycle effects. Journal of Management, 37(5), 13901412 . 
Shaw, E., \& Carter, S. (2007). Social entrepreneurship: Theoretical antecedents and empirical analysis of entrepreneurial processes and outcomes. Journal of Small Business \& Enterprise Development, 14(3), 418-434.

Siggelkow, N. (2007). Persuasion with case studies. The Academy of Management Journal, 50(1), 20-24.

Slavin, R. E. (1984). Research Methods in Education: A practical Guide. Englewood Cliffs, NJ: PrenticeHall.

Smith, W. K., Binns, A., and Tushman, M., (2010). "Complex Business Models: Managing Strategic Paradoxes Simultaneously." Long Range Planning 43 (2-3): 448-461.

Sosna, M., Trevinyo-Rodríguez, R. N., and Velamuri, S. R. (2010). Business Model Innovation through Trial-and-Error Learning. Long Range Planning, 43(2-3), 383-407.

Spiess-Knafl, W., Mast, C., \& Jansen, S. A. (2015). On the nature of social business model innovation. Social Business, 5(2), 113-130.

Spieth, P., Schneckenberg, D., \& Ricart, J. E. 2014. Business model innovation: State of the art and future challenges for the field. $R \& D$ Management, 44, 237-247.

Spieth, P., \& Schneider, S. (2016). Business model innovativeness: designing a formative measure for business model innovation. Journal of Business Economics, 86(6), 671-696.

Sen, A. (1999). Development as Freedom. Oxford, UK: Oxford University Press.

Star, S. L., \& Griesemer, J. R. (1989). Institutional ecology ,translations' and boundary objects: Amateurs and professionals in Berkeley's Museum of Vertebrate Zoology, 1907-39. Social Studies of Science, 19(3), 387-420.

Strauss, A., \& Corbin, J. (1990). Basics of qualitative research (Vol. 15). Newbury Park, CA: Sage.

Suchman, M. C. (1995). Managing legitimacy: Strategic and institutional approaches. Academy of management review, 20(3), 571-610.

Suddaby, R. 2010. Editor's comments: Construct clarity in theories of management and organization. Academy of Management Journal, 35, 346-357.

Sundaramurthy, C., \& Lewis, M. (2003). Control and collaboration: Paradoxes of governance. Academy of Management Review, 28(3), 397-415.

Sušnik, J., \& van der Zaag, P. (2017). Correlation and causation between the UN Human Development Index and national and personal wealth and resource exploitation. Economic Research, 30(1), 17051723 .

Sutter, C. J., Webb, J. W., Kistruck, G. M., \& Bailey, A. V. (2013). Entrepreneurs' responses to semiformal illegitimate institutional arrangements. Journal of Business Venturing, 28(6), 743-758.

$\mathbf{T}$

Tate, W. L., \& Bals, L. (2018). Achieving shared triple bottom line (TBL) value creation: toward a social resource-based view (SRBV) of the firm. Journal of Business Ethics, 152(3), 803-826.

Tate, W. L., Ellram, L. M., \& Kirchoff, J. F. (2010). Corporate social responsibility reports: a thematic analysis related to supply chain management. Journal of Supply Chain Management, 46(1), 19-44.

Teasdale, S. (2010). Explaining the multifaceted nature of social enterprise: impression management as (social) entrepreneurial behaviour. Voluntary Sector Review, 1, pp. 271-292.

Teasdale, S. (2012). What's in a name? Making sense of social enterprise discourses. Public Policy and Administration, 27, pp. 99-119.

Teece, D. J. (2018). Business models and dynamic capability. Long Range Planning, 51(1), 40-49.

Teece, D. J. (2010). Business models, business strategy and innovation. Long Range Planning. 43, 172-194. 
Teece, D. J. (2007). Explicating dynamic capabilities: The nature and micro-foundations of (sustainable) enterprise performance. Strategic Management Journal, 28: 1319-1350.

Teece, D. J., Pisano, G., \& Shuen, A. 1997. Dynamic capabilities and strategic management. Strategic Management Journal, 18: 509-533.

Thomke, S., Von Hippel, E., \& Franke, R. (1998). Modes of experimentation: an innovation process-and competitive-variable. Research Policy, 27(3), 315-332.

Thompson, J. D., and I. C. MacMillan. 2010. "Business Models: Creating New Markets and Societal Wealth." Long Range Planning 43 (2-3): 291-307.

Thompson, J. D. (1967). Organizations in action: Social science bases of administrative theory. New York: McGraw-Hill.

Townsend, D.M. \& Hart, T.A. (2008). Perceived institutional ambiguity and the choice of organizational form in social entrepreneurial ventures. Entrepreneurship Theory \& Practice, 32, pp. 685-700.

Tolkamp, J., Huijben, J. C. C. M., Mourik, R. M., Verbong, G. P. J., \& Bouwknegt, R. (2018). User-centred sustainable business model design: The case of energy efficiency services in the Netherlands. Journal of Cleaner Production, 182, 755-764.

Tracey, P. \& Jarvis, O. (2007). Toward a theory of social venture franchising. Entrepreneurship Theory \& Practice, 31, 60-80.

Tracey, P., Phillips, N. \& Jarvis, O. (2011). Bridging institutional Entrepreneurship and the Creation of new organizational Forms: a multilevel Model. Organization Science, 22(7), 60-80.

Trevino, L. K. (1992). Moral reasoning and business ethics: Implications for research, education, and management. Journal of Business Ethics, 11(5-6), 445-459.

Trice, H. M., \& Beyer, J. (1993). The Cultures of Work Organizations. New Jersey, Prentice Hall.

Tripsas, M., \& Gavetti, G. (2000). Capabilities, Cognitions, and Inertia: Evidence from digital imaging. Strategic Management Journal, 21(11), 1147-1161.

Tushman, M., \& O'Reilly III, C. (2007). Research and Relevance: Implications of Pasteur's Quadrant for doctoral programs and faculty development. Academy of Management Journal, 50(4), 769-774.

$\mathbf{U}$

United Nations (2017). World Economic Situation and Prospects 2016. Sales No. E16. II.C.2.

Upreti, P. (2015). Factors affecting economic Growth in Developing Countries. Major Themes in Economics, 17(1), 37-54.

Utterback, J. M. (1971). The Process of Technological Innovation within the firm. Academy of Management Journal, 14(1), 75-88.

Uvin, P., Jain, P. S., \& Brown, L. D. (2000). Think large and act small: Toward a new paradigm for NGO scaling up. World Development, 28(8), 1409-1419.

V

van de Ven, A. H. (2007). Engaged Scholarship: a Guide for organizational and social Research. Oxford University Press on Demand. van de Ven, A. H., \& Engleman, R. M. (2004). Event-and outcome-driven explanations of entrepreneurship. Journal of Business Venturing, 19(3), 343-358.

van de Ven, A. H., \& Poole, M. S. (2005). Alternative approaches for studying organizational Change. Organization Studies, 26(9), 1377-1404. 
Velamuri, V. K., Bansemir, B., Neyer, A. K., \& Moeslein, K. M. (2013). Product Service Systems as a Driver for Business Model Innovation: Lessons learned from the Manufacturing Industry. International Journal of Innovation Management, 17(1),134-156.

Verschuren, P. (2003). Case Study as a Research Strategy: some Ambiguities and Opportunities. International Journal of Social Research Methodology, 6(2), 121-139.

Verganti, R. (2011). Radical Design and Technology Epiphanies: A new focus for research on design management. Journal of Product Innovation Management, 28(3), 384-388.

Visnjic. I, \& van Looy, B. (2013). Servitization: Disentangling the Impact of Service Business Model innovation on manufacturing firm performance. Journal of Operations Management, 31(4), 169-180.

Viswanathan, M., Jung, K., Venugopal, S., Minefee, I., \& Jung, I. (2014). Subsistence and Sustainability: from micro-level behavioral Insights to macro-level Implications on Consumption, Conservation, and the Environment. Journal of Macromarketing, 34(1), 8-27.

Viswanathan, M., Rosa, J. A., \& Ruth, J. A. (2010). Exchanges in Marketing Systems: the case of subsistence consumer-merchants in Chennai, India. Journal of Marketing, 74(3), 1-17.

Voelpel, S. C., Leibold, M., \& Tekie, E. B. (2004). The Wheel of Business Model Reinvention: How to reshape your Business Model to Leapfrog Competitors. Journal of Change Management, 4(2), 259-276.

von Krogh, G., Rossi, C., \& Haefliger, S. (2012). Phenomenon-based Research in Management and Organisation Science: When is it rigorous and does it matter? Long Range Planning, 45(4), 277-298.

Voss, C., Tsikriktsis, N., \& Frohlich, M. (2002). Case Research in Operations Management. International Journal of Operations \& Production Management, 22(2), 195-219.

W

Wang, C. L., \& Ahmed, P. K. (2007). Dynamic Capabilities: a Review and Research Agenda. International Journal of Management Reviews, 9(1), 31-51.

Webb, J. W., Tihanyi, L., Ireland, R. D., \& Sirmon, D. G. (2009). You say illegal, I say legitimate: Entrepreneurship in the Informal Economy. Academy of Management Review, 34(3), 492-510.

Weerawardena, J., \& Mort, G. S. (2006). Investigating Social Entrepreneurship: A multidimensional Model. Journal of World Business, 41(1), 21-35.

Wei, Z., Yang, D., Sun, B., \& Gu, M. (2014). The Fit between technological Innovation and Business Model Design for Firm Growth: Evidence from China. $R \& D$ Management, 44(3), 288-305.

Weick, K. E., Sutcliffe, K. M., \& Obstfeld, D. (2005). Organizing and the process of sense-making. Organization Science, 16(4), 409-421.

Weick, K. E. (1979). The Social Psychology of Organizing, 2nd edition. New York, McGraw-Hill.

Wernerfelt, B. (1984). A Resource-based View of the Firm. Strategic Management Journal, 5(2), 171-180.

WHO, (2015). Joint Water Supply, \& Sanitation Monitoring Programme. Progress on Sanitation and Drinking Water: 2015 Update and MDG Assessment.

Wiggins, R. R., \& Ruefli, T. W. (2005). Schumpeter's Ghost: Is hyper-competition making the best of times shorter?. Strategic Management Journal, 26(10), 887-911.

Wilson, F. \& Post, J.E. (2013). Business Models for People, Planet (\& Profits): exploring the Phenomena of Social Business, a market-based Approach to Social Value Creation. Small Business Economics, 40(8), 715-737.

Winter, S. G. (2003). Understanding Dynamic Capabilities. Strategic Management Journal, 24(10), 991995.

Winter, S. G., \& Szulanski, G. (2001). Replication as Strategy. Organization Science, 12(6), 730- 743. 
Wirtz, B. W., Pistoia, A., Ullrich, S., \& Gottel, V. (2016). Business Models: Origin, development and future research. Long Range Planning, 49(1), 36-54.

World Bank (2016). Poverty Overview. http://www.worldbank.org/en/topic/poverty/overview\#1. Accessed on May 31, 2017.

Wry, T., \& York, J. G. (2017). An Identity-based Approach to Social Enterprise. Academy of Management Review, 42(3), 437-460.

$\mathbf{Y}$

Yin, R. K. (2017). Case Study Research and Applications: Design andMmethods. London, Sage.

Yin, R. K. (2009). Case Study Research: Design and Methods. London: Sage.

Yunus, M., Moingeon, B., \& Lehmann-Ortega, L. (2010). Building Social Business Models: Lessons from the Grameen Experience. Long Range Planning, 43(2), 308-325.

$\mathbf{Z}$

Zoogah, D. B., Peng, M. W., \& Woldu, H. (2015). Institutions, Resources, and organizational Effectiveness in Africa. Academy of Management Perspectives, 29(1), 7-31.

Zott, C., \& Amit, R. (2007). Business Model Design and the Performance of entrepreneurial Firms. Organization Science, 18(1), 181-199.

Zott, C., \& Amit, R. (2008). The Fit between Product Market Strategy and Business Model: implications for firm performance. Strategic Management Journal, 29(1), 1-26.

Zott, C., \& Amit, R. (2010). Business Model Design: An Activity System Perspective. Long Range Planning, 43(3), 216-226.

Zott, C., Amit, R., \& Massa, L. (2011). The Business Model: Recent Developments and Future Research. Journal of Management, 37(4), 1019-1042. 


\section{Appendices}

\subsection{Appendix I}

\section{Literature Review I: Business Models}

The first review is focused on the most influential contributions regarding the conceptualization of business models. In order to identify them, I looked at the most cited papers, based on the standard assumption that citation counts are a valid measure of prominence and influence ${ }^{55}$. From the SCOPUS database, I retrieved a listing of management articles published on the topic of business models (by article title, in English). The result of this search led to an initial set of 1191 articles. I identified the most influential papers in this listing as those published prior to 2019, with citation scores in the upper $10 \%$ percentile of the panel set. This procedure led to the selection of 17 articles that were cited over 300. These have been referenced to at least 15 times as much as the average publication in the panel set with 19 citations. After reading each paper, five of the articles were removed from the final set of contributions, because they neither focused on or conceptualized the business model.

The resulting twelve seminal contributions are listed in Table 1. The body of work has been published over a ten-year time span, ranging from 2001-2011. Out of the final set of articles, 9 articles are conceptual, while the remaining three pursue qualitative or quantitative empirical research methods. The aim of the review was to understand how the business model is theoretically underpinned and conceptually advanced. As such, Table 1 also provides rendered definitions and BM elements that were discussed by the authors. These are discussed in more detail under Section 2.2.

I realize however that citation analysis can be a crude method of assessing article influence. However, it fit the review purpose in that essential business model definitions were sought to develop a conceptual foundation for the thesis. Moreover, in identifying such a large number of studies, I found it to be an especially practical means. Moreover, and maybe more importantly it served its purpose in developing an understanding about BM's in the essentialist sense. In other words; although other lesscited studies might have been considered in the process, the reviewed articles served their purpose in shedding light about the distinctive purpose and nature of the BM in Management research. In fact, the derived understandings converge with more recent reviews in business model research (cf. Massa et al., 2017; Foss and Saebi, 2017; Wirtz et al., 2016).

\footnotetext{
${ }^{55}$ Garfield (1989); Peteraf et al. (1993)
} 
Seminal Business Model Definitions, ordered by citation

\begin{tabular}{|c|c|c|c|}
\hline Works & Citation & BM Conceptualization & EM Elements \\
\hline $1 ' 600$ & Amit \& Zott (2001) & $\begin{array}{l}\text { "A business model depicts the content, structure, and } \\
\text { governance of transactions designed so as to create } \\
\text { value through the exploitation of business } \\
\text { opportunities" (p. 511). }\end{array}$ & $\begin{array}{l}\text { - } \text { Content } \\
\text { - Structure } \\
\text { - Governance } \\
\text { - Revenue Model }\end{array}$ \\
\hline $1 ’ 585$ & $\begin{array}{l}\text { Teece } \\
(2010)\end{array}$ & $\begin{array}{l}\text { "A business model articulates the logic and provides } \\
\text { data and other evidence that demonstrates how a } \\
\text { business creates and delivers value to customers. It } \\
\text { also outlines the architecture of revenues, costs, and } \\
\text { profits associated with the business enterprise } \\
\text { delivering that value." (p. 173) }\end{array}$ & $\begin{array}{l}\text { - Customer benefits } \\
\text { - Revenue streams } \\
\text { - Technologies }\end{array}$ \\
\hline 988 & Zott et al. (2011) & $\begin{array}{l}\text { "The core logic of a business model, instead, revolves } \\
\text { around a firm's revenues and costs, its value } \\
\text { proposition to the customer, and the mechanisms to } \\
\text { capture value" (p. 22) }\end{array}$ & $\begin{array}{l}\text { - Value proposition } \\
\text { - Value capture }\end{array}$ \\
\hline 906 & Margretta (2002) & $\begin{array}{l}\text { "The business model tells a logical story explaining who } \\
\text { your customers are, what they value, and how you will } \\
\text { make money in providing them that value" (p. 4) }\end{array}$ & $\begin{array}{l}\text { - Value proposition } \\
\text { - Customer definition } \\
\text { - Revenue logic }\end{array}$ \\
\hline 785 & $\begin{array}{l}\text { Chesbrough \& } \\
\text { Rosenbloom (2002) }\end{array}$ & $\begin{array}{l}\text { "The functions of a business model are to articulate the } \\
\text { value proposition, }[\ldots] \text { identify a market segment, }[\ldots] \\
\text { define the structure of the value chain, [...] estimate the } \\
\text { cost structure and profit potential, }[\ldots] \text { describe the } \\
\text { position of the firm within the value network, }[\ldots] \text { and } \\
\text { formulate the competitive strategy" (p. 533) }\end{array}$ & $\begin{array}{l}\text { - Value proposition } \\
\text { - Market Segment } \\
\text { - Value Chain } \\
\text { - Value Network } \\
\text { - Cost and Profit } \\
\quad \text { Structure } \\
\end{array}$ \\
\hline 761 & Morris et al., (2005) & $\begin{array}{l}\text { "A business model is a concise representation of how } \\
\text { an interrelated set of decision variable in the areas of } \\
\text { venture strategy, architecture, and economics are } \\
\text { addressed to create sustainable competitive advantage } \\
\text { in defined markets" (p. 727) }\end{array}$ & $\begin{array}{l}\text { - Value creation } \\
\text { - Target customer } \\
\text { - Value capture } \\
\text { - Strategy }\end{array}$ \\
\hline 657 & Zott \& Amit (2010) & $\begin{array}{l}\text { A business model depicts the content, structure, and } \\
\text { governance of transactions designed so as to create } \\
\text { value through the exploitation of business } \\
\text { opportunities. }\end{array}$ & $\begin{array}{l}\text { - Content } \\
\text { - Structure } \\
\text { - Governance, }\end{array}$ \\
\hline 508 & $\begin{array}{l}\text { Johnson et al. } \\
\text { (2008) }\end{array}$ & $\begin{array}{l}\text { "A business model consists of four interlocking } \\
\text { elements that taken together create and deliver value" } \\
\text { (p. 52) }\end{array}$ & $\begin{array}{l}\text { - Customer value } \\
\text { proposition } \\
\text { - Key resources } \\
\text { - Key processes } \\
\text { - Profit formula }\end{array}$ \\
\hline 508 & $\begin{array}{l}\text { Casadesus- } \\
\text { Masanell \& Ricart } \\
(2010)\end{array}$ & $\begin{array}{l}\text { "Business model is a reflection of a firm's realized } \\
\text { strategy" (p.205) }\end{array}$ & $\begin{array}{l}\text { - Choices } \\
\text { - Tactics }\end{array}$ \\
\hline 498 & Shafer et al. (2005) & $\begin{array}{l}\text { "We define a business model as a representation of a } \\
\text { firm's underlying core logic and strategic choices for } \\
\text { creating and capturing value within a value network" (p. } \\
\text { 202) }\end{array}$ & $\begin{array}{l}\text { - Value creation } \\
\text { - Value capture } \\
\text { - Strategic choices }\end{array}$ \\
\hline 469 & Zott \& Amit (2008) & $\begin{array}{l}\text { "The business model is a structural template of how a } \\
\text { focal firm transacts with customers, partners, and } \\
\text { vendors; that is, how it chooses to connect with factor } \\
\text { and product markets" (p. 3) }\end{array}$ & $\begin{array}{l}\text { - Content } \\
\text { - Structure } \\
\text { - Governance }\end{array}$ \\
\hline 372 & $\begin{array}{l}\text { Baden-Fuller \& } \\
\text { Morgan (2010) }\end{array}$ & $\begin{array}{l}\text { "One role of business models is to provide a set of } \\
\text { generic level descriptors of how a firm organizes itself } \\
\text { to create and distribute value in a profitable manner" ( } p \text {. } \\
\text { 157) }\end{array}$ & $\begin{array}{l}\text { - Value creation } \\
\text { - Value distribution } \\
\text { - Profit Equation }\end{array}$ \\
\hline
\end{tabular}




\section{Literature Review II: Business Model Design}

To gain a better understanding of business model design, I initially began the review process with a topic search on Business Model Innovation. The term "business model innovation" was thus searched on the SCOPUS database in the subject areas "business, management, and accounting", and limited to articles written in English articles. Interestingly, the searched produced a list with substantially less articles $(n=184)$, compared to the previous search on BM's. A first reading across the titles and abstracts of the extant literature portrayed a highly fragmented body of literature in terms of conceptual consistency ${ }^{56}$. Moreover, a large majority of these studies focused on high-income market contexts and as such mostly focused on reconfigurations of existing BM's, rather than the design and development of novel BM's 'from scratch'. Given the empirical context in this study, the review thus was narrowed down to examine the topic of business model design.

The review process thus continued by retrieving a listing of management articles published on the topic of business model design (by article title, in English) on the SCOPUS database. The result of this search led to an assessable set of 30 articles. By reading each article, I identified an article as relevant if it had been cited at least once and did not implicitly refer to business model reconfiguration, which led to the removal of 8 studies; further I removed three studies that took place in emerging economies to review them together with other social business model related studies in Review III.

The resulting body of literature reviewed thus consisted of 19 articles, published between 2007 to 2018 (see Table 2). The articles are not only more recent, but differ in terms of research methods; compared to the previous review in which most studies remained conceptual. The aim of the review was to identify conceptual advancements and major research themes, of which three became salient. Hence, Table 2 also indicates the related themes: design themes, design antecedents and capabilities that facilitate the business model design process. These are reviewed further in Section 2.2.

\footnotetext{
${ }^{56}$ such observations have been made also in recent reviews that offer a mapping of the current research landscape. See Schneider and Spieth (2013), Wirtz and colleagues (2016), as well as Foss and Saebi (2017).
} 
Relevant Literature on Business Model Design, ordered by citation

\begin{tabular}{|c|c|c|c|}
\hline Citation & Authors & Study & Focus \\
\hline 716 & $\begin{array}{l}\text { Zott \& Amit } \\
(2010)\end{array}$ & Business Model Design: an Activity System Perspective & $\begin{array}{l}\text { Design } \\
\text { Themes }\end{array}$ \\
\hline 422 & $\begin{array}{l}\text { Zott \& Amit } \\
(2007)\end{array}$ & $\begin{array}{l}\text { Business Model Design and the Performance of entrepreneurial } \\
\text { Firms }\end{array}$ & $\begin{array}{l}\text { Design } \\
\text { Themes }\end{array}$ \\
\hline 102 & $\begin{array}{l}\text { Nenonen \& } \\
\text { Storbacka (2010) }\end{array}$ & $\begin{array}{l}\text { Business Model Design: conceptualizing networked Value Co- } \\
\text { Creation }\end{array}$ & Capabilities \\
\hline 50 & $\begin{array}{l}\text { Amit \& Zott } \\
(2015)\end{array}$ & $\begin{array}{l}\text { Crafting Business Architecture: the Antecedents of Business Model } \\
\text { Design }\end{array}$ & Antecedents \\
\hline 28 & Wei et al., (2014) & $\begin{array}{l}\text { The Fit between technological Innovation and Business Model } \\
\text { Design for Firm Growth: Evidence from China }\end{array}$ & $\begin{array}{l}\text { Design } \\
\text { Themes }\end{array}$ \\
\hline 15 & $\begin{array}{l}\text { Kulins et al., } \\
(2016)\end{array}$ & A configurational Approach in Business Model Design & $\begin{array}{l}\text { Design } \\
\text { Themes }\end{array}$ \\
\hline 14 & $\begin{array}{l}\text { Daas et al., } \\
\text { (2013) }\end{array}$ & Developing a Decision Support System for Business Model Design & Capabilities \\
\hline 10 & Cosenz (2017) & $\begin{array}{l}\text { Supporting Start-up Business Model Design through System } \\
\text { Dynamics Modelling }\end{array}$ & Capabilities \\
\hline 8 & $\begin{array}{l}\text { Kajanus et al., } \\
(2017)\end{array}$ & Business model design: new Tools for Business Systems Innovation & Capabilities \\
\hline 9 & $\begin{array}{l}\text { Yu \& Janssen } \\
(2016)\end{array}$ & $\begin{array}{l}\text { The need for Strategic Management and Business Model Design in } \\
\text { Government and Public Administration }\end{array}$ & Antecedents \\
\hline 7 & $\begin{array}{l}\text { Pucci et al., } \\
(2017)\end{array}$ & Firm Capabilities, Business Model Design and Performance of SMEs & Capabilities \\
\hline 5 & $\begin{array}{l}\text { Gronum et al., } \\
(2016)\end{array}$ & $\begin{array}{l}\text { Business Model Design and Innovation: Unlocking the Performance } \\
\text { Benefits of Innovation }\end{array}$ & $\begin{array}{l}\text { Design } \\
\text { Themes }\end{array}$ \\
\hline 6 & $\begin{array}{l}\text { Pfisterer et al., } \\
(2016)\end{array}$ & $\begin{array}{l}\text { Business Model Design and Architecture for the Internet of } \\
\text { Everything }\end{array}$ & Antecedents \\
\hline 6 & Wei et al., (2017) & $\begin{array}{l}\text { Manufacturing Flexibility, Business Model Design, and Firm } \\
\text { Performance }\end{array}$ & Capabilities \\
\hline 4 & $\begin{array}{l}\text { de Oliveira \& } \\
\text { Cortimiglia } \\
(2017)\end{array}$ & $\begin{array}{l}\text { Value Co-creation in web-based multisided Platforms: A conceptual } \\
\text { Framework and Implications for Business Model Design }\end{array}$ & Capabilities \\
\hline 2 & $\begin{array}{l}\text { Tolkamp et al., } \\
(2018)\end{array}$ & $\begin{array}{l}\text { User-centred sustainable Business Model Design: The case of } \\
\text { energy efficiency services in the NL }\end{array}$ & Capabilities \\
\hline 1 & $\begin{array}{l}\text { D'Souza et al., } \\
(2018)\end{array}$ & $\begin{array}{l}\text { Designing viable multi-commodity energy Business Ecosystems: } \\
\text { Corroborating the Business Model Design Framework for Viability }\end{array}$ & Capabilities \\
\hline 1 & $\begin{array}{l}\text { Hahn et al., } \\
\text { (2018) }\end{array}$ & $\begin{array}{l}\text { Business Model Design in Sustainable Entrepreneurship: Illuminating } \\
\text { the commercial logic of hybrid businesses }\end{array}$ & $\begin{array}{l}\text { Design } \\
\text { Themes }\end{array}$ \\
\hline 1 & $\begin{array}{l}\text { Gerdoçi et al., } \\
(2017)\end{array}$ & $\begin{array}{l}\text { Business Model Design and Firm Performance: Evidence of } \\
\text { interactive Effects from a Developing Economy }\end{array}$ & $\begin{array}{l}\text { Design } \\
\text { Themes }\end{array}$ \\
\hline
\end{tabular}

Source: own table 


\section{Literature Review III: Social Business Model Design}

To infer to which degree the previously reviewed concepts have been applied to the context of social development, I applied a similar review approach with the term social business model and social business model design. From the SCOPUS database, I retrieved a listing of management articles published on the topic of social business models (by article title, in English). This process resulted in 41 contributions, of which I discarded articles that discussed business models in the context of environmental issues (4), profit-oriented multinationals (2), or social value creation in developed market contexts (12). Moreover, I also discarded studies that were not topically relevant - e.g. "social [media] business models" -(11). Additionally, I included three studies on social business model design that took place in BoP contexts, which stemmed from the Literature Review II process.

The review thus begun with a set of 12 contributions, each of which were reviewed in terms of how they conceptualized a social business model and/or the corresponding design process (see table 3 ). The studies rely on qualitative methodologies, conducted between 2007 to 2018 . The comparatively low search results and average citation level point toward the nascence of the research topic. Considering the citation count of the top two cited contributions however, it appears that business model scholars have acknowledged its importance, as pointed to in previous reviews (cf. Massa and Tucci, 2013; Foss and Saebi, 2017). A careful reading of the articles however shows that only few of the articles focus on conceptualizing what concretely may constitute a social business model, offering descriptions which set it apart from previous business model concepts. Moreover, few of these articles discuss the topic of business model design (the articles are reviewed further in Chapter 2.3). Consequently, these findings led to the development of the theoretical gap, articulated in Section 2.3. 


\begin{tabular}{|c|c|c|c|c|}
\hline Citation & Authors & Title & Definition & Theme \\
\hline 321 & $\begin{array}{l}\text { Yunus et al., } \\
(2010)\end{array}$ & $\begin{array}{l}\text { Building social business } \\
\text { models: lessons from the } \\
\text { Grameen experience }\end{array}$ & $\begin{array}{l}\text { "We suggest that a business model has three components: a } \\
\text { value proposition [...]; a value constellation [...]. These two } \\
\text { components need to fit together like pieces of a puzzle in } \\
\text { order to generate: a positive profit equation." (p. 312) }\end{array}$ & BM/D \\
\hline 334 & $\begin{array}{l}\text { Seelos \& } \\
\text { Mair (2005) }\end{array}$ & $\begin{array}{l}\text { Social Entrepreneurship: } \\
\text { creating new business models } \\
\text { to serve the poor }\end{array}$ & ${ }^{2}$ & $\mathrm{BM}$ \\
\hline 62 & $\begin{array}{l}\text { Wilson \& } \\
\text { Post (2013) }\end{array}$ & $\begin{array}{l}\text { Business models for people, } \\
\text { plant \& profits: exploring the } \\
\text { phenomena of social } \\
\text { business, a market-based } \\
\text { approach to social value } \\
\text { creation }\end{array}$ & $\begin{array}{l}\text { "The tight coupling of all three elements - the social mission, } \\
\text { the market-based approach, and the business model } \\
\text { inherent in the implementation - is integral to the creation of } \\
\text { social value, by allowing the reallocation of benefits (normally } \\
\text { reserved for shareholders) to multiple stakeholders." (p. 728) }\end{array}$ & BMD \\
\hline 56 & $\begin{array}{l}\text { Sinkovics et } \\
\text { al., (2014) }\end{array}$ & $\begin{array}{l}\text { The role of social value } \\
\text { creation in business model } \\
\text { formulation at the BoP - } \\
\text { Implications for MNE's }\end{array}$ & $\begin{array}{l}\text { "Shafer et al. (2005, p. 202) define business models as the } \\
\text { "representation of a firm's underlying core logic and strategic } \\
\text { choices for creating and capturing value within a value } \\
\text { network." In this paper, we adopt this definition." (p. 695) }\end{array}$ & $\mathrm{BM}$ \\
\hline 46 & $\begin{array}{l}\text { Mair \& } \\
\text { Schoen } \\
(2007)\end{array}$ & $\begin{array}{l}\text { Successful social } \\
\text { entrepreneurial business } \\
\text { models in the context of } \\
\text { developing economies }\end{array}$ & $\begin{array}{l}\text { "a business model can be understood to be a simplification of } \\
\text { a planned or existing business [...] definition based on the } \\
\text { work of Hamel (2000) who defines a business model as a } \\
\text { "business concept that has been put into practice" (Hamel, } \\
2000, \text { pp. } 65-112 \text { ). More specifically, a business concept } \\
\text { comprises [...] core strategy, strategic resources, customer } \\
\text { interface and value network." (p. 56) }\end{array}$ & $\mathrm{BM}$ \\
\hline 5 & $\begin{array}{l}\text { Dohrmann } \\
\text { et al., (2015) }\end{array}$ & $\begin{array}{l}\text { Monetizing social value } \\
\text { creation - a business model } \\
\text { approach }\end{array}$ & $\begin{array}{l}\text { "Within a standard business model framework, we develop a } \\
\text { conceptual setting in which business models of social } \\
\text { enterprises can be analyzed as well as categorized." (p. 128) }\end{array}$ & $\mathrm{BM}$ \\
\hline 5 & $\begin{array}{l}\text { Ortega et } \\
\text { al., (2014) }\end{array}$ & $\begin{array}{l}\text { The science of social impact } \\
\text { innovation: how to deliver } \\
\text { more impact through } \\
\text { innovative business models }\end{array}$ & $\mathrm{n} / \mathrm{a}$ & $\mathrm{BM}$ \\
\hline 3 & $\begin{array}{l}\text { Margiono et } \\
\text { al., (2007) }\end{array}$ & $\begin{array}{l}\text { A typology of social venture } \\
\text { business model configurations }\end{array}$ & $\begin{array}{l}\text { "we identify four key characteristics that make social } \\
\text { ventures: mission to create public/social value, private } \\
\text { ownership logic, public or private funding, and public or } \\
\text { private control. These four characteristics serve as the } \\
\text { building blocks" (p. 633) }\end{array}$ & $\mathrm{BM}$ \\
\hline 2 & $\begin{array}{l}\text { Hlady \& } \\
\text { Servantie } \\
(2010)\end{array}$ & $\begin{array}{l}\text { Business models impacting } \\
\text { social change in violent and } \\
\text { poverty-stricken } \\
\text { neighborhoods }\end{array}$ & $\begin{array}{l}\text { "representation of a venture's core logic for creating value." } \\
\text { (p. 431) }\end{array}$ & $\mathrm{BM}$ \\
\hline 2 & $\begin{array}{l}\text { Sabatier et } \\
\text { al., (2017) }\end{array}$ & $\begin{array}{l}\text { Social business model design } \\
\text { and implementation in } \\
\text { developing countries: } \\
\text { Learning from an affordable } \\
\text { medicine developed in } \\
\text { Burkina Faso }\end{array}$ & $\begin{array}{l}\text { "Yunus et al. (2010) proposed four inter-related components } \\
\text { of social business models: the value proposition, the value } \\
\text { constellation, the economic profit equation, and the social } \\
\text { profit equation." (p. 50) }\end{array}$ & BMD \\
\hline 2 & $\begin{array}{l}\text { Ausrød et al. } \\
(2017)\end{array}$ & $\begin{array}{l}\text { Business model design at the } \\
\text { base of the pyramid }\end{array}$ & $\begin{array}{l}\text { "we apply a definition of business models that can } \\
\text { accommodate both perspective [...] based on the } \\
\text { understanding that the model can also shape its context [...] } \\
\text { a business model consists of the following elements: (1) value } \\
\text { proposition; (2) supply chain; (3) customer interface; and (4) } \\
\text { financial model." (p. 982) }\end{array}$ & BMD \\
\hline 2 & $\begin{array}{l}\text { Mason \& } \\
\text { Chakrabarti } \\
(2017)\end{array}$ & $\begin{array}{l}\text { The role of proximity in } \\
\text { business model design: } \\
\text { making business models work } \\
\text { for those at the bottom of the } \\
\text { pyramid }\end{array}$ & $\begin{array}{l}\text { "Business models are understood as being epistemic } \\
\text { devices that represent, order and organise business } \\
\text { activities connecting the firm and the market. At an abstract } \\
\text { level, business models are conceptualised as a three- } \\
\text { dimensional construct, including: (1) technologies: used in } \\
\text { structuring the product/service offerings, and delivery } \\
\text { management; (2) market offerings: the structuring of the } \\
\text { producer-user interactions that generate the firm's offering; } \\
\text { and (3) network architectures: the structuring of business } \\
\text { activities of all buyers and sellers needed to make that } \\
\text { market offering possible." (p. } 74)\end{array}$ & BM \\
\hline
\end{tabular}




\subsection{Appendix II: Case Summaries}

Case Summaries

\begin{tabular}{|c|c|c|c|}
\hline Case $\left(\mathrm{N}^{\circ}\right)$ & $\begin{array}{l}\text { Founded } \\
\text { In Year }\end{array}$ & Region & Case Description \\
\hline Aqua (1) & 2010 & $\begin{array}{l}\text { South } \\
\text { Asia }\end{array}$ & $\begin{array}{l}\text { Aqua was founded as a social business by a large NGO, operating in South Asia } \\
\text { since 1985. The NGO consists of multiple sub-businesses that aim at fostering } \\
\text { employment, entrepreneurship, sustainable technologies, as well as meeting } \\
\text { basic needs of poor communities. As the NGO began to realize the lack of } \\
\text { access to clean drinking water at the household level in remote rural areas, they } \\
\text { developed a household solution for purifying water and founded Aqua as a social } \\
\text { business to commercialize the technology. A liquid chlorine product for } \\
\text { household usage. Aqua then began to produce, market and sell the bottled } \\
\text { sodium hypochlorite solution at } 0.6 \text { USD per bottle, which could last a household } \\
\text { of four for a month. Currently, they serve around } 0.1 \mathrm{M} \text { people and plan to expand } \\
\text { their business. }\end{array}$ \\
\hline
\end{tabular}

Pani was also founded as a social business by an international NGO, in South Asia. By applying electro-chlorination, Pani found a cost-effective and environmentally friendly technology to purify drinking water for poor people living

Pani (2) $2011 \quad \begin{aligned} & \text { South } \\ & \text { Asia }\end{aligned}$
in remote rural areas. It thus began piloting different funding models in 2010; and eventually began to run its operations in 2011, selling safe drinking water within ten-liter jerry-cans, at 0.04/jerry-can, through a network of water kiosks in small rural villages. Currently, the organization counts around 0.3M customers and plan to reach 5'000 villages by 2020.

Hydro represents a for-profit 'subsidiary' of an international NGO known for its innovative business approaches towards poverty eradication. The for-profit business has been operating since 2008 in South East Asia, priorly running as a South small NGO before for ten years. Their mission is to provide safe water through East manufacturing and selling ceramic household water filters. Hydrologic Enterprises Sells two models: a basic filter at 13 USD, and a more sophisticated model at 36 Asia USD. The business has become the leading distributor of effective and affordable water and sanitation products throughout the country, providing around one million households with improved access to safe drinking water. Their aim is to now additionally provide sanitation and hygiene products by 2020 .

Eau is a socially responsible company, which tapped into the water market of a Northern African country since 2011. It targets the base of the pyramid customers by providing water between 0.003 to 0.0015 USD per liter, North experimenting with different business models to do so: safe water via water Africa kiosks in cities and villages, recycling waste water from industrial treatment, and drinking water and tap water for gastronomy and private higher income segments. Currently, the organization counts around 0.3M customers and the management plans an expansion to South America, which presents an interesting development in the ongoing business.

Fonto was founded based on long standing experience in delivering water services to large rural and semi-urban communities through market based East approaches and strong local empowerment. The founder of Fonto then decided

Fonto (5) $2017 \quad$ Central
to found a social business that repurposes existing water infrastructure, left behind from disused NGO projects, providing water services in conflict areas at the right quality, quantity and price. In its first year, the social business was able to become financially independent from investors and reach around 100'000 BoP customers. The management plans to tripple this figure by 2020. 


\subsection{Appendix III: Appended Papers}

Study I Exploring Design Themes for Social BM's in the BoP

Study II Overcoming Constraints in BoP Markets through BM Innovation

Study III Social Business Models Design

Study IV Social Business Model Development through Co-creation

Study V Maintaining Hybridity during Social BM Development 


\section{Studies}

The studies associated with this thesis have been removed for copyright reasons. For more details about these see:

http://urn.kb.se/resolve?urn=urn:nbn:se:liu:diva-157018 


\section{FACULTY OF ARTS AND SCIENCES}

Linköping Studies in Arts and Sciences No. 772, 2019

Department of Management and Engineering

Division of Business Administration

Linköping University

SE-581 83 Linköping, Sweden

www.liu.se 